\title{
Ethnicity and Nationality in the Irish Labour Market
}

Frances McGinnity, Raffaele Grotti, Sarah Groarke \& Sarah Coughlan

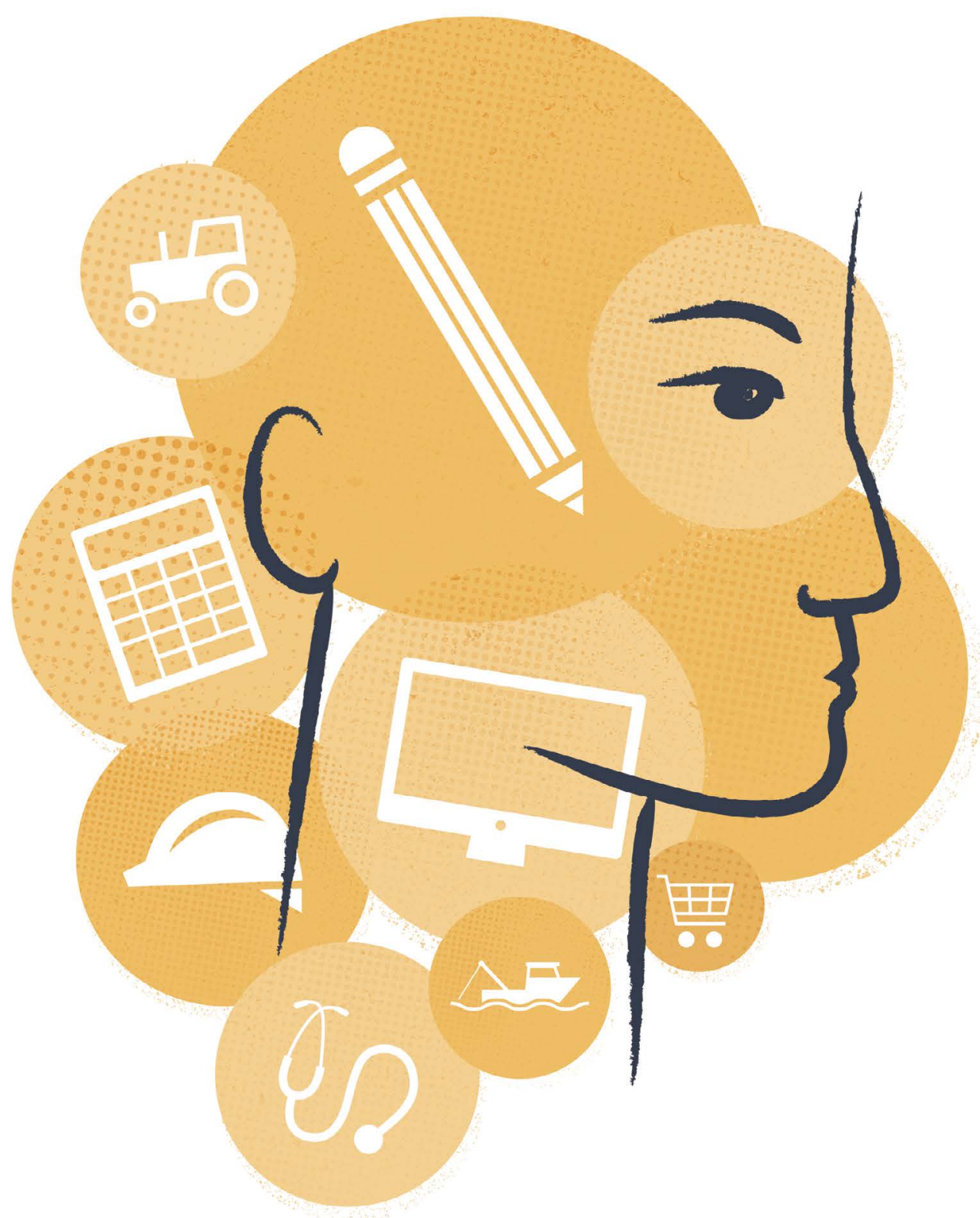

Coimisiún na hÉireann um Chearta an Duine agus Comhionannas

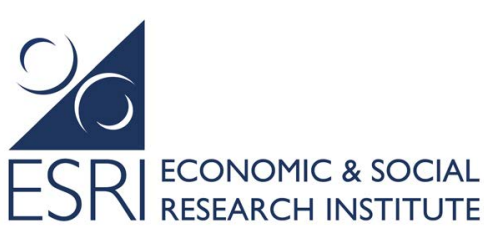




\section{Ethnicity and Nationality in the Irish Labour Market}

Frances McGinnity, Raffaele Grotti,

Sarah Groarke \& Sarah Coughlan 
This report was written by Frances McGinnity, Raffaele Grotti, Sarah Groarke and Sarah Coughlan. It was prepared for the Irish Human Rights and Equality Commission by the Economic and Social Research Institute as part of the Research Programme on Human Rights and Equality. The report has been peer-reviewed prior to publication. The views expressed in this report are those of the authors and do not necessarily represent those of the Economic and Social Research Institute or the Irish Human Rights and Equality Commission.

The Irish Human Rights and Equality Commission was established under statute on 1 November 2014 to protect and promote human rights and equality in Ireland, to promote a culture of respect for human rights, equality and intercultural understanding, to promote understanding and awareness of the importance of human rights and equality, and to work towards the elimination of human rights abuses and discrimination.

The Economic and Social Research Institute (ESRI) is an independent research institute working towards a vision of 'Informed policy for a better Ireland'. The ESRI seeks to support sustainable economic growth and social progress in Ireland by providing a robust knowledge base capable of providing effective solutions to public policy challenges.

Available to download from www.esri.ie and www.ihrec.ie

(C) 2018. Copyright is held jointly by the Economic and Social Research Institute and the Irish Human Rights and Equality Commission.

Irish Human Rights and Equality Commission, 16-22 Green Street, Dublin 7. The Economic and Social Research Institute, Whitaker Square, Sir John Rogerson's Quay, Dublin 2

ISBN 978-0-7070-0479-2

DOI https://doi.org/10.26504/bkmnext369
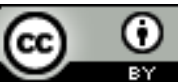

This Open Access work is licensed under a Creative Commons Attribution 4.0 International License (https://creativecommons.org/licenses/by/4.0/), which permits unrestricted use, distribution, and reproduction in any medium, provided the original work is properly credited. 


\section{FOREWORD}

I am very pleased to introduce this report Ethnicity and Nationality in the Irish Labour Market. It is the fifth report conducted by the Economic and Social Research Institute as part of the Commission's Research Programme on Human Rights and Equality.

The principle of equality is articulated in our most basic law, the Irish Constitution, which provides in Article 40 that 'all citizens shall, as human persons, be held equal before the law.' The general principle of equality and non-discrimination is a fundamental element of all core international human rights treaties. Article 1 of the Universal Declaration of Human Rights states 'All human beings are born free and equal in dignity and rights'. The right to a life free from racial discrimination is articulated most comprehensively in the International Convention on the Elimination of All forms of Racial Discrimination.

The Commission works in a variety of ways to protect and promote human rights and equality in Ireland, building a culture of respect for human rights, equality and intercultural understanding. The importance of employment for integration, and for inclusion in the wider life of the community, cannot be overstated. This has been a key driver of the Commission's own work to date, most notably in its contribution as amicus curiae in the successful appeal to the Supreme Court which found an outright ban on access to employment for applicants for international protection to be unconstitutional. Quite simply, in a just society, everyone should have equal access to employment opportunities, experience equal treatment in the workplace and, enjoy equal labour market outcomes regardless of their ethnicity.

The first report from this Research Programme Who Experiences Discrimination in Ireland? Evidence from the QNHS Equality modules (2017) highlighted that some minority ethnic groups experience high rates of discrimination. This occurred in both accessing employment and in the workplace.

This report presents a more in-depth analysis of discrimination in the labour market to ascertain if certain ethnic groups experience higher rates of work related discrimination than others. Using data from the Equality module of the Quarterly National Household Survey and the Labour Force Survey, this report examines if labour market outcomes differed across ethnic groups between 2002 to 2014 . It also examines the likelihood of being 
employed rather than unemployed for different ethnicities, and the grades of employment secured.

The picture emerging from the data is a timely reminder that the experience of different ethnicities in Ireland cannot be reduced to simple generalisations. For example, the evidence presented here shows that some ethnic groups, such as those who identify as Asian-Irish or White EU-West, are at an advantage in the Irish labour market, both in terms of access to employment and progression.

Of those groups who experience higher rates of exclusion from the labour market, and higher rates of discrimination in work, that experience also varies. Of these, the group which emerges as being most seriously disadvantaged are people who identify as Black or Black Irish. While this group represents only a small fraction of the population -1.4 per cent in the last census - the lasting consequences of persistent exclusion from the labour market or discrimination in work are significant enough to warrant close attention from policymakers.

Furthermore, given the importance of ethnicity in access to, and progression in, the labour market, and the movement between some categories as people acquire Irish citizenship, it is important that the measurement of this data is adequate to the complexities involved. It is only by having an accurate picture of how different ethnic minorities fare in the labour market that we can develop effective policy responses to address disadvantage and discrimination.

The findings of this report are particularly timely, as Ireland is expected to be examined by the UN Committee on the Elimination of All Forms of Racial Discrimination in 2019. The Commission anticipates that the evidence presented in this report will be of assistance to policymakers in the course of that examination, and potential policy responses in the context of the State's own Migrant Integration Strategy.

I would like to convey my thanks to the authors of this report, Professor Frances McGinnity, Dr Raffaele Grotti, Sarah Groarke and Sarah Coughlan.

Emily Logan

Chief Commissioner, Irish Human Rights and Equality Commission. 


\section{THE AUTHORS}

Frances McGinnity is an Associate Research Professor at the ESRI and an Adjunct Professor of Sociology at TCD. Raffaele Grotti was a Post-doctoral Research Fellow at the ESRI and is currently a Research Fellow at the European University Institute (Italy). Sarah Groarke is a Research Assistant at the Irish National Contact Point of the European Migration Network (EMN), which is based in the ESRI. Sarah Coughlan was on a research internship at the ESRI at the time of writing.

\section{ACKNOWLEDGEMENTS}

We gratefully acknowledge the funding received from the Irish Human Rights and Equality Commission (IHREC) to support this research programme. We would like to thank Cliona Doherty (IHREC), Iris Elliott (IHREC) and Gráinne Collins (NDA) for their input and constructive comments. Other comments from IHREC were also incorporated. The report also benefited greatly from the comments of two ESRI reviewers, and an external expert reviewer, as well as Professor Emer Smyth, who acted as editor of the report. 


\section{TABLE OF CONTENTS}

GLOSSARY

EXECUTIVE SUMMARY . $\mathrm{IX}$

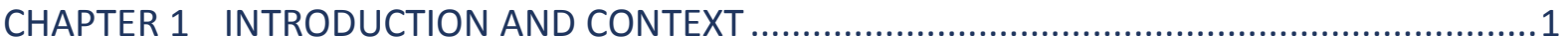

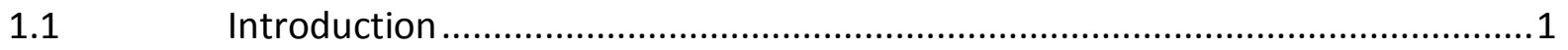

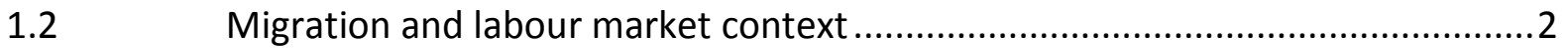

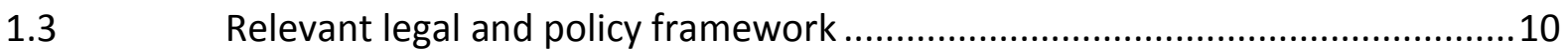

CHAPTER 2 WHY DO LABOUR MARKET OUTCOMES DIFFER ACROSS ETHNIC/NATIONAL

GROUPS?

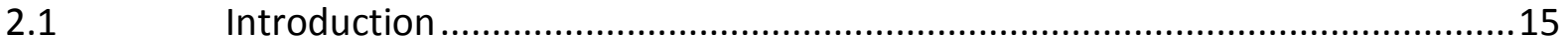

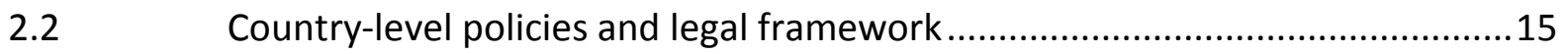

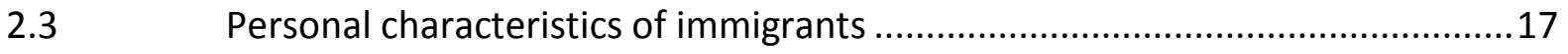

Employer/host country behaviour ............................................................18

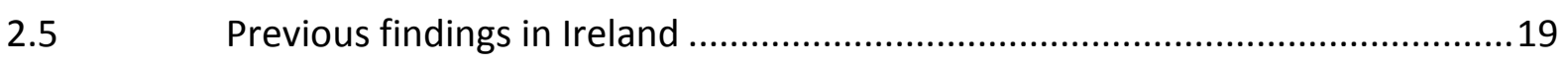

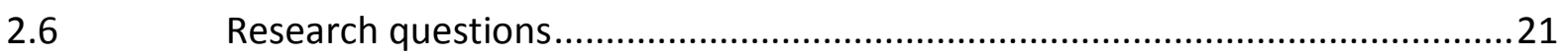

CHAPTER 3 MEASURING ETHNIC/NATIONAL GROUPS IN THE EQUALITY MODULES ...........23

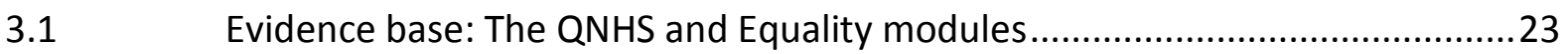

3.2 Defining ethnic/national groups in the Equality modules................................25

3.3 The profile of migrants: education, age, sex, length of residence and principal

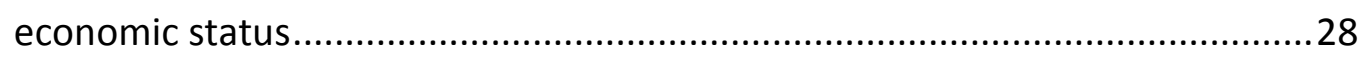

CHAPTER 4 LABOUR MARKET INEQUALITIES ACROSS ETHNIC AND NATIONAL GROUPS.....35

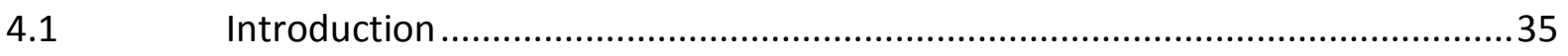

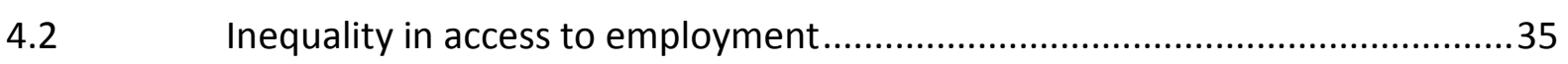

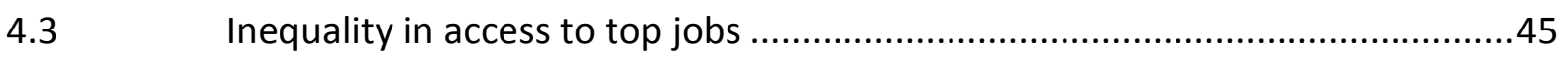

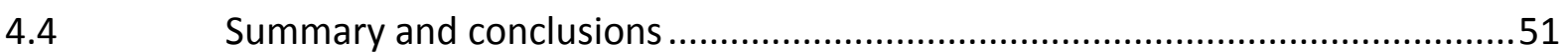


CHAPTER 5 THE EXPERIENCE OF DISCRIMINATION AMONG ETHNIC AND NATIONAL GROUPS

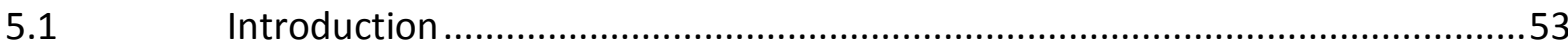

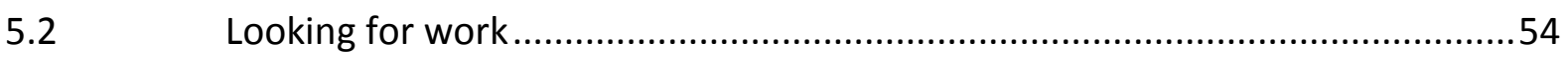

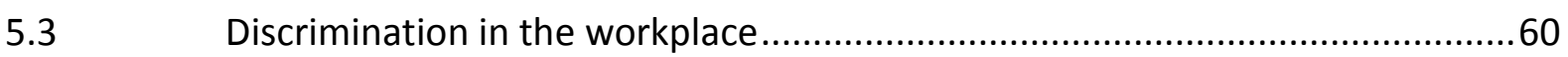

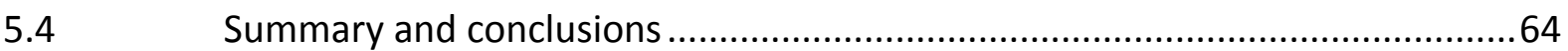

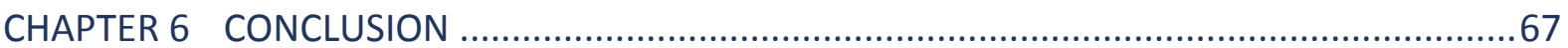

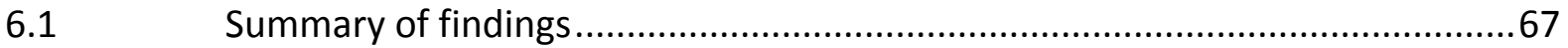

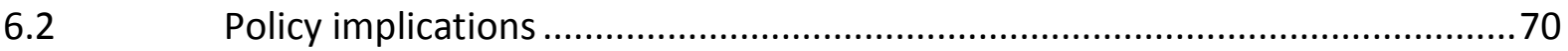

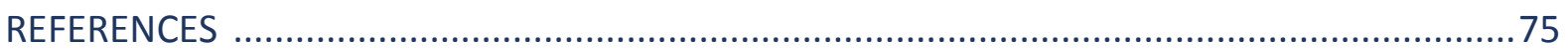




\section{LIST OF TABLES}

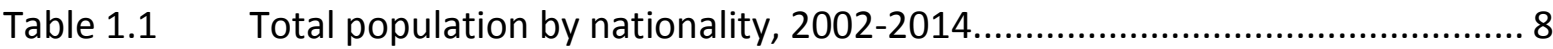

Table 1.2 Population by ethnic or cultural background 2006, 2011 and 2016 ............. 9

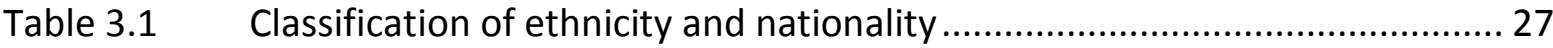

Table 4.1 Logistic regression for employment versus unemployment (odds ratios) .... 39

Table 4.2 Logistic regression for accessing top jobs (odds ratios) .............................. 48

Table 5.1 Logistic regression of discrimination seeking work (odds ratios) .................. 57

Table 5.2 Logistic regression: discrimination in the workplace (odds ratios) ...............62 62

Table 6.1 Summary of model findings on labour market outcomes and the experience of discrimination for each ethnic/national group ..................... 68

\section{LIST OF BOXES}

Box 3.1 Definition of discrimination provided for Equality module (prompt card)... 25 


\section{LIST OF FIGURES}

Figure 1.1 Immigration, emigration and net migration, 1987-2017 ............................ 3

Figure $1.2 \quad$ Nationality of immigration flows, 2004-2014 …....................................... 4

Figure 1.3 Unemployment rates (ILO), Ireland, 2002-2016 ..................................... 10

Figure $3.1 \quad$ Highest educational attainment by ethnic/national group ......................... 29

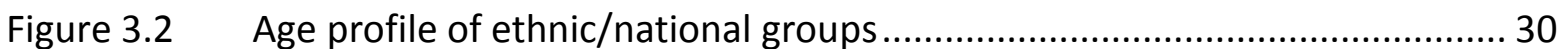

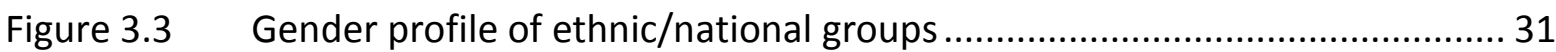

Figure $3.4 \quad$ Length of residence in Ireland by ethnic/national group ............................. 32

Figure $3.5 \quad$ Principal economic status by ethnic/national group ................................. 33

Figure $4.1 \quad$ Employment rate by ethnicity and nationality ....................................... 37

Figure 4.2 Differences in the predicted probabilities of being employed for ethnic/national groups compared with White Irish over time 44

Figure 4.3 Share of top jobs among employed people by ethnicity and nationality...... 46

Figure 4.4 Differences in the predicted probabilities of being in a top job position for ethnic/national groups compared with White Irish over time 50

Figure 5.1 Experience of discrimination seeking work by ethnic/national group 55

Figure 5.2 Differences in the predicted probabilities of experiencing recruitment discrimination for ethnic/national groups compared to White Irish over time

Figure 5.3 Experience of workplace discrimination by ethnic/national group 61

Figure 5.4 Differences in the predicted probabilities of experiencing workplace discrimination for ethnic/national groups compared to White Irish over time 


\section{GLOSSARY}

CSO

EEA

Ethnicity

Ethnic/national group

EU-East

EU-West

FRA

GDP

ILO

Labour market active

Nationality

OECD

OPMI

PES

QNHS

QQI
Central Statistics Office

European Economic Area, which comprises the EU Member States plus Iceland, Liechtenstein and Norway

Self-defined ethnic group based on Irish Census classification of ethnicity

Unique classification into up to ten groups based on a combination of self-defined ethnicity and whether respondents are Irish citizens or not.

EU Member States that joined the EU in 2004 (Cyprus, Czech Republic, Estonia, Hungary, Latvia, Lithuania, Malta, Poland, Slovakia and Slovenia), 2007 (Bulgaria and Romania) and 2013 (Croatia).

'Old' EU Member States, excluding Ireland and the UK: Austria, Belgium, Denmark, Finland, France, Germany, Greece, Italy, Luxembourg, Netherlands, Portugal, Spain and Sweden.

Fundamental Rights Agency

Gross Domestic Product

International Labour Organization

Active in the labour market, includes employed and unemployed

Respondents are asked if they are an Irish citizen. If they are not Irish citizens, they are asked for their nationality

Organisation for Economic Co-operation and Development

Office for the Promotion of Migrant Integration

Principal Economic Status (as defined by the respondent)

Quarterly National Household Survey

Quality and Qualifications Ireland 



\section{EXECUTIVE SUMMARY}

The marked increase in immigration that accompanied the economic boom of the late 1990s and early 2000s has brought considerable ethnic and national diversity to Ireland. ${ }^{1}$ This report investigates how different ethnic and national groups have fared in the Irish labour market. Employment leads to financial independence and reduces the risk of poverty and social exclusion: it also facilitates immigrants' integration into society as a whole (OECD, 2015).

The report uses three large, identical, nationally representative surveys of the population to examine outcomes in 2004, 2010 and 2014; three very different labour market contexts in Ireland (boom, recession and early recovery). The data used measured both an individual's employment status and the kind of jobs they held (specifically whether they were working in a professional/managerial job), as well as their experience of discrimination in looking for work and in the workplace. Discrimination is understood here as a situation in which individuals are treated less favourably due to their membership of a specific group. Respondents were asked whether they believed they had experienced discrimination according to a definition that reflects Irish law. ${ }^{2}$

Is there evidence of disadvantage for ethnic minorities and does nationality play any role in labour market inequality and the experience of discrimination? The role of ethnicity and nationality is explored by creating ten ethnic/national groups based on respondents' reported ethnicity and whether or not they are Irish citizens - White Irish, Black Irish, Asian Irish, Other ethnicity Irish, White UK, White EU-West, White EU-East, Black non-Irish, Asian non-Irish and Other ethnicity non-Irish (see Glossary). Ethnic minority Irish nationals can include foreign-born immigrants who acquired Irish citizenship through naturalisation (either by residing in Ireland for at least five years or through marriage) and individuals who were born in Ireland.

$1 \quad$ Irish Travellers are a small Irish ethnic minority group who are extremely disadvantaged in the Irish labour market (Watson et al., 2017). They are separately identified in the Equality surveys only in 2014, so it was not possible to include them in this study, but reference is made to earlier work on their experience of labour market discrimination where relevant (McGinnity et al., 2017).

2 See Chapter 3 for how exactly discrimination is defined for survey respondents. 


\section{HEADLINE FINDINGS}

When we account for differences between groups that we expect to influence labour market outcomes - educational qualifications, age, gender, family type, broad region and length of time living in Ireland - we find for all three years combined:

- Differences between White UK nationals and the White Irish group are minimal for all outcomes - employment rates, occupational position, and the experience of discrimination seeking work and in the workplace;

- White EU-West nationals are actually more likely to be employed than White Irish, while there is no difference in terms of occupational position, in discrimination seeking work and in the workplace;

- For White EU-East nationals, we find no difference in employment rates or reported discrimination seeking work, but this group are more likely to experience discrimination in the workplace (1.5 times as likely). Members of this group are also considerably less likely to occupy managerial/professional jobs (0.2 times as likely);

- The White non-EU group shows no difference in employment rates or occupational position compared to White Irish, but their experience of discrimination in the Irish labour market differs from their Irish counterparts. They are more likely to report discrimination seeking work, possibly due to the fact that most of them need an employment permit to work in Ireland. They are also more likely to experience discrimination in the workplace than White Irish (1.6 times as likely);

- $\quad$ The Black non-Irish group is much less likely to be employed (0.4 times as likely) and when individuals from this group do have a job, they are also much less likely (0.3 times as likely) to hold a managerial/professional job than White Irish. The Black non-Irish group are five times as likely as White Irish to experience discrimination seeking work and 2.7 times as likely to experience discrimination in the workplace;

- $\quad$ The Black Irish group shows little difference to the majority White Irish population in terms of overall employment. Yet for occupational position, the group shows considerable disadvantage, being much less likely ( 0.3 times as likely) to hold a managerial/professional job than White Irish. Black Irish are twice as likely to 
experience discrimination seeking work and 3.4 times as likely to experience discrimination in the workplace as White Irish. In overall employment rates and in seeking work there seems to be an advantage to being Irish for those of Black ethnicity, but not in the workplace or occupational position of the job;

- The Asian non-Irish group does not differ from White Irish in terms of their overall employment rates but they are less likely to be in the top jobs ( 0.5 times as likely). Asian non-Irish do not differ significantly from White Irish in discrimination seeking work;

- The Asian Irish group does not differ from White Irish in terms of employment rates and Asian Irish are actually advantaged in occupational position that is more likely to be working in professional/managerial occupations than White Irish (1.9 times as likely). This may be related to immigration policy, which restricts employment permits for non-EU nationals to high-skilled jobs;

- Asian Irish do not differ from White Irish in their experience of discrimination seeking work but are 1.9 times as likely to experience discrimination in the workplace than White Irish. Workplace discrimination can include bullying or harassment, unfair treatment in terms of working conditions, promotion, pay and other forms of discrimination.

- No clear trends emerge when we look at changes over the period 2004-2014, but we observe some interesting patterns for individual groups. For example the gap in employment rates between White Irish and Black non-Irish is much smaller in 2014 than in earlier years. For most ethnic/national groups the gap between them and White Irish in terms of occupational position is smaller in 2014 too; the exception here is the White Non-EU group.

- Looking at change over time in the experience of discrimination seeking work, we find gaps between White Irish and most groups narrowing somewhat in the period 2004-2014. In terms of the experience of discrimination in the workplace, by contrast, the gap between White Irish and Minorities Irish was larger in 2014 compared to earlier years. Note some of these changes over time may be due to changes in the composition of the groups over time. 


\section{IMPLICATIONS FOR POLICY AND DATA COLLECTION}

This report documents considerable variation in the outcomes of ethnic/national groups in the Irish labour market in this period and reflects on the policy implications of these differences. One implication of the findings is the importance of recognising qualifications acquired abroad. While Quality and Qualification Ireland (QQI) provides assistance to nonIrish nationals in having qualifications recognised, it is crucial that awareness of this system is promoted among both immigrants and employers to prevent skills being underutilised and facilitate occupational mobility. Programmes that allow migrants to acquire and develop skills relevant to the Irish labour market, including English language programmes, should complement efforts to ensure recognition of qualifications, in order to address the disadvantage migrants may experience and ensure occupational progression.

The much higher rates of labour market discrimination experienced by some ethnic/national groups highlights the need for both government and employer-led policies to monitor, prevent and respond to incidences of discrimination in recruitment and in the workplace. While legislative measures to respond to employment discrimination have been in place in Ireland for some time, other measures to prevent discrimination are also necessary to promote equality of opportunity. Given low knowledge of rights among some minority, ethnic and immigrant groups, awareness-raising efforts should be coupled with provision of information to immigrant communities about equality legislation and the supports available to them.

Ethnicity is a key locus of disadvantage in this report. However it is rarely measured in repeated survey data in Ireland. The regular collection of ethnicity in labour market surveys is a key priority at this time. Furthermore, the acquisition of Irish citizenship among non-EU nationals and also the growing second generation brings new challenges to measure and monitor the experience of immigrants in Ireland and these challenges also have to be addressed if adequate policy responses to disadvantage are to be developed. 


\section{CHAPTER 1}

\section{Introduction and context}

\section{$1.1 \quad$ INTRODUCTION}

The inward migration that accompanied the economic boom of the late 1990s and early 2000 s has brought increased ethnic and national diversity to Ireland. There has always been some ethnic and national diversity in Ireland - in particular an Irish-born ethnic-minority group, Irish Travellers (Watson et al., 2017), and a significant minority of UK nationals ( $\mathrm{O}^{\prime}$ Connell and McGinnity, 2008) - but ethnic and national diversity increased considerably as a result of rapid immigration. This report investigates how these different ethnic and national groups have fared in the Irish labour market using large representative datasets from 2004, 2010 and 2014.

While some research has focused on the difficulties immigrants face in labour market integration, other work has highlighted the role of ethnicity, arguing that ethnic minorities face disadvantage regardless of whether they were born in the country due, among other factors, to ethnic/racial discrimination. This report combines a focus on country of origin, nationality and ethnicity to explore both labour market outcomes and the experience of labour market discrimination. As a sizeable proportion of those from an ethnic minority background are now Irish citizens, the report also explores if having Irish citizenship is associated with less disadvantage and discrimination.

Chapter 1 sets the context by describing the changing pattern of immigration and key features of Irish migration policy - the employment permit system and the international protection system. It documents the increased national and ethnic diversity in Ireland, as well as dramatic change in the Irish labour market during the period (2004-2014). It also discusses the equality and non-discrimination framework and the recent Migrant Integration Strategy. Chapter 2 discusses country-level policies and the legal framework which determines the conditions under which migrants can work in Ireland, as well as the role of factors such as education, duration of residence and discrimination in understanding migrants' labour market outcomes. Chapter 3 presents the evidence base, the Equality 
modules combined with the Labour Force Survey (QNHS), and in particular how we create the ethnic/national groups to investigate key research questions. A profile of ethnic/national groups is also presented. Chapter 4 looks at labour market inequalities across ethnic and national groups, and whether they have changed over time. Specifically it considers employment rates and the likelihood of having a professional/managerial job, while controlling for other characteristics related to occupational position, such as education, age and length of residence in Ireland. Chapter 5 focuses on ethnic/national variation in the experience of discrimination both in seeking a job and in the workplace. Chapter 6 presents a summary and a reflection of some policy implications.

\subsection{MIGRATION AND LABOUR MARKET CONTEXT}

\subsubsection{Immigration flows}

A country where more people left than arrived prior to the 1990s, Ireland has experienced considerable changes in migration flows in the past two decades, due to the expansion of the European Union in 2004 and the economic boom from the mid-1990s up to 2007 known as the 'Celtic Tiger'. Figure 1.1 shows that the inflow of migrants almost tripled from around 58,500 in 2004 to a peak of around 151,100 in 2007. Ireland's entry into recession in 2008 led to a rapid decrease in immigration, with rising emigration of both Irish and non-Irish nationals resulting in net emigration from 2009. However, with economic recovery and the renewed demand in the labour market that followed, immigration flows have risen steadily since 2010, increasing by almost 60 per cent from 41,800 in 2010 to 66,500 in 2014 and by a further 27 per cent to 84,600 in 2017. 


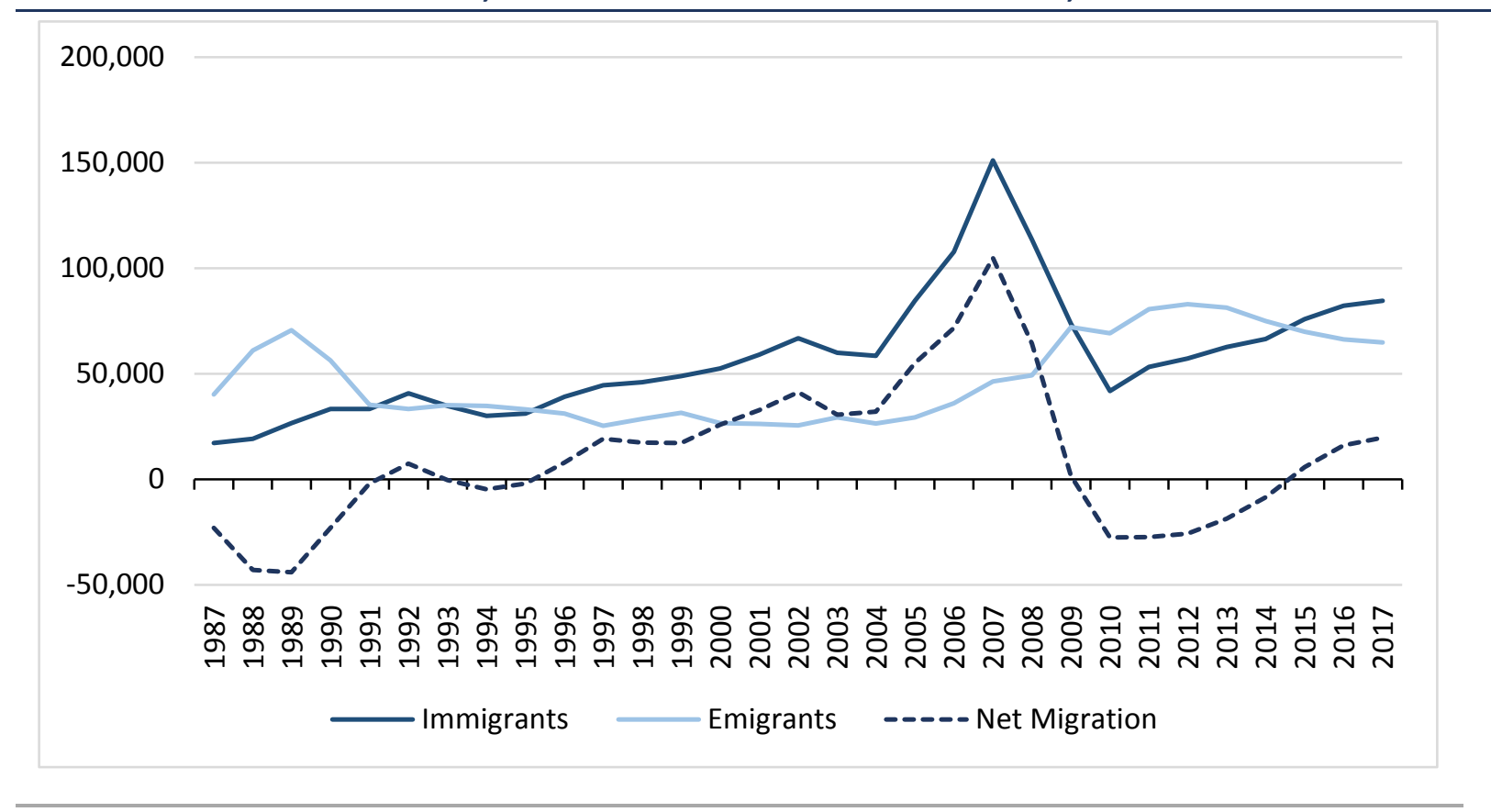

Source: CSO, Population and Migration Estimates.

Note: Year to April of reference year.

Figure 1.2 presents the composition of immigration flows according to nationality and shows how the expansion of the EU had a considerable impact on immigration flows. When ten countries joined the EU in 2004, Ireland was one of only three EU Member States to grant nationals of those countries immediate and full access to the labour market. By 2007, nationals of EU-East accounted for 56 per cent of immigration flows to Ireland. In contrast, when Bulgaria and Romania joined the EU in 2007, nationals of both Member States were not automatically granted full access to the labour market. It was only in 2012 that Bulgarian and Romanian nationals were granted full access to the labour market and accordingly afforded employment rights equivalent to those enjoyed by other EU nationals.

Immigration of both EU-East and non-EU nationals subsequently declined between 2007 and 2010, when inflows of EU-East in particular sharply decreased by 89 per cent during the recession. Figure 1.2 shows that overall immigration increased for all national groups between 2010 and 2014, particularly among non-EU nationals, with non-EU arrivals increasing from 6,000 to 19,000 . 
FIGURE 1.2 NATIONALITY OF IMMIGRATION FLOWS, 2004-2014

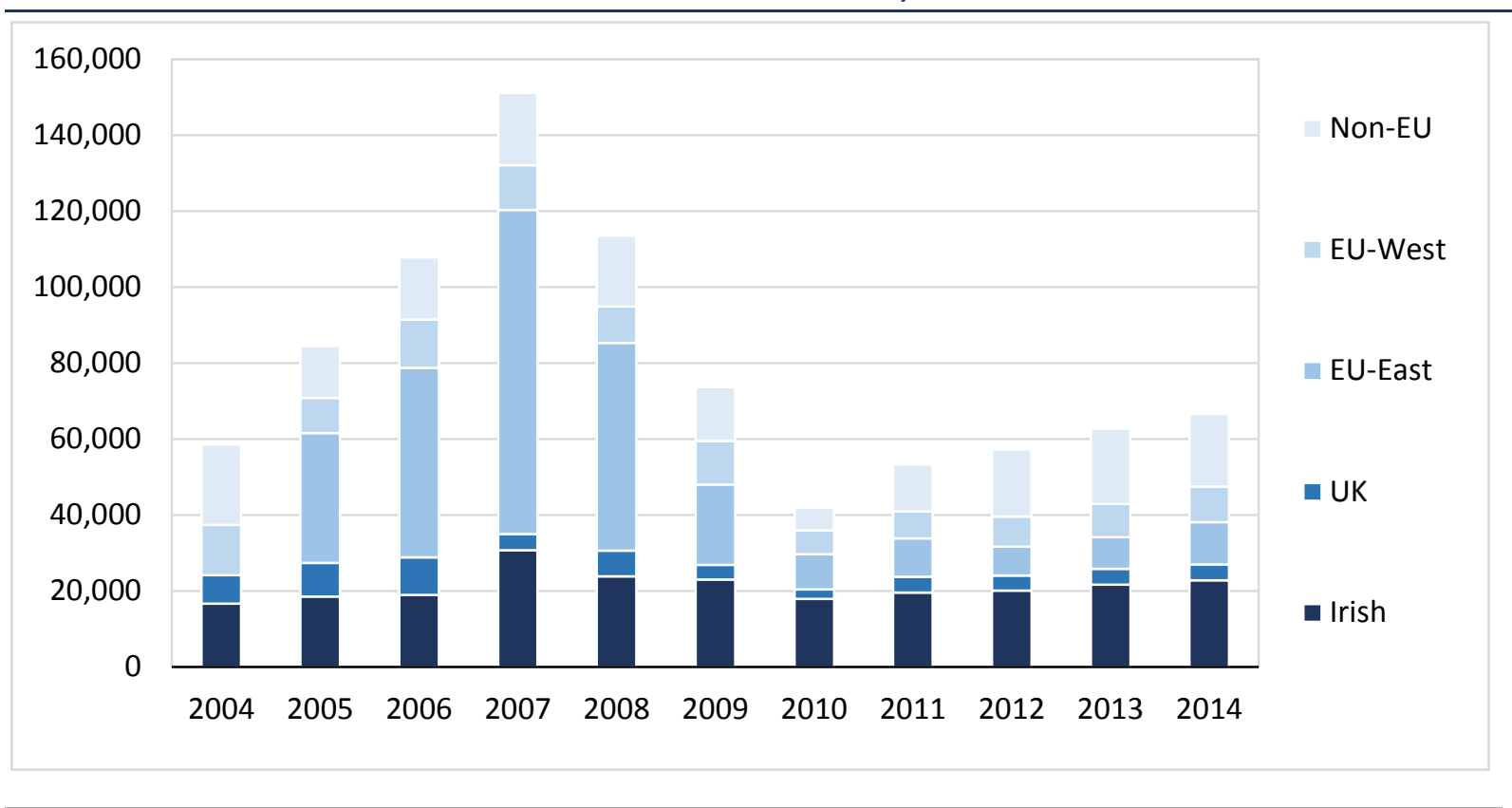

Source: $\quad$ CSO 'Population and Migration Estimates', various releases.

Notes: Year to April of reference year. For definitions of EU-East and EU-West see Glossary.

\subsubsection{Access to employment for non-EU nationals}

The low proportion of non-EU nationals in immigration flows to Ireland is reflective of Ireland's labour migration policy. Nationals of the European Economic Area (EEA) are entitled to reside and work in Ireland without restriction. The EEA includes citizens of the EU in addition to Iceland, Liechtenstein and Norway. For the purposes of this study, non-EU nationals refer to nationals of countries outside of the EEA. Unlike EU nationals who have the right to reside and work in Ireland, access to the labour market for non-EU nationals is regulated by labour migration policy. Most newly arrived non-EU nationals are not entitled to automatic access to the Irish labour market and must hold an employment permit in order to take up employment. The employer permit system is employer-based, meaning permit holders can only work for the employer and in the occupation stated on the permit.

In 2003 , over 47,500 employment permits were issued to non-EU nationals for occupations across skill levels (Ruhs, 2005). However, to coincide with EU enlargement in 2004, the government adopted the Employment Permits Act 2003, which introduced a number of regulations limiting non-EU migration to the most highly-skilled occupations, on the basis of a policy oriented towards meeting labour market needs from within the EU. 
The move to a more restrictive, skills-based permit system, and implementation of policies requiring employers to give preference to EU nationals in recruitment, played an important part in the shifting nature of immigration flows to Ireland (Ruhs, 2005). By 2007, the number of employment permits issued to non-EU nationals decreased by over 50 per cent to 23,604 and continued to decrease until 2013, when only 3,863 permits were issued. In 2014, the Employment Permits (Amendment) Act 2014 introduced a number of reforms to the permit system, including providing for flexibility to respond to labour market needs. In light of economic recovery at the time and growing shortages in certain sectors of the labour market, the issuing of employment permits began to increase again in 2014 , when 5,495 permits were granted to non-EU nationals (Gusciute et al., 2015).

Some non-EU nationals may also access employment without the need for an employment permit in certain circumstances. Non-EU nationals who hold a Stamp 4 residence permission, such as beneficiaries of international protection, and other resident non-EU nationals, such as those who may have permission to remain as a spouse, civil partner or dependant of an Irish/EU citizen, enjoy rights equivalent to those enjoyed by Irish and EU nationals in seeking employment. Non-EU students who hold a Stamp 2 residence permission may also access the labour market for up to 20 hours during term-time and on a full-time basis during holiday periods, while certain non-EU graduates may access employment on a Stamp $1 \mathrm{G}$ permission for periods of up to two years following graduation. Migrants working in Ireland who entered Ireland legally may also become undocumented through exploitation or administrative delay and may be in situations of precarious employment (Arnold et al., 2017).

\subsubsection{The international protection system}

Non-EU nationals fleeing persecution or serious harm in their country of origin may be granted international protection in Ireland, in line with Ireland's obligations to provide protection to refugees under the 1951 Convention on the Status of Refugees. In line with overall immigration flows in Ireland, the number of persons seeking international protection in Ireland grew in the late 1990s, with applications significantly increasing from 39 in 1992 to 11,634 in 2002. From 2002, applications decreased year-on-year to 946 in 2013. In 2014, applications for international protection rose sharply by 53 per cent to 1,448 (Office of the Refugee Applications Commissioner, 2014). From 2001 to 2013, Nigeria was recorded as the 
top country of origin of persons seeking international protection, while nationals of Pakistan, Democratic Republic of the Congo, Zimbabwe and China have also regularly featured in the top five countries of origin over this period.

Persons awaiting a decision on an application for international protection are accommodated in direct provision. ${ }^{3}$ While it was initially intended that international protection applicants would spend only short periods in the international protection system, in practice many have spent several years awaiting a decision on their application. At the end of 2014, 4,364 international protection applicants were residing in direct provision accommodation centres in Ireland, 2,722 (63 per cent) of whom had been in the international protection system for more than three years. In the same year, 894 international protection applicants (20 per cent) were awaiting a final decision for seven years or more (Reception and Integration Agency, 2015). In 2015 the government introduced the International Protection Act 2015, which includes a number of measures to improve the efficiency of the international protection process and to reduce the time international protection applicants spend awaiting a decision in the direct provision system.

Until recently international protection applicants were prohibited from seeking employment in Ireland. In May 2017, the Supreme Court in NHV v. Minister for Justice and Equality and ors ${ }^{4}$ held that, in circumstances where there is no time limit on the international protection process, the absolute prohibition on seeking employment is contrary to the constitutional right to seek employment. Following the judgment, the Government announced in June 2018 that international protection applicants who had not received a first instance decision on their application for international protection within nine months would be permitted to seek employment, subject to conditions, in line with the EU (recast) Reception Conditions Directive (2013/33/EU). As of October 2018, 2,150 international protection applicants had applied to the Minister for Justice and Equality for labour market access permission, 1,521

\footnotetext{
3 Direct provision is the system in which international protection applicants are given full board in accommodation centres operated by the Reception and Integration Agency, while waiting for a decision on their application for international protection. Each international protection applicant currently receives a personal allowance of $€ 21.60$ per week.
} [2017] IESC 35. 
of whom were granted permission. Of the 1,521 applicants granted permission, 330 applicants had secured employment. ${ }^{5}$

As highlighted by the Irish Human Rights and Equality Commission in its submissions as amicus curiae to the Supreme Court in the NHV case, the denial of the right to work to international protection applicants over a period of many years may have had a severe impact on their ability to access employment once they are entitled to do so (see also Ní Raghallaigh et al., 2016). ${ }^{6}$

\subsubsection{Immigration stock: nationality and ethnicity}

Ireland's relatively recent history of large-scale immigration is reflected in the high proportion of foreign-born persons in the Irish population. Table 1.1 shows that the proportion of non-Irish persons in 2002 almost doubled from 5.8 per cent to reach 10.2 per cent in 2006.

The proportion of non-Irish nationals resident in Ireland further increased to 12.7 per cent in 2009. Table 1.1 shows that this proportion gradually decreased to 12.3 per cent in 2010 and continued to fall to 11.4 per cent in 2014 . The decrease in the years leading up to 2014 is partly attributed to the increase of non-Irish nationals acquiring Irish citizenship particularly from 2011, both due to an increase in eligible migrants applying for naturalisation and the introduction of reforms to reduce a backlog of applications at the time (Barrett et al., 2017). The number of new Irish citizens increased from 6,300 in 2010 to over 25,000 in 2012 and decreased to 21,104 in 2014 (Eurostat, 2018).

www.rte.ie/news/2018/1022/1005825-asylum-seekers.

Section 10(2)(e) of the Irish Human Rights and Equality Commission Act 2014 provides that the Irish Human Rights and Equality Commission may apply to the High Court or Supreme Court as amicus curiae (friend of the court) in proceedings that concern human rights or equality of any person. 
TABLE 1.1 TOTAL POPULATION BY NATIONALITY, 2002-2014

\begin{tabular}{|l|r|r|r|r|r|}
\hline \multicolumn{1}{|c|}{ Nationality } & \multicolumn{1}{c|}{$\mathbf{2 0 0 2}$} & \multicolumn{1}{c|}{$\mathbf{2 0 0 6}$} & \multicolumn{1}{c|}{$\mathbf{2 0 1 0}$} & \multicolumn{1}{c|}{$\mathbf{2 0 1 4}$} & $\begin{array}{c}\text { \% Change } \\
\mathbf{2 0 0 2}-\mathbf{2 0 1 4}\end{array}$ \\
\hline Irish & $3,584,975$ & $3,802,400$ & $3,994,700$ & $4,117,600$ & 14.9 \\
\hline UK & 103,476 & 115,500 & 115,900 & 107,100 & 3.5 \\
\hline EU-West & 29,960 & 43,800 & 52,400 & 56,900 & 89.9 \\
\hline EU-East & $\mathrm{N} / \mathrm{A}$ & 132,500 & 233,000 & 242,800 & $83.2 *$ \\
\hline Non-EU & 90,825 & 138,800 & 158,700 & 121,000 & 33.2 \\
\hline Total Population & $3,917,200$ & $4,232,900$ & $4,554,800$ & $4,645,400$ & 18.6 \\
\hline Total non-Irish & 224,261 & 430,600 & 560,000 & 527,800 & 135.4 \\
\hline \% non-Irish & 5.8 & 10.2 & 12.3 & 11.4 & \\
\hline
\end{tabular}

Source: CSO, Census 2002; CSO, 'Population and Migration Estimates', various releases.

Notes: $\quad$ Population by nationality was not available for 2004.

EU-East 2006 data represent the ten EU Member States that joined the EU in 2004: Cyprus, Czech Republic, Estonia, Hungary, Latvia, Lithuania, Malta, Poland, Slovakia, Slovenia; EU-East 2010 data also include Bulgaria and Romania, which joined the EU in 2007; EU-East 2014 data include Croatia, which joined the EU in 2013.

* Percentage change for EU-East represents change between 2006 and 2014. As the countries in the EU-East category would have been included in the 2002 non-EU figure, the percentage change for EU-East between 2002 and 2014 is likely to be much greater.

Information on ethnicity and cultural background was collected for the first time in Census 2006, and was subsequently collected in 2011 and 2016. ${ }^{7}$ Table 1.2 shows that the population is of a predominantly White ethnic or cultural background, at 92.4 per cent of the population in 2016. The number and proportion of people who indicated an ethnicity or cultural background other than 'White Irish' increased significantly between 2006 and 2016. Of the population who indicated an ethnic or cultural background other than 'White Irish', 'Other White' remains the largest group, at 9.5 per cent $(446,727)$ of the population in 2016 , increasing by more than 54.6 per cent since 2006. While persons reporting an Asian or Asian Irish ethnic or cultural background increased between 2006 and 2016, persons of Asian ethnic or cultural background account for a much smaller proportion of the population, at 2.1 per cent $(98,720)$ in 2016 . The number of persons reporting a 'Black or Black Irish' ethnic or cultural background also increased between 2006 and 2016, however they have remained at a consistently low proportion of the population, amounting to 1.4 per cent $(64,639)$ in 2016. A large number of people did not disclose their ethnic or cultural background in the 2016 Census. 
TABLE 1.2 POPULATION BY ETHNIC OR CULTURAL BACKGROUND 2006, 2011 AND 2016

\begin{tabular}{|l|r|r|r|r|r|r|}
\hline $\begin{array}{c}\text { Reported ethnic or } \\
\text { cultural background }\end{array}$ & \multicolumn{2}{|c|}{2006} & \multicolumn{3}{c|}{2011} & \multicolumn{3}{c|}{2016} \\
\hline & Persons & $\%$ & Persons & \multicolumn{1}{c|}{$\%$} & Persons & $\%$ \\
\hline White & $3,956,609$ & 94.8 & $4,264,465$ & 94.2 & $4,331,940$ & 92.4 \\
\hline Irish & $3,645,199$ & 87.4 & $3,821,995$ & 84.5 & $3,854,226$ & 82.2 \\
\hline Irish Traveller & 22,369 & 0.5 & 29,495 & 0.7 & 30,987 & 0.7 \\
\hline Other White & 289,041 & 6.9 & 412,975 & 9.1 & 446,727 & 9.5 \\
\hline Black or Black Irish & 44,318 & 1.1 & 65,078 & 1.4 & 64,639 & 1.4 \\
\hline Asian or Asian Irish & 52,345 & 1.3 & 84,690 & 1.9 & 98,720 & 2.1 \\
\hline Other, including Mixed & 46,438 & 1.1 & 40,724 & 0.9 & 70,603 & 1.5 \\
\hline Not Stated & 72,303 & 1.7 & 70,324 & 1.6 & 124,019 & 2.6 \\
\hline Total & $4,172,013$ & 100.0 & $4,525,281$ & 100.0 & $4,689,921$ & 100.0 \\
\hline
\end{tabular}

Source: CSO, Census 2006; Census 2011; Census 2016.

\subsubsection{The Irish labour market}

The period of 2004 to 2014, which the data analysis in later chapters covers, was also one of dramatic change for the Irish labour market. Between 2000 and 2007, Ireland experienced extremely strong economic growth: construction boomed, standards of living were at an alltime high and the unemployment rate averaged 4.5 per cent per annum. However, the collapse of the construction and banking sectors precipitated by the global financial crisis meant that the Irish economy entered a deep recession in 2008, with severe labour market consequences. Figure 1.3 shows that by the fourth quarter of 2010, 14 per cent of the labour force in Ireland were unemployed (CSO, 2012). Job losses were particularly dramatic in the construction sector, but also administrative and support services, industry, wholesale and retail sectors (Russell et al., 2014). 
FIGURE 1.3 UNEMPLOYMENT RATES (ILO), IRELAND, 2002-2016

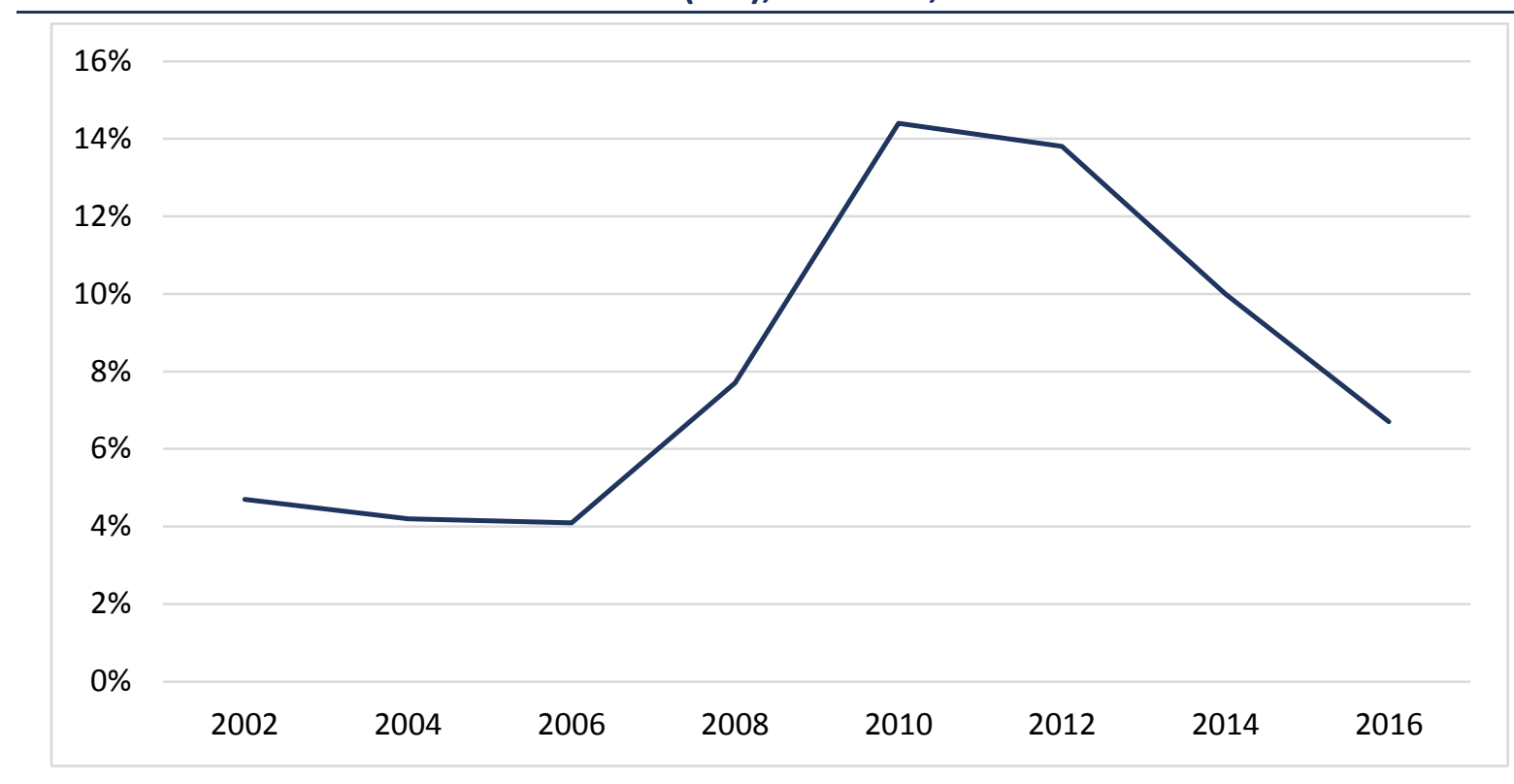

Source: $\quad$ CSO QNHS Q4 2002-2016.

Note: Unemployment rate for the labour market active population in Ireland.

Job losses were combined with dramatic cuts in public expenditure and public sector wages, a recruitment freeze in the public sector, and large tax increases ( $O^{\prime}$ Connell, 2013). The Irish economy began to recover in 2011. After three successive years of falling GDP, Ireland recorded a positive GDP growth rate in 2011 of 1.4 per cent, and unemployment rates began to decrease after 2010 as the economy showed signs of recovery. Figure 1.3 shows that unemployment continued to fall, reaching around 10 per cent by 2014 - the final time point in the data used for this study. ${ }^{8}$ Unemployment would continue to decrease in the years following 2014 , which reflects the sustained improvements in the labour market since the recession.

\subsection{RELEVANT LEGAL AND POLICY FRAMEWORK}

\subsubsection{Equality and non-discrimination in Irish law}

The Employment Equality Acts 1998-2015 and Equal Status Acts 2000-2015

In Ireland, protection against discrimination is provided for by the Employment Equality Acts 1998-2015, which prohibit discrimination in employment-related areas and by the Equal Status Acts 2000-2015, which prohibit discrimination in the provision of goods and services,

8 Source: CSO Statbank, Quarterly National Household Surveys. 
accommodation and access to education. Under the Acts, discrimination is deemed to occur when a person is treated less favourably than another person is, has been or would be treated in a comparable situation on the grounds of gender, civil status, family status, age, disability, race, sexual orientation, religious belief, membership of the Traveller Community and/or (in the case of the Equal Status Acts 2000-2015) receipt of housing assistance. ${ }^{9}$ Discrimination on the ground of race is described as discrimination on the basis of being of different race, colour, nationality or ethnic or national origins. ${ }^{10}$ The Acts address both direct and indirect discrimination: direct discrimination occurs when a person is treated less well than another person in the same situation or circumstances under any of the ten grounds covered in the Acts; indirect discrimination refers to practices or policies that do not appear on the face of it to be discriminatory but have a discriminatory impact.

The Employment Equality Acts 1998-2015 aim to ensure equality of opportunity in relation to employment for both Irish and non-Irish nationals. The Acts prohibit discrimination in relation to accessing employment, working conditions, training in the workplace, harassment, as well as other employment-related areas. A person who believes they have been discriminated against on the grounds of race may seek redress via the Workplace Relations Commission ${ }^{11}$ and on appeal to the Labour Court. ${ }^{12}$ In 2017, 189 of 1,113 complaints referred to the Workplace Relations Commission under the Employment Equality Acts were based on the race ground, comprising 17 per cent of all complaints made (WRC, 2018). The race ground was the highest and second highest ground cited in appeals to the Labour Court in 2014 and 2015 respectively (Labour Court, 2015; 2016).

Informal means of reporting discrimination and racism in the workplace are also provided through NGOs such as the European Network Against Racism Ireland, which established the online iReport Racist Incident Reporting System in $2013 .{ }^{13}$ This discussion focuses on current

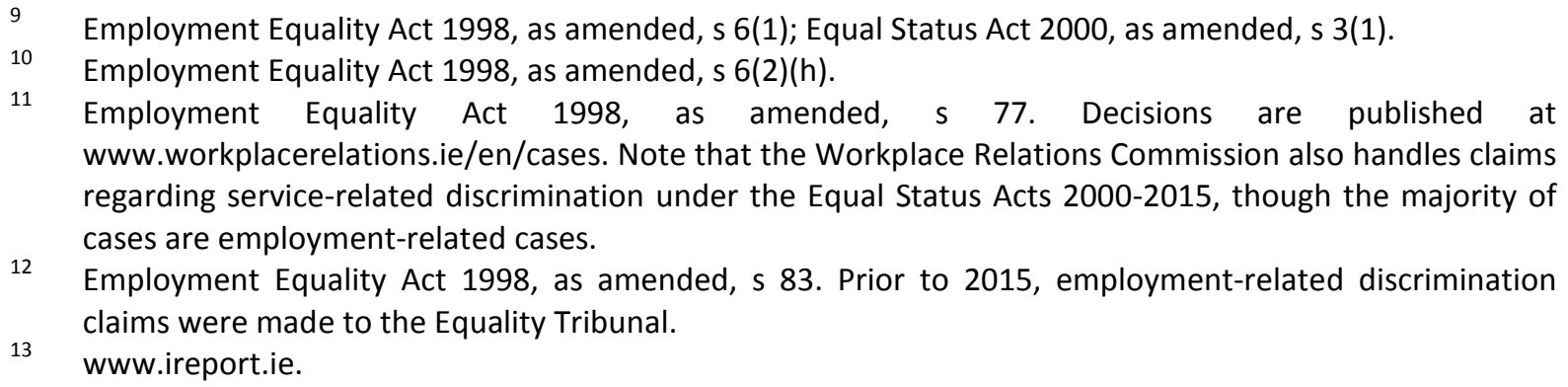
www.workplacerelations.ie/en/cases. Note that the Workplace Relations Commission also handles claims regarding service-related discrimination under the Equal Status Acts 2000-2015, though the majority of cases are employment-related cases.

12 Employment Equality Act 1998, as amended, s 83. Prior to 2015, employment-related discrimination claims were made to the Equality Tribunal. www.ireport.ie.

13 
provision, though note the period covered by the data in this report, 2004-2014, was a period of considerable change in institutions concerned with discrimination in Ireland. Fanning and Michael (2017) argue that much of the institutional infrastructure for monitoring, reporting and responding to racism and discrimination in Ireland, such as the National Consultative Committee on Racism and Interculturalism, was dismantled during the recession and has not been replaced.

\section{The Irish Human Rights and Equality Commission Act 2014}

The Irish Human Rights and Equality Commission (IHREC) was established in 2014 as the national human rights institution and national equality body for Ireland, merging two organisations, the Equality Authority and the Irish Human Rights Commission. In line with the Irish Human Rights and Equality Commission Act 2014 (the 2014 Act), IHREC has a specific role in promoting human rights and equality and working toward the elimination of discrimination, including in the areas covered by the Employment Equality Acts. ${ }^{14}$ IHREC is responsible for providing information to the public on the Acts, reviewing the effectiveness of the Acts and, where it deems necessary, making proposals to the Minister to amend the Acts. ${ }^{15}$ IHREC may in some circumstances provide legal assistance to persons who wish to bring a claim relating to discrimination under the Acts to the Workplace Relations Commission. ${ }^{16}$ IHREC can also prepare codes of practice relating to the elimination of discrimination, ${ }^{17}$ and can invite particular organisations to carry out an equality review, or can itself carry out reviews of organisations with more than 50 employees, to determine whether the policies and practices are conducive to the promotion of equality of opportunity. $^{18}$

The 2014 Act also established the Public Sector Equality and Human Rights Duty, which is a statutory obligation that requires public bodies to have regard to the need to promote equality, prevent discrimination and protect the human rights of employees, customers and

\footnotetext{
Irish Human Rights and Equality Commission Act 2014, s 10. Irish Human Rights and Equality Commission Act 2014, s 30(1). Irish Human Rights and Equality Commission Act 2014, s 40. Irish Human Rights and Equality Commission Act 2014, s 31. Irish Human Rights and Equality Commission Act 2014, s 32.
} 
service users. ${ }^{19}$ The Act sets out three steps that must be taken by public bodies to implement the duty, which include setting out in their strategic plan an assessment of human rights and equality issues relevant to their functions, setting out the policies and practices in place or proposed to be put in place to address these issues, and reporting on developments and achievements in this regard. Public sector duties in other jurisdictions have been shown to enhance the provision of public services to reduce inequalities and drive cultural change within the public sector (Equality and Rights Alliance, 2015). In carrying out assessments, public bodies have identified issues such as the need to promote and raise awareness of cultural diversity to inform employment practices, support staff from diverse backgrounds and inform service delivery to diverse communities. IHREC promotes the implementation of the duty by public bodies and may invite public bodies to review their implementation of the duty if there is evidence of failure by a public body to perform its functions in line with the duty. The duty encourages a more proactive approach by public bodies to equality for groups protected under equality legislation, by seeking to prevent unfair treatment occurring in the first instance.

\subsubsection{Migrant Integration Strategy}

In the context of a continued rise in immigration and acquisition of Irish citizenship by naturalisation, policy developments have begun to focus on the integration of migrants and persons with a migrant background in Ireland. The Office for the Promotion of Migrant Integration within the Department of Justice and Equality is responsible for developing, leading and coordinating migrant integration policy across government departments, agencies and services. In 2014, the Government set about reviewing Ireland's approach to the integration of migrants, culminating in the publication of the Migrant Integration Strategy 2017-2020 (Department of Justice and Equality, 2017). The Strategy seeks to identify and address barriers to integration in order to enable migrants or persons of migrant origin to participate on an equal basis with those of Irish heritage in Irish society. It applies to EU nationals, non-EU nationals and persons with a migrant background, however international protection applicants are excluded from its remit. Acknowledging that unemployment rates are considerably higher for specific migrant groups, particularly

19 Irish Human Rights and Equality Commission Act 2014, s 42. 
migrants of African origin, the Strategy includes several actions specific to labour market integration. The Strategy also recognises racism and discrimination as barriers to integration and includes commitments to combat racism and xenophobia, through strengthening hate crime legislation, intercultural awareness and training and working with communities affected by stigmatisation and developing appropriate relationships with minority communities. 


\section{CHAPTER 2}

\section{Why do labour market outcomes differ across ethnic/national} groups?

\section{$2.1 \quad$ INTRODUCTION}

The difference in labour market outcomes between immigrants and those born in the host country has been a persistent concern in Western societies: immigrants typically have lower employment rates, higher unemployment and lower job quality, though there is considerable variation between groups, depending on host country context and country of origin (Heath and Cheung, 2007). This chapter reviews some previous evidence on labour market outcomes across immigrant and ethnic minorities in Ireland and internationally, and some proposed explanations. Research in the area differs according to the groups defined: some studies consider immigrants or those who are not citizens of the host country: others focus primarily on different ethnic groups, regardless of whether groups are from an immigrant background. Some authors propose that differences between groups are because of personal characteristics such as educational qualifications, work experience, language and other job-related skills and resources. Other authors stress employer behaviour, in particular unequal treatment in the form of discrimination, as underlying group differences. The legal framework in terms of who is allowed to come to Ireland and who is allowed to work is also salient for understanding outcomes. These differing perspectives form the structure of the chapter and allow us to formulate key research questions.

\subsection{COUNTRY-LEVEL POLICIES AND LEGAL FRAMEWORK}

One set of factors that influence immigrants' and ethnic minorities' labour market outcomes are state policies and laws that govern who can come to a country, whether and under what conditions they can work, and if and when they can acquire citizenship of that country.

One example of such regulations is that all EU nationals may move to Ireland and take up employment without restriction. Non-EU nationals are subject to managed migration policy that, since 2004, is designed to meet most labour market needs from within the EU and 
relies on the employment permit system to meet skill shortages, mostly in highly-skilled occupations (see Chapter 1). The employment permit system has been revised a number of times, but does require non-EU nationals to have an employment permit for a specific job to work in Ireland, restricts mobility between employers, and many permits restrict family reunification.

Another way state regulations can affect labour market outcomes relates to those seeking international protection. Until very recently, international protection applicants awaiting decisions on their applications were not allowed to work in Ireland (see Chapter 1). The direct provision system of accommodation was designed as a short-term transition system; in practice some applicants seeking international protection status wait years to receive a decision and, until 2018, were unable to enter the labour market (Gusciute et al., 2016). Kingston et al. (2013) suggest that this extended period out of the labour market has led to a negative effect on future employment prospects of those granted international protection, particularly for the African group in Ireland (see also O'Connell, 2018).

A final state policy in the area concerns naturalisation. Adult non-Irish nationals can apply for Irish citizenship if they are of 'good character' and have lived in Ireland for five of the previous eight years. ${ }^{20}$ As noted in Chapter 1 , there was a rapid increase in naturalisation rates in the years immediately preceding 2014 , both due to an increase in eligible applicants and the introduction of reforms to reduce a backlog of applications at the time (Barrett et al., 2017). By the end of 2015, Barrett et al. (2017) estimate that a sizeable minority (up to 45 per cent) of adult non-EU immigrants had acquired Irish citizenship. This is an upper bound estimate, as it doesn't account for the fact that some who have naturalised might have left Ireland, but it does imply that many immigrants and ethnic minorities of non-EU origin may be Irish citizens in 2014 . As Irish citizens, this group are free to live and work in Ireland without restrictions.

20 See Barrett et al., 2017, Box 5.1 for detailed regulations. 


\subsection{PERSONAL CHARACTERISTICS OF IMMIGRANTS}

Human capital theory has been hugely influential in explanations of labour market outcomes. The main premise of the theory is that education, in addition to work experience, is the key to success (Becker, 1975). From this, it may be inferred that poorer labour market outcomes among immigrants may be due to lower educational attainment, or at the very least educational qualifications play a key role in understanding labour market outcomes such as unemployment. In fact as Barrett et al. (2017) show, non-Irish nationals in Ireland typically have higher qualifications than Irish nationals, partly related to the younger age profile of immigrants. Those from Western Europe and from non-EU countries are particularly highly qualified. The latter is partly due to the fact that non-EU immigrants in Ireland can only get an employment permit for highly-skilled occupations (see Chapter 1 and also Section 2.2).

One restriction for immigrants is that educational qualifications acquired abroad may not have the same value in the Irish labour market as Irish qualifications. The same may be true of work experience, which employers may rate more highly if acquired in Ireland than abroad.

Host country language skills, while not explicitly mentioned by Becker, have been shown by studies to be key to labour market success (Chiswick and Miller, 1995). This implies that immigrants from English-speaking countries like the UK may fare better in the Irish labour market than those from non-English speaking countries, as found by Barrett and McCarthy (2007). ${ }^{21}$ But it may be true that even those from non-English speaking countries will improve their language as they stay in the country longer. Using 2011 Census data, O'Connell (2018) finds fluency in English increases the likelihood of employment among minority ethnic groups.

The survey data used do not include a measure of English language skills. Census 2016 data on self-assessed language indicate that 83 per cent of the 612,000 people who spoke another language at home indicated that they could speak English 'well' or 'very well', while

\footnotetext{
21 Note that some countries are more difficult to classify in terms of whether they are English-speaking or not, for example India and Nigeria.
} 
14 per cent indicated 'not well' or 'not at all'. The ten nationalities with the highest (selfrated) language ability included EU-West nationals (Swedish, German, Dutch, French); African nationals (Nigerian) and Asian (Filipino and Indian). EU-East nationals were among the lowest ability (Polish, Romanian, Latvian, Lithuanian), along with Brazilians, Chinese and Afghans, although even among these groups around 75 per cent rated their language as good or very good (CSO, 2017).

This brings us to Borjas' (1999) argument that immigrants will 'assimilate' the longer they reside in the host country: in other words, the more they invest in specific local skills such as language and acquire country-specific work experience and social networks that help them find new and better jobs. Esser (2004) argues that successful integration may depend on the situation and context; in any event it is difficult to integrate into a new labour market without some knowledge of the 'rules' of the host society. Immigrants are more likely to have learned these 'rules' the longer they have lived in Ireland.

\subsection{EMPLOYER/HOST COUNTRY BEHAVIOUR}

Yet explanations about education, experience, language and duration often do not adequately explain the disadvantage observed in labour market outcomes for some immigrants and ethnic minority groups. A third group of factors relates to the behaviour of host country nationals, particularly employers. Employers may discriminate against immigrants or ethnic/racial minorities either because they consider the groups as a whole to be less productive ('statistical discrimination'), or because they prefer to hire from their own national or ethnic group ('taste-based discrimination') (Becker, 1975; Arrow, 1973).

Whatever the explanation, discrimination suggests that despite having the same education, experience and labour market skills, some groups will always have poorer outcomes in the labour market (OECD, 2013). The presence of discrimination is a powerful counter to theories of labour market assimilation, and it implies certain groups will never achieve their potential and integrate fully into the labour market.

Groups experiencing labour market discrimination can vary over time and across countries (Eichhorst et al., 2018). Discrimination on the basis of ethnic or racial group is often highlighted, implying that White immigrants will fare better in predominantly White host countries. Yet even in the case of ethnic or racial discrimination, what it means to be Black 
or Asian or even a White immigrant can vary across countries (McGinnity and Gijsberts, 2017). Past practices, legal rules, social attitudes, the media portrayal of certain groups and the behaviour of political elites, can all contribute to the position of particular groups.

Measuring the extent of discrimination is challenging (Pager and Shepherd, 2008). Legal cases may represent the 'tip of the iceberg' in terms of how many incidents of discrimination actually make it to court and are successful (OECD, 2013). Field experiments provide compelling evidence of discrimination but are typically limited in terms of time and space and some situations are less amenable to testing (see McGinnity et al., 2017 for further discussion). One approach is to compare the labour market outcomes of the groups, taking account of gender, education, length of residence in Ireland as well as other relevant characteristics. This is very informative for relative group performance, and indeed exactly what we do in Chapter 4, but it is not clear that all remaining differences between the groups are due to employer discrimination. Another approach is to ask respondents directly about their experience of discrimination in the labour market, either in looking for work, or in the workplace if they have a job. McGinnity et al. (2017) consider evidence from selfreports for a wide range of life domains, including the labour market: Chapter 5 in this report considers this for ethnic/national groups in Ireland. While self-reports of discrimination entail an element of subjectivity, and not everyone will be aware of discrimination, using evidence from both self-reports (Chapter 5) and a detailed examination of labour market outcomes (Chapter 4) will give us a more comprehensive picture of the labour market outcomes of ethnic/national groups.

\subsection{PREVIOUS FINDINGS IN IRELAND}

Early work by Barrett and Duffy (2008) found immigrants in Ireland were less likely to be working in high-level occupations, and those from Eastern Europe had the lowest occupational attainment, with little evidence of improved attainment over time among this group. Analysing the impact of the recession, Barrett and Kelly (2012) find immigrant employment fell sharply, particularly the employment of East European nationals. Unemployment rates also rose more sharply for immigrants during the recession. While the raw or unadjusted gap in earnings between immigrants and natives also widened during the recession, Barrett et al. (2016) find that much of the earnings gap was accounted for by the changing composition of immigrants who were employed. For example the authors found 
this was partly due to a fall in the share of the immigrant employees with third-level degrees between 2006 and 2009 (Barrett et al., 2016).

More recent descriptive analysis in the recovery period found the gap in unemployment rates between Irish and non-Irish nationals narrowed to less than 0.5 per cent in Quarter 1 of 2017 (7.1 per cent for Irish nationals, 7.5 per cent among non-Irish nationals) (McGinnity et al., 2018). The labour market activity rate of non-Irish nationals exceeded that of Irish nationals by almost 4 per cent in $2017 .^{22}$

There is considerable variation between national groups in employment rates. Successive integration monitors have found very low rates of employment among African nationals (McGinnity et al., 2014; Barrett et al., 2016). In 2014, for example, the year of the final Equality module, the employment rate of African nationals was 37 per cent compared to 61 per cent for both Irish nationals and non-Irish nationals on average.

McGinnity and Lunn (2011) in their field experiment exploring discrimination in recruitment, found that candidates with clearly African, Asian or German names were half as likely as Irish candidates to be invited for an interview. Discrimination among Africans was somewhat higher than the other groups, but this difference was not significant for the number of applications tested.

Analysing semi-structured interviews with Spanish, Polish and Nigerian immigrants, as well as the Irish 2011 Census and data from an employability programme, Joseph (2017) argues that there is a 'racial order' in Ireland that disadvantages Nigerian (and by extension other Black African) immigrants. White Irish are at the top of the 'hierarchy', followed by West Europeans, then East Europeans. Joseph (2017) argues that Black workers are at the 'bottom of the ladder' not because of their achievement attributes, but because of their race.

In terms of the experience of discrimination, Kingston et al. (2015) found that between 2004 and 2010, the overall rates of discrimination experienced by minority groups declined, yet

22 The labour market activity rate is those active in the labour market (employed and unemployed), expressed as a proportion of the working age population. See also Glossary. 
high levels of work-related discrimination reported by Black Africans persisted. Later work by McGinnity et al. (2017) also found much higher levels of reported discrimination in the workplace by Black respondents and that the gap between Black and White Irish respondents grew between 2004 and 2014. Conversely, in recruitment, McGinnity et al. (2017) found that the gap between White non-Irish and White Irish fell, so that by 2014 there was no difference between these groups.

Ethnic minorities also report higher rates of discrimination in public and private services. Compared to White Irish respondents, Black respondents reported higher discrimination in both public services (education, health, transport and other public services) and in private services (shops/pubs/restaurants, banks/other financial services and housing) in 2014. Asian respondents report higher discrimination than White Irish in private services. Evidence from racist incident monitoring in a report for the European Network Against Racism suggests that between July 2013 and July 2015, the largest number of racist incidents in Ireland were reported by those of African descent (Michael, 2015). A comparative survey conducted by the European Agency for Fundamental Rights (FRA) in early 2016 found the highest rates of discrimination in the workplace experienced by sub-Saharan African respondents were documented in Luxembourg, Sweden and Ireland (in the 12 months prior to the survey) (FRA, 2017).

\subsection{RESEARCH QUESTIONS}

One question is whether there are differences between Irish and non-Irish (or immigrants) in the Irish labour market, in terms of both employment rates and job quality, after controlling for factors like education, gender and family status. A first expectation is that, if Irish citizenship is the main significant factor, we would find a large difference between those who are Irish citizens and those who are not citizens, but we may find little or no difference between the non-Irish groups.

A second expectation, drawing on previous literature both internationally and in Ireland, is that it is ethnicity or race that matters. If this is true we would find no or negligible difference between White Irish and White non-Irish in the Irish labour market, but an 'ethnic hierarchy' whereby Asians are the best placed non-White group, followed by those of Other or mixed ethnicity, followed by those of Black ethnicity. 
A third expectation, combining the role of the nationality and ethnicity, would be that there is a difference between White Irish and White immigrants/non-Irish in the labour market, but that White immigrants would be better placed than ethnic minority immigrants.

Of course this report considers three distinct years. Patterns may vary as Irish society adapts to immigration. While the relative group positions may stay the same, it could be that some groups get closer to White Irish in terms of outcomes, while some groups become more disadvantaged.

It is also important to bear in mind that the report considers a range of outcomes, both employment but also job quality, in the form of occupational position. An important complement to labour market outcomes is the experience of discrimination in the labour market, both in getting a job and in the workplace. It could be that the groups fare differently depending on whether we examine employment, job quality or the experience of discrimination, or at least there is not an entirely consistent 'ranking' of groups for each outcome considered.

To explore these expectations about the role of ethnicity and nationality in the Irish labour market, we need to create groups that combine ethnic or racial groups with whether or not respondents are Irish citizens, and explore whether and how the experience of these groups in the Irish labour market differs. This is the subject of the next chapter. 


\section{CHAPTER 3}

\section{Measuring ethnic/national groups in the Equality modules}

\subsection{EVIDENCE BASE: THE QNHS AND EQUALITY MODULES}

The analyses in this report are based on the Quarterly National Household Survey (QNHS) and its associated Equality modules. The QNHS is a large and nationally representative random sample of private households in Ireland, designed mainly to collect data on labour market indicators. ${ }^{23}$ Special survey modules are often included in the survey. In this report we use the Equality module, available for the years 2004, 2010 and 2014. The Equality module is of particular interest to us because it includes information about ethnicity, which is otherwise not collected in the main QNHS. In addition, this module includes information on the individuals' experience of discrimination in several domains, including the labour market ('in the workplace' and 'looking for work'). When combined with the rich data from the QNHS on labour market outcomes and the quality of jobs, these sources of data are thus particularly suitable given the focus of this report.

The sample sizes range from just under 15,000 to almost 25,000 across the years and are comprised of all respondents aged 18 years and over who were interviewed directly - there were no proxy respondents. ${ }^{24}$ Some ethnic and national group samples can be very small; therefore in order to provide more robust estimates of the group effects, we have pooled the data across survey years $(2004,2010$ and 2014). This provides us with a total sample of more than 56,000 individuals across the three waves. Our final analytical sample, however, ranges between 19,000 and 34,000 depending on whether we focus on the labour market active population, on people exposed to discrimination in the workplace or on people exposed to discrimination while looking for work. For descriptive analysis the sample is weighted to be representative of the population; statistical models are unweighted.

\footnotetext{
23 For further details see: www.cso.ie/en/qnhs/abouttheqnhs/whatistheqnhs.

24 If a respondent reports on behalf of another person or group of persons (e.g. their child, partner or an entire household), the respondent is said to be a proxy respondent.
} 
In the following chapters we study the experiences of various ethnic and national groups in the labour market focusing on both objective outcomes (employment indicators) and subjective outcomes (the experience of discrimination), using data on labour market outcomes from the main QNHS survey and data on the experience of discrimination from the Equality modules.

Chapter 4 uses data from the main QNHS, to examine objective outcomes such as

1. The likelihood of being employed rather than unemployed; and

2. The likelihood of occupying a top job position among those that are employed.

The definition of 'top jobs' is based on the first two major groups of the Standard Occupational Classification from the QNHS: Managers, directors and senior officials; and professional occupations. Top job positions here are meant to capture positions of advantage in the labour market and serve as proxies of job quality. Indeed, while on the one hand these positions are characterised by high wage rates and prestige, more security of employment and more career prospects, they are also associated with better working conditions and access to a wide range of employment related services and entitlements.

Chapter 5 examines the subjective experience of discrimination in two labour market domains: in the workplace and while looking for work. The Equality modules investigate these experiences with the following questions:

1. In the past two years, have you personally felt discriminated against in the workplace?

2. In the past two years, have you personally felt discriminated against while looking for work?

Possible answers to these questions are: 'Yes'; 'No'; 'Not applicable' (if the individual had not been employed or looking for work); and 'Don't know'.

In collecting this information, the survey follows international best practice to minimise bias in the estimates of discrimination (see Blank et al., 2004). Firstly, respondents were provided with a clear definition of discrimination and a number of concrete examples of 
what is and is not considered discrimination (see Box 3.1). This includes a clarification of the nine equality grounds covered under Equality legislation up to 2014.

BOX 3.1 DEFINITION OF DISCRIMINATION PROVIDED FOR EQUALITY MODULE (PROMPT CARD)

I am going to ask you some questions about your experiences of discrimination in Ireland. The focus of this section of the questionnaire is to collect data on discrimination as defined in Irish law. Under Irish law, discrimination takes place when one person or a group of persons is treated less favourably than others because of their gender, marital status, family status, age, disability, 'race' (skin colour or ethnic group), sexual orientation, religious belief, and/or membership of the Traveller Community.

When the term discrimination is used in this questionnaire, it refers to this legal definition only.

If you believe you were treated less favourably than someone else but it was for another reason (such as your qualifications, being over an income limit or because you are further back in a queue for something), this is not considered discrimination under Irish law.

Secondly, the experience of discrimination is linked to specific social contexts or domains, for example 'while looking for work'. Thirdly, the questions refer to a specific period, in this case the two years preceding the interview. More details about the survey instrument are provided in McGinnity et al. (2017).

\subsection{DEFINING ETHNIC/NATIONAL GROUPS IN THE EQUALITY MODULES}

The process of defining ethnic and national groups is often a challenge. Firstly, because of the theoretical complexity of concepts such as ethnicity, race and nationality. Secondly, because we often do not have all the information needed to distinguish between these concepts. Thirdly, because some groups are excluded. As the QNHS is a survey of private households, international protection applicants living in Direct Provision Centres are not included in this survey, nor are homeless people. McGinnity et al. (2018) also raise the point that the QNHS was not designed to survey immigrants and some immigrant groups may be underrepresented. 
The classification of ethnicity and nationality that we have constructed takes into account both theoretical considerations and data limits. Our classification, which is unique, distinguishes between people of White, Black, Asian and Other ethnicity, based on the Census classification of ethnicity, which has been used in Ireland since 2006.

Measuring a concept as complex as ethnicity in survey data is fraught with problems (Burton et al., 2010). King-O’Riain (2007) highlights the limitations of the Irish measure, described as a compromise between the need for simple categories to measure diversity in the population and the complex lived reality of race and ethnicity in Ireland. The resulting Census question is a combination of racial and ethnic meta-categories, which are those used here. Notwithstanding the limitations, this is the only measure in survey data in Ireland which allows us to capture the racial or ethnic background of the respondents, a key focus of this report. ${ }^{25}$ Some might argue that we risk 'racialising' society by measuring groups in this way, but the alternative risks not having data to measure the potential presence of ethnic/racial differences in labour market outcomes and their experience of discrimination.

One problem with the ethnicity measure is that we cannot distinguish ethnic minority individuals who are Irish. For example, 'Black and Black Irish' are one category. Yet for our research questions we are interested in whether or not being Irish makes a difference to labour market outcomes. So for this we use the question in the survey 'Are you an Irish citizen?' to distinguish between Irish and non-Irish nationals within ethnic groups. ${ }^{26}$ The distinction according to nationality is more detailed for people of White ethnicity for whom we distinguish between Irish nationals, UK nationals, EU-West nationals, EU-East nationals, and non-EU nationals (see Glossary). While there are not enough numbers in the sample to distinguish the Black, Asian and Other ethnicity non-Irish groups, we need to group ethnic minorities who have Irish citizenship into 'Minorities Irish' for some analyses (see Table 3.1).

The QNHS allows us to disaggregate nationality with such level of detail in 2004 and 2010 only. In 2014 we can only distinguish between Irish and non-Irish nationals. However, the

\footnotetext{
25 Note also that in the Equality legislation the 'race' round covers race or skin colour, nationality or ethnicity: Employment Equality Act 1998, as amended, s 6(2)(h); Equal Status Act 2000, as amended, s $3(2)(h)$.

26 Respondents may hold dual citizenship. For the purposes of this report, we are simply concerned with whether they are an Irish citizen or not, which this question identifies.
} 
QNHS also provides information on place of birth, which to a very large extent overlaps with nationality. Therefore, while for 2004 and 2010 we define the ethnicity and nationality classification using information about nationality, in 2014 we use information about nationality to distinguish between Irish and non-Irish nationals and information on place of birth to proxy the nationality of non-Irish nationals. ${ }^{27}$

\section{TABLE 3.1 CLASSIFICATION OF ETHNICITY AND NATIONALITY}

\begin{tabular}{|l|c|c|c|c|}
\hline & $\mathbf{2 0 0 4}(\mathbf{\%})$ & $\mathbf{2 0 1 0}(\mathbf{\%})$ & $\mathbf{2 0 1 4}(\mathbf{\% )}$ & $\begin{array}{c}\text { Overall Pooled Average } \\
\text { for all Years (\%) }\end{array}$ \\
\hline White Irish & 92.07 & 88.31 & 87.92 & 89.35 \\
\hline White UK & 1.96 & 1.91 & 1.62 & 1.82 \\
\hline White EU-West & 1.00 & 0.98 & 1.35 & 1.11 \\
\hline White EU-East & 1.07 & 4.83 & 5.04 & 3.73 \\
\hline White non-EU & 1.39 & 1.00 & 0.56 & 0.97 \\
\hline Black non-Irish & 0.60 & 0.77 & 0.45 & 0.60 \\
\hline Asian non-Irish & 0.81 & 0.98 & 1.03 & 0.94 \\
\hline Other non-Irish & 0.86 & 0.78 & 0.70 & 0.78 \\
\hline Minorities Irish & 0.25 & 0.43 & 1.35 & 0.69 \\
\hline Total & 100 & 100 & 100 & 100 \\
\hline
\end{tabular}

Source: QNHS Equality modules, 2004, 2010 and 2014. Weighted percentages. N=56,141.

Note: $\quad$ Minorities refers to Black, Asian, and people of Other ethnicity.

Table 3.1 shows some interesting changes over time in the proportion in each of the groups. As the population becomes more diverse, the proportion of White Irish falls - from 92 per cent in 2004 to around 88 per cent in subsequent years. Another striking change is the proportion of White EU-East, which changes from around 1 per cent in 2004 to around 5 per cent of the population in 2010 and 2014. This is consistent with immigration flows postAccession in 2004 (see Chapter 1). A final notable change is the rise in the proportion in the Minorities Irish category, that is those from minority ethnic groups who have Irish citizenship. This rises from 0.25 per cent of the population in 2010 , to 0.43 in 2010, to 1.35 in 2014, consistent with the dramatic rise in Irish citizenship acquisition among non-EU nationals between 2010 and 2014 (see Chapter 1): some of this group were also born in Ireland.

27 As a robustness check, we also performed the analyses using a classification based on place of birth for all three waves and results are identical. In fact, there is a very high overlap between the classification based on nationality and the classification based on place of birth for both 2004 (92 per cent overlap) and 2010 (95 per cent). The vast majority of non-overlapping observations are UK nationals born in Ireland. 
What nationalities make up these groups? ${ }^{28}$ For the White EU-West group the most common nationalities in 2014 are Spanish, German and Italian. The White EU-East group is dominated by Polish nationals, followed by Lithuanians. For the White non-EU group, the most common nationality is Brazilian. For the Black Irish the most common group is Nigerian: this is also true of the Black non-Irish group. Somalis and Zimbabweans are the next most common Black-non-Irish group. For the Asian Irish the top nationality group is Filipino followed by Indian. For Asian non-Irish, the most common group is Indian, followed by Chinese and Pakistani. The 'Other ethnicity' is a very heterogeneous group with a whole range of nationalities and includes people from Poland, Romania, Brazil, and the UK among the other countries in 2014. The group includes those of mixed ethnic background, but we cannot rule out that some respondents did not fully understand the question and so recorded their ethnicity as 'Other'.

\subsection{THE PROFILE OF MIGRANTS: EDUCATION, AGE, SEX, LENGTH OF RESIDENCE AND PRINCIPAL ECONOMIC STATUS}

\subsubsection{Educational attainment}

Figure 3.1 displays the educational profile of the working age sample for each ethnic/national group. Respondents' educational qualifications are classified into four groups: lower secondary or less (including people with no formal qualifications); upper secondary (Leaving Certificate and post-Leaving Certificate); third-level non-degree (short cycle tertiary qualification) and third-level degree qualification.

The proportion of respondents with tertiary degrees is lower for the White Irish group than all of the other ethnic/national groups. Approximately 50 per cent of the most highly educated groups (Minorities Irish, White EU-West and Asian non-Irish) report having achieved this level of education as compared to 24.9 per cent of the White Irish group. Those groups that are relatively underrepresented in this category demonstrate a greater concentration in the upper secondary category instead, with 38.3 per cent and 47.6 per cent of the White Irish and White EU-East groups respectively reporting this as their highest level of educational attainment. Specifically for the White Irish group, this observed education

28 This discussion aims to give readers a flavour of the composition of the groups but is not comprehensive. Detailed country of birth is only available for 2014 , so the discussion is based on this. 
gap may in part be due to the differences in age profile discussed above, given the age gradient in educational attainment that has previously been documented (Barrett et al., 2017).

The Black non-Irish group is of particular interest given the documented high rates of labour market disadvantage experienced by this group (Kingston et al., 2013). The Black non-Irish group held a mid-ground position in most educational categories, with the exception of the third-level degree category in which they were among the ethnic/national groups exhibiting the highest concentration (21.6 per cent). However, given that this group excludes Irish citizens of Black ethnicity, this educational profile cannot be considered to represent the entirety of the Black working age population in Ireland.

\section{FIGURE 3.1 HIGHEST EDUCATIONAL ATTAINMENT BY ETHNIC/NATIONAL GROUP}

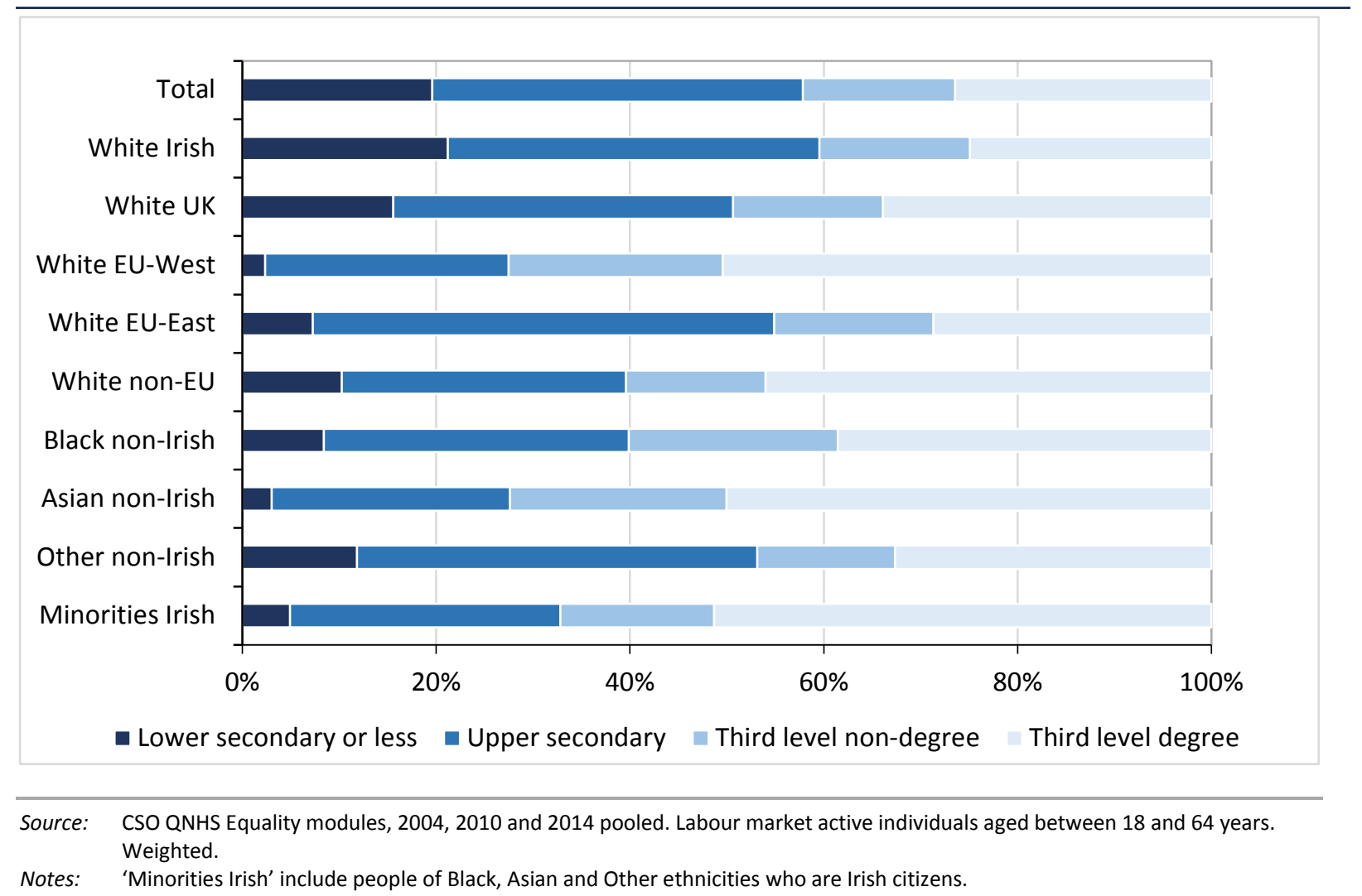

\subsubsection{Age}

Figure 3.2 presents the age profiles of the working age sample for each ethnic/national group. All of the groups were most likely to be in the 25 to 44 years age range, with the Black non-Irish (78.6 per cent), White EU-East (75.7 per cent) and Asian non-Irish (75.6 per cent) groups recording the highest concentrations. Among all of the ethnic/national groups, 
the group with the largest proportion of its sample in the 45 to 64 years category was the White UK group at 43 per cent, and the White EU-East (17.8 per cent) and Other non-Irish (17.8 per cent) groups for the 18 to 24 years age bracket. In contrast, the White UK, Black non-Irish and particularly the Minorities Irish groups were less likely to be in the younger (18 to 24 years) age bracket, thereby implying that the labour market active individuals in these groups overall are older than those belonging to the other ethnic/national minority groups.

\section{FIGURE 3.2 AGE PROFILE OF ETHNIC/NATIONAL GROUPS}

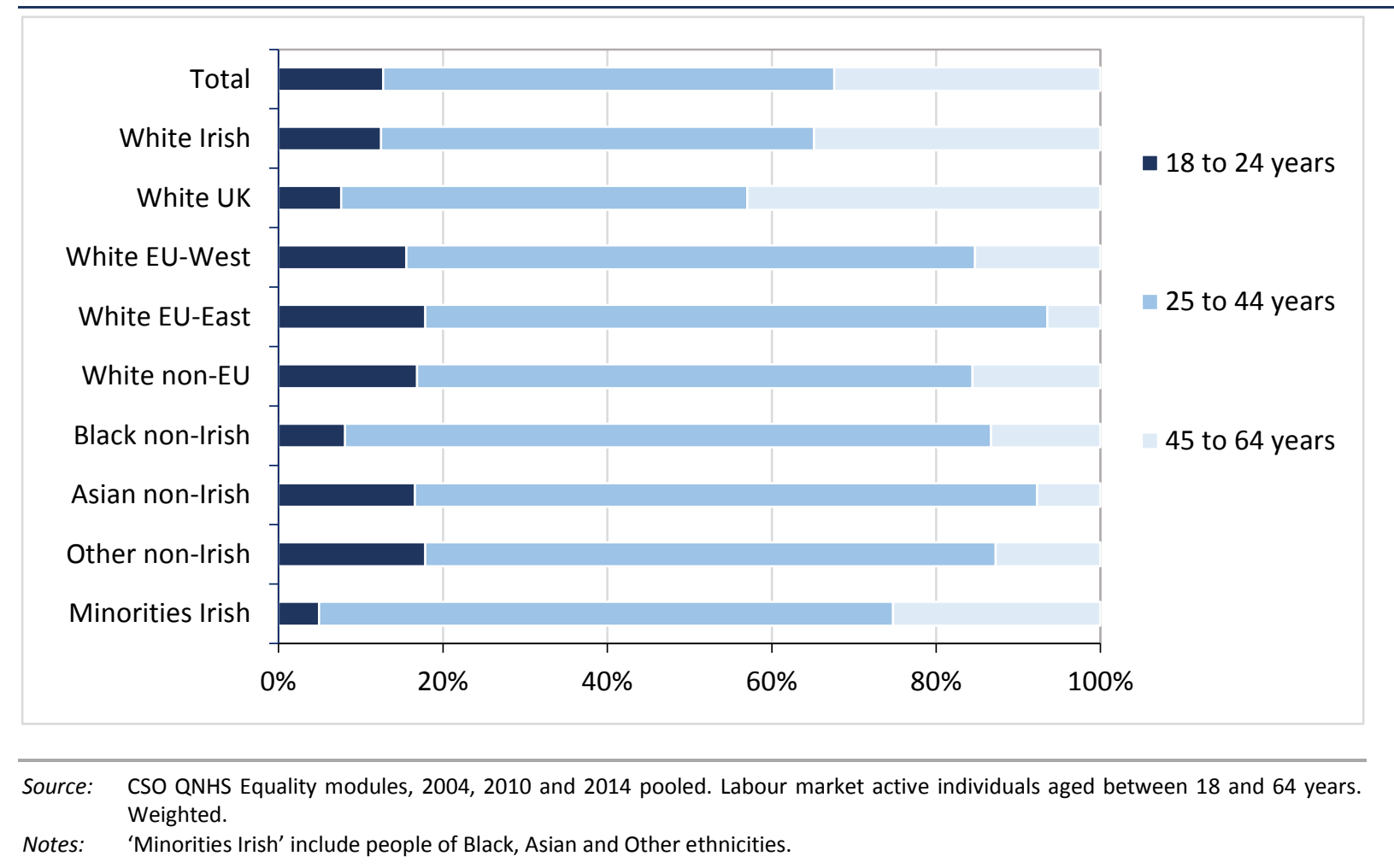

\subsubsection{Gender profile of groups}

Figure 3.3 displays the gender profile of the working age sample for each ethnic/national group. To varying degrees across all groups there was a higher proportion of males than females. This male over-representation was least pronounced in the White Irish group at 55.1 per cent, and most pronounced in the Other non-Irish and Minorities Irish groups with approximately 69 per cent of their samples comprised of males. However, when interpreting these findings, consideration should be given to the gender profile that characterises the labour market active population (aged between 18 and 64 years) only, and therefore should not be considered to be reflective of the gender composition of these ethnic/national groups among the general population in Ireland. 


\section{FIGURE 3.3 GENDER PROFILE OF ETHNIC/NATIONAL GROUPS}

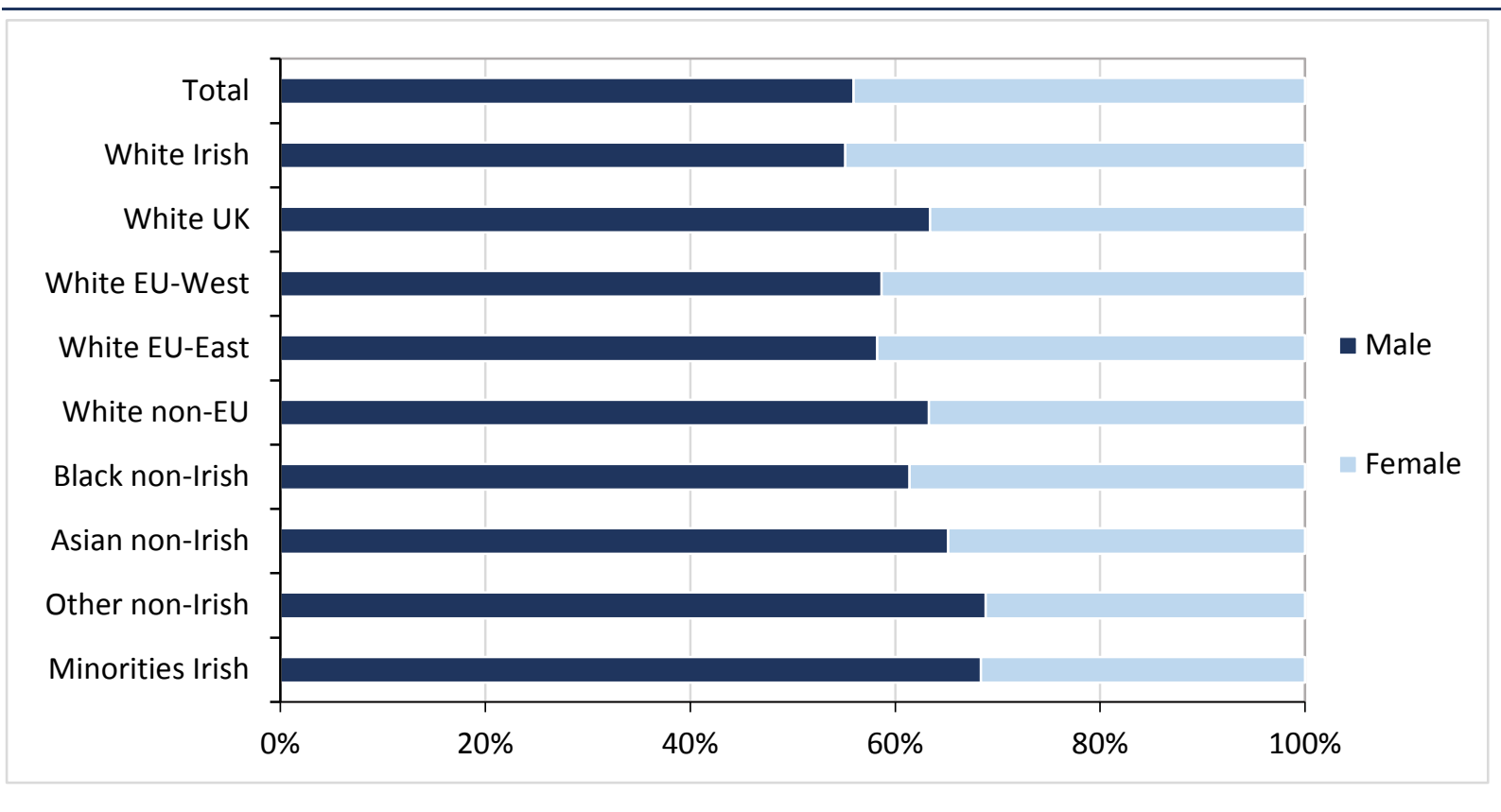

Source: $\quad$ CSO QNHS Equality modules, 2004, 2010 and 2014 pooled. Labour market active individuals aged between 18 and 64 years. Weighted.

Notes: 'Minorities Irish' include people of Black, Asian and Other ethnicities.

\subsubsection{Length of residence}

Figure 3.4 presents the distribution of the length of residence in Ireland for each ethnic/national group. As can be seen in the Figure below, greater than 60 per cent of the White UK group had been living in Ireland for over five years, with just under 50 per cent having lived in Ireland for over ten years. In line with Ireland's relatively recent transition from being a country of net emigration to becoming one of net immigration (see Chapter 1 for a more detailed discussion), the other ethnic/national minority groups are observed to have resided in Ireland for a shorter period of time. Indeed, reflecting the rapid increase in immigration that followed the expansion of the EU in 2004, only small proportions of these ethnic/national minority groups are seen to record a length of residence in Ireland of 20 years or more. Furthermore, over half of the White EU-West, White EU-East, White non-EU, Asian non-Irish and other non-Irish groups report living in Ireland for five years or less. 


\section{FIGURE 3.4 LENGTH OF RESIDENCE IN IRELAND BY ETHNIC/NATIONAL GROUP}

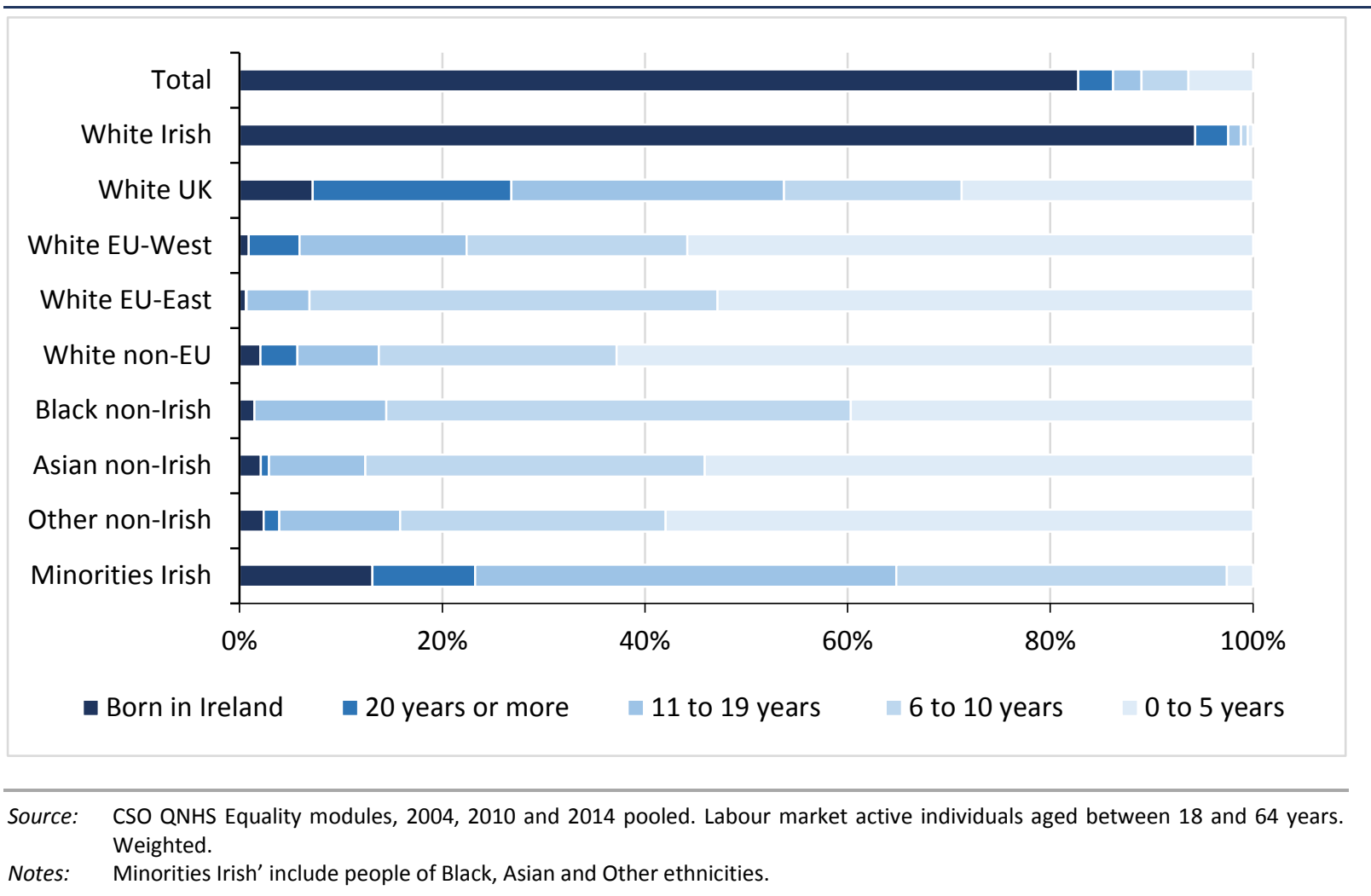

Interestingly, the Minorities Irish and Black non-Irish groups depart from these trends. The proportion of the Minorities Irish group that had lived in Ireland for five years or less was substantially smaller at 2.6 per cent. This trend is a likely outcome of the Irish naturalisation process requiring a minimum of five years residence in Ireland for a valid citizenship application to be made. A similar but less pronounced trend of an under-representation in the zero to five years residence category in the Black non-Irish group is accompanied by 0 per cent of this group reporting a period of residence in Ireland spanning 20 years or more. As a result, over half of the Black non-Irish group records a length of residence of between six and 19 years.

These variations in length of residence in Ireland point to the importance of accounting for differences in this variable in the statistical models that will be discussed in Chapters 4 and 5.

\subsubsection{Principal economic status}

Principal Economic Status (PES) is a measure of economic activity that derives from survey respondents' self-reports of the activity that best represents their usual situation with regard to work. These principal activities are chosen out of six mutually exclusive options 
including 'at work', 'unemployed' and 'on home duty'. The inclusion of options that extend beyond those applicable to the labour market active population only (i.e. those at or seeking work) allows for a more nuanced representation of economic activity to be generated through allowing for the identification of the reasons underlying the disengagement of certain subgroups from employment.

\section{FIGURE 3.5 PRINCIPAL ECONOMIC STATUS BY ETHNIC/NATIONAL GROUP}

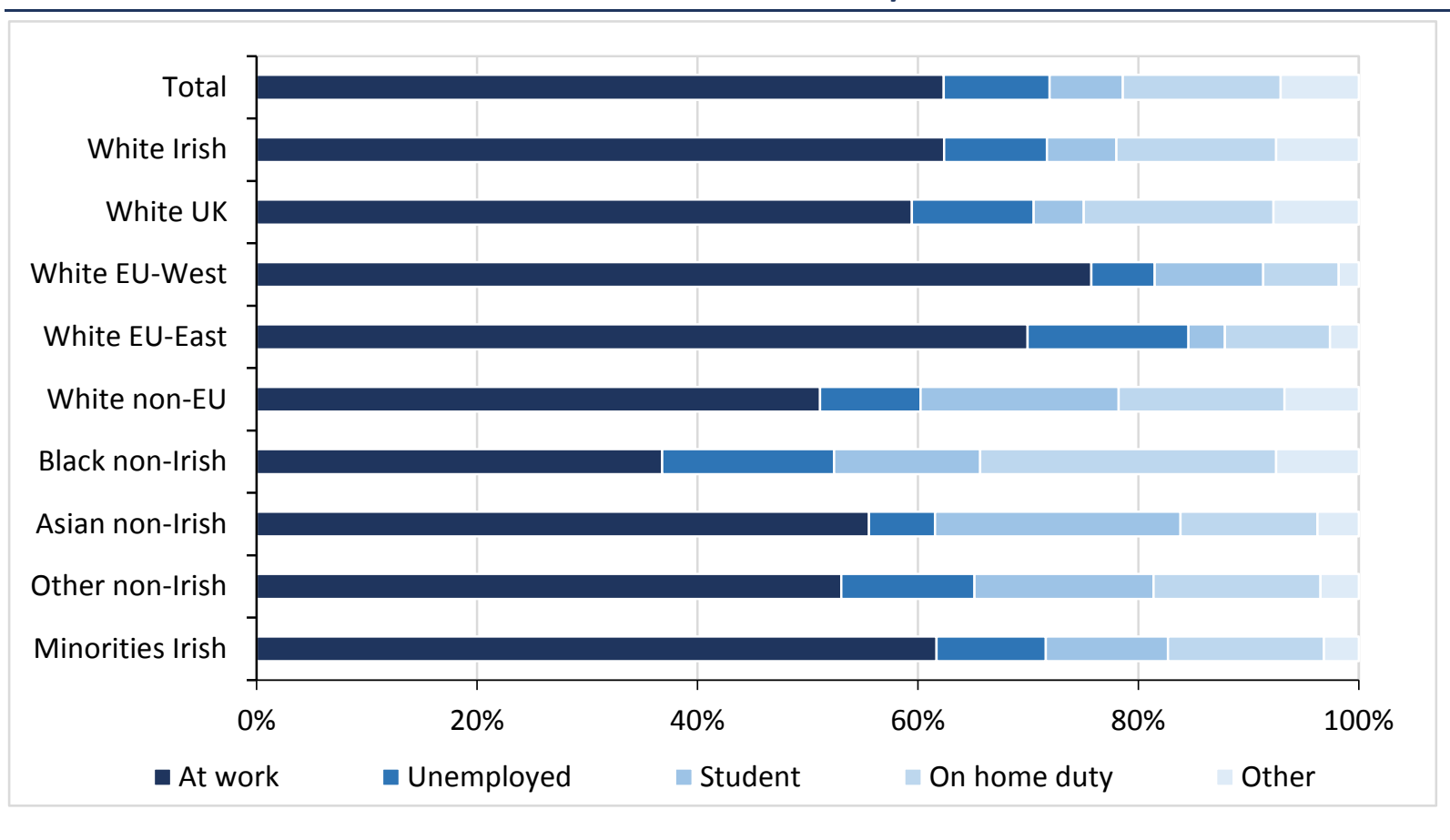

Source: $\quad$ CSO QNHS Equality modules, 2004, 2010 and 2014 pooled. Adults aged between 18 and 64 years. Weighted.

Notes: $\quad$ 'Minorities Irish' include people of Black, Asian and Other ethnicities.

As can be observed in Figure 3.5, each of the groups were most highly concentrated in the 'at work' category, with the White EU-West group recording the largest representation at 75.7 per cent and thereby surpassing the White Irish group (62.4 per cent). In contrast to all of the other ethnic/national groups that report greater than 50 per cent of their sample to be 'at work', the Black non-Irish group was particularly underrepresented, with only 36.8 per cent falling within this category. Interestingly, a pattern is observed across the 'at work', 'unemployed' and 'on home duty' categories for the two stand-out groups mentioned above. The White EU-West group that is relatively overrepresented in the 'at work' category is found to record the lowest representations among all ethnic/national groups in the 'unemployed' (5.8 per cent) and 'on home duty' (6.9 per cent) categories, with an inverse pattern of over-representation in these latter two categories observed among the Black non-Irish group (15.6 per cent and 26.8 per cent respectively). 
The ethnic/national group with the greatest representation in the 'student' category was found to be Asian non-Irish, with a percentage substantially higher than that recorded for the White Irish group (6.3 per cent) at 22.3 per cent. The White EU-East and White UK groups had the smallest representation in this category, with the latter instead recording the highest concentration of all groups in the 'Other' category (7.7 per cent). Given that 'Other' can include a retired status, these differences between the Asian non-Irish and White UK groups may at least partially be a reflection of age profile differences, with the Asian non-Irish group being relatively younger than the White UK group. Although the Black non-Irish group records a concentration of a similarly high degree (7.5 per cent) in this 'Other' category, the finding for this ethnic/national group cannot be accounted for by age, but may instead represent those in the process of seeking international protection, who in the survey years (2004, 2010 and 2014) would not be allowed to be in the labour market. 


\section{CHAPTER 4}

\section{Labour market inequalities across ethnic and national groups}

\subsection{INTRODUCTION}

The integration of individuals in the labour market is crucial for their participation in the social, cultural and political life of a society, and more generally for their integration in the society as a whole. In addition, employment is important for both material and non-material aspects. On the one hand, employment is associated with lower poverty and deprivation risks; on the other hand, unemployment is linked to poor health (Tattarini et al., 2018). This chapter sets out to study the integration into the Irish labour market of people from different ethnic/national groups. In particular, it asks whether the chances of being employed and the chances of working in top jobs are unevenly distributed across groups that are defined by an individual's ethnicity and nationality.

In Section 4.2 we focus on the labour market active population (i.e. the economically active population that includes both employed and unemployed individuals) and investigate inequalities in accessing employment; while in Section 4.3 we focus on the employed population and investigate inequalities in accessing top level jobs. We firstly study the extent to which ethnicity and nationality are associated with these labour market outcomes, and secondly, we study whether these associations can be explained by other individual factors, most importantly human capital - i.e. education. To do this we employ statistical models which allow us to evaluate inequalities between people of different ethnicity and nationality while controlling for other relevant characteristics. Finally, we investigate how the labour market advantages and disadvantages of ethnic and national groups have evolved over time.

\subsection{INEQUALITY IN ACCESS TO EMPLOYMENT}

Our first objective in this chapter is to study whether individuals of different ethnicity and nationality experience different chances of being employed rather than unemployed. Figure 4.1 reports the share of employed individuals by nationality and ethnicity. The employment shares are rather high; overall, we register that 88.5 per cent of people are employed. Such 
a high rate is not surprising because here we focus only on the labour market active population and thus we exclude all individuals aged 65 or over and those who are not in the labour market. Had we looked at the share of employed people among the whole population, we would have observed much lower rates and much more variation between groups (see Figure 3.5). ${ }^{29}$

While we observe an overall employment rate close to 90 per cent, we also observe significant variations between groups. Indeed, among the groups the employment rate ranges between 70 and 92 per cent. At one extreme, Black non-Irish people experience the largest barriers in accessing employment. At the other extreme, White EU-West people have the highest employment rates, even higher than White Irish people who present an employment rate of 89 per cent - a rate similar to Asian non-Irish people.

The disadvantage experienced by Black non-Irish people seems to be particularly striking. Indeed, the second most disadvantaged group, 'Other' ethnicity non-Irish people, presents a much higher employment rate; 12 percentage points higher. The employment rate for all remaining groups ranges between 84 and 87 per cent.

29 In defining employment, we use here the International Labour Office (ILO) definition rather that the principal economic status presented in Chapter 3. The ILO defines a person as in employment if he/she has worked any amount of time in the reference week. Therefore, students who for example have a small job and categorise their principal economic status as 'student' will be counted as employed according the ILO definition. 


\section{FIGURE 4.1 EMPLOYMENT RATE BY ETHNICITY AND NATIONALITY}

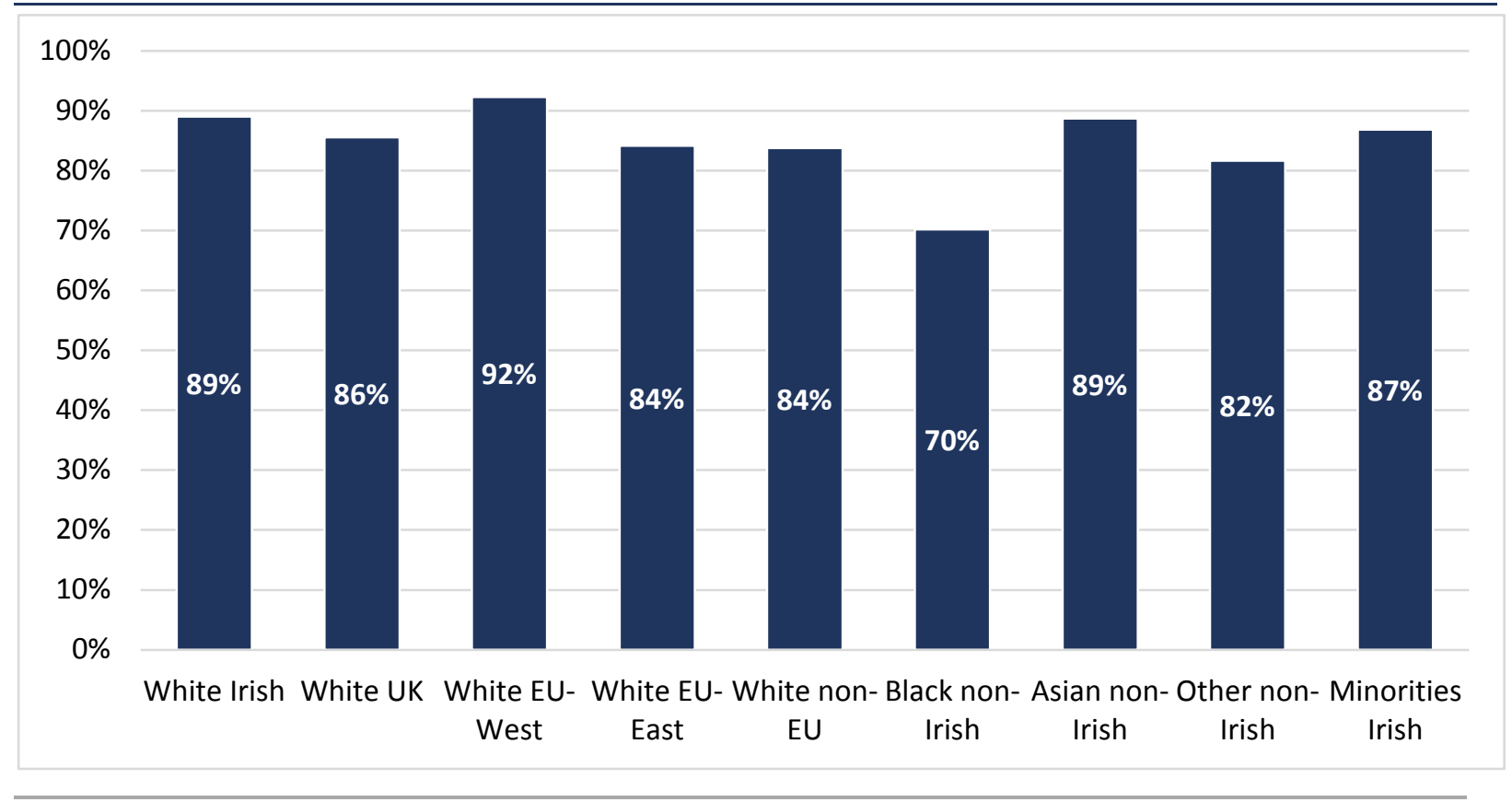

Source: $\quad$ QNHS Equality modules, 2004, 2010 and 2014 pooled. Labour market active adults aged 18 to 64 years old. Note: $\quad$ Minorities refers to Black, Asian, and people of Other ethnicity.

As Figures 3.1 to 3.5 in Chapter 3 have shown, immigrants of different ethnicity and nationality differ from White Irish people, but also vary between themselves in many respects. These include their age profile, level of education and length of stay, among others. Importantly, these characteristics not only are associated with ethnicity and nationality status, but also with employment outcomes. If we do not take this interrelationship into account, the estimated differences in the labour market outcomes between groups might be biased. Therefore, in the following we employ regression models to study the role that ethnicity and nationality play, net of other relevant characteristics.

Model 1 in Table 4.1 includes the ethnicity and nationality status of individuals and the year of the survey; Model 2 adds the individual's level of education; finally Model 3 controls for the full set of socio-demographic characteristics.

The models we present are logistic regression models; the coefficients are expressed as odds ratios and have to be compared with the reference category which in the case of ethnicity and nationality is White Irish. An odds ratio of 1 means that the group considered has the same likelihood of being employed as the reference group. A value higher than 1 indicates a higher likelihood compared with the reference group. For example, an odds ratio of 2 indicates that the likelihood of being employed of the group considered is twice the 
likelihood of the reference group. Conversely, odds ratios smaller than 1 indicate a lower likelihood for the group considered compared with the reference group. For example, if the odds ratio is equal to 0.5 , it means that the group experiences half the likelihood of the reference group.

As was said previously, Model 1 only includes the individuals' membership of the ethnicity and nationality groups and the year of the survey. Concerning the latter, we see that in 2004 the likelihood of being employed rather than unemployed was three times as high as the likelihood in 2014 (the reference year). On the contrary, the likelihood of being employed in 2010 was lower than in 2014. This trend over time in employment chances is in line with the striking economic downturn that the Irish economy experienced with the Great Recession (Figure 1.3).

We now turn our attention towards the main theme of this report: ethnicity and nationality. Results from Model 1 follow the pattern presented in Figure 4.1 in terms of differences between groups. This is not surprising given that this first model does not take into account other relevant characteristics associated with both employment and ethnicity and nationality. In particular, Model 1 shows that while White EU-West people do not significantly differ from White Irish people in their employment outcomes, the employment chances for all other White people (UK, EU-East and non-Irish) are lower; about two-thirds as high as the employment chances of White Irish people.

In contrast to Figure 4.1, the models in Table 4.1 partition what in the Figure was labelled 'Minorities Irish' into Black Irish, Asian Irish and Other ethnicity Irish groups. Distinguishing the minority groups between Irish and non-Irish allows us to observe some important variations. Indeed, we observe that non-Irish nationals tend to be more disadvantaged than Irish nationals - this is true for both Black and Asian non-Irish individuals. Asian Irish people even experience better employment chances (odds ratio of 1.6) than White Irish people (the reference group), although the association is not statistically significant. At the other extreme, we observe Black non-Irish and other non-Irish people who are much less likely between 0.27 and 0.46 times as likely - to be employed compared to White Irish people. 
TABLE 4.1 LOGISTIC REGRESSION FOR EMPLOYMENT VERSUS UNEMPLOYMENT (ODDS RATIOS)

\begin{tabular}{|c|c|c|c|c|}
\hline & & Model 1 & Model 2 & Model 3 \\
\hline \multirow{10}{*}{$\begin{array}{l}\text { Ethnicity and } \\
\text { nationality } \\
\text { (ref. White Irish) }\end{array}$} & White UK & $0.624 * * *$ & $0.554 * * *$ & 0.899 \\
\hline & White EU-West & 1.281 & 0.895 & $1.728^{*}$ \\
\hline & White EU-East & $0.659 * * *$ & $0.575^{* * *}$ & 1.173 \\
\hline & White non-EU & $0.636^{*}$ & $0.487 * * *$ & 0.909 \\
\hline & Black Irish & 0.574 & $0.496 *$ & 0.783 \\
\hline & Black non-Irish & $0.267^{* * *}$ & $0.207^{* * *}$ & $0.400 * * *$ \\
\hline & Asian Irish & 1.583 & 1.118 & 1.890 \\
\hline & Asian non-Irish & 0.840 & $0.580 * *$ & 1.098 \\
\hline & Other ethnicity Irish & $0.305 * *$ & $0.212 * * *$ & $0.348 * *$ \\
\hline & Other non-Irish & $0.455^{* * *}$ & $0.392 * * *$ & 0.808 \\
\hline \multirow[t]{2}{*}{ Year (ref. 2014) } & 2004 & $2.928 * * *$ & $3.422 * * *$ & $3.661 * * *$ \\
\hline & 2010 & $0.784 * * *$ & $0.803 * * *$ & $0.807^{* * *}$ \\
\hline \multirow{3}{*}{$\begin{array}{l}\text { Education } \\
\text { (ref. Lower } \\
\text { secondary or less) }\end{array}$} & Upper secondary & & $1.675^{* * *}$ & $1.812^{* * *}$ \\
\hline & Third-level non-degree & & $2.863 * * *$ & $2.795^{* * *}$ \\
\hline & Third-level degree & & $3.717 * * *$ & $3.682 * * *$ \\
\hline \multirow[t]{2}{*}{ Age (ref. 18-24) } & $25-44$ & & & $1.430 * * *$ \\
\hline & $45-64$ & & & $1.815^{* * *}$ \\
\hline Sex (ref. Male) & Female & & & $1.527 * * *$ \\
\hline \multirow{4}{*}{$\begin{array}{l}\text { Family type } \\
\text { (ref. Couple } \\
\text { no children) }\end{array}$} & Couple with children & & & $0.793 * * *$ \\
\hline & Lone parent & & & $0.437 * * *$ \\
\hline & Living with parents & & & $0.282 * * *$ \\
\hline & Single (childless) & & & $0.597 * * *$ \\
\hline \multirow[t]{2}{*}{ Region (ref. Dublin) } & Border/Midlands/West & & & $0.779 * * *$ \\
\hline & South and East & & & $0.752 * * *$ \\
\hline \multirow{6}{*}{$\begin{array}{l}\text { Length of } \\
\text { residence } \\
\text { (ref. Born in } \\
\text { Ireland) }\end{array}$} & 20 or more & & & $0.687 * * *$ \\
\hline & $11-19$ & & & $0.500 * * *$ \\
\hline & $6-10$ & & & $0.473 * * *$ \\
\hline & $0-5$ & & & $0.491 * * *$ \\
\hline & Pseudo R-squared & 0.0476 & 0.0756 & 0.1068 \\
\hline & Observations & 30,818 & 30,818 & 30,818 \\
\hline
\end{tabular}

Source: QNHS Equality modules, 2004, 2010 and 2014 pooled. Labour market active adults aged 18 to 64 years old. Note: $\quad{ }^{* * *} \mathrm{p}<0.001,{ }^{* *} \mathrm{p}<0.01, * \mathrm{p}<0.05$

As said in Chapter 2, differences in employment outcomes between ethnic and national groups are often considered to be determined by differences in human capital endowments - where human capital is mainly captured by the level of education and work experience (Becker, 1975). Accordingly, Model 2 in Table 4.1 includes the level of education. Concerning the direct role that education plays on employment chances, as expected, the higher the educational level the higher the likelihood of being employed. For example, people with 
tertiary degrees are almost 4 (odds ratio of 3.7) times as likely as people with lower secondary or lower education to be employed rather than unemployed.

We now focus on ethnicity and nationality. Model 2 shows that when controlling for education, the employment disadvantage for all ethnic and national groups increases compared to the reference group of White Irish. This can be attributed to the fact that ethnic/national minority groups are on average more educated than White Irish people, as shown in Chapter 3. Therefore, if we take into account the labour market advantage that immigrants experience because of their higher level of education compared to White Irish, the disadvantage associated with their ethnic and national status increases: for example, Black non-Irish and Other ethnicity Irish people are considerably less likely (odds ratio of 0.2 ) to be employed compared with White Irish people.

Finally, Model 3 controls for a wider set of characteristics, including age, sex, family type, region of residence and, most importantly, length of residence. While all of these characteristics are associated with employment chances, it is only when we include the length of residence that we observe the association of ethnic and national status with employment to vary. For this reason we decided to show only the complete model here, although in our analysis we proceeded by adding variables to the model one by one (complete set of models available from the authors).

Unsurprisingly, the length of residence emerges as an important factor for employment opportunities: the longer the length of residence in Ireland, the higher the likelihood of being employed. Indeed, it is not only associated with the possibility of obtaining Irish citizenship, but also with the accumulation of human and social capital. As Borjas (1999) and Esser (2004) argue, on the one hand, the length of residence is associated with the accumulation of work experience in the country, and other skills and competencies such as improvements in English language proficiency and knowledge about the 'rules of the game', both of which are important for having success in the labour market. On the other hand, the length of residence is associated with the size of the network individuals may avail of, for example, for getting information about vacancies.

In Model 3, people born in Ireland are held as the reference category for the length of residence variable. Compared to this group, we observe an odds ratio of 0.7 for people who 
are in Ireland for 20 years or more, and an odds ratio of about 0.5 for people living in Ireland for less than 20 years. In other words, compared with people born in Ireland, people who are in the country for less than 20 years are considerably less likely to be employed. Overall, it seems that what matters most is being born in Ireland or not, while we do not observe considerable variations in the odds ratios between different lengths of residence.

Even more interesting are the variations in the association between ethnic and national group and employment chances after controlling for length of stay. Indeed, when we take into account the fact that immigrants are in Ireland for a shorter period of time compared with White Irish and have thus accumulated a lower amount of human and social capital, the negative association between ethnicity and nationality and employment decreases and becomes non-significant for most of the groups. The employment chances of White people who are UK, EU-East and non-EU nationals are now substantially equivalent to the chances of White Irish. The same is true for Asian non-Irish and Other ethnicity non-Irish. Conversely, controlling for the length of stay, Black non-Irish and Other ethnicity Irish are still disadvantaged compared with White Irish, although to a lesser extent. Finally, the association between membership in the White EU-West group and employment becomes positive and strengthens substantially: White EU-West people are now more likely (1.7 times as likely) than White Irish to be employed.

As a further in-depth analysis we studied whether the impact of length of stay varies with age. ${ }^{30}$ Interestingly, our analyses show that the association between length of residence and employment chances varies with individuals' age. While for those under 25 , length of residence does not affect employment chances, length of residence has more of an impact the older a person is. The largest difference is visible for the oldest working-age group, those aged 45-64. Among this group, people who have lived in Ireland for more than ten years are 5 percentage points less likely to be employed compared with people born in the country, while people who are in Ireland for less than ten years are 15 percentage points less likely to be employed. This might be explained by the fact that young people, even if not born in Ireland, are likely to have studied in Ireland. This may imply that they have developed better language skills and have been trained for the Irish labour market. It also

\footnotetext{
30 Results not shown but available from the authors.
} 
suggests that age at migration has an impact on employment chances: the older a person is when they come to Ireland, the more difficult they may find it to get a job, but this would require more detailed analyses to substantiate.

Concerning the other characteristics that we take into account in the model, we observe age to be positively associated with employment; employment chances increase with age. This can be explained by the fact that older people have accumulated more work experience while the youngest respondents may have just entered the labour market and might still be looking for their first job.

Concerning sex, we observe women to be more likely to be employed. This can in part be explained by the fact that the Great Recession has hit men's employment chances more than women's, for example via the shrinkage of the construction sectors (Russell et al., 2014). ${ }^{31}$ Also, women who are in the labour market might be more positively selected than men. This means that women who decide to enter the labour market may have characteristics that are positively associated with labour market success. In other words, while women are much more likely to be out of the labour market (labour market inactive) compared to men - who are basically all labour market active - when in the labour market, they might be more motivated and career-oriented than men.

Family type is also associated with employment chances. People living in a couple without children (who are the reference group) are those who experience the best employment chances. On the contrary, the worst employment chances are experienced by people living with parents where they may be younger and just entering the labour market or they may be caring for an older parent in the household; and also by lone parents, most likely because of the barriers they face due to caring responsibilities. ${ }^{32}$ Finally, concerning region of residence, we observe people living in Dublin experience the best employment chances.

31 To address this result, we tested the interaction between sex and year. Our test shows that the women's higher likelihood of being employed is driven by the 2010 wave, in line with the expectation about the role of the recession for male employment. Indeed, while we find no gender differences in 2004, women are much more likely to be employed than men in 2010 and also in 2014, although to a lesser extent. Results of models are not shown but available from the authors.

32 The association between family type and employment chances might in some cases go in the opposite direction. For example, the negative association between living with parents and employment chances 


\subsubsection{Changes over time?}

As stated, our study relies on three waves of the QNHS Equality module: 2004, 2010 and 2014. The results presented so far refer to the overall association between ethnic and national group and employment over the decade examined. The period we focus on, however, is a period of important economic change. It is characterised by a period of economic boom, a period of recession and a period of recovery and, as a result, employment opportunities have changed dramatically over time (Figure 1.3). In this section we ask whether inequality in access to employment between people of different ethnicity and nationality have changed over time, i.e. whether the Great Recession first, and the early recovery later, led to polarisation or convergence between groups.

Figure 4.2 shows differences in predicted probabilities of being employed between White Irish and every other ethnic and national group at different points in time. Predicted probabilities are computed based on a model that adds the interaction between ethnic and national groups and the year of the survey to Model 3 in Table 4.1. In addition, in contrast to the models presented in Table 4.1, we aggregate Black Irish, Asian Irish and Other ethnicity Irish into Minorities Irish. This was necessary because of the small size of these groups. The bars in the Figure represent differences in percentage points. Negative values indicate that the group experiences lower employment chances than White Irish; while positive values indicate higher employment chances. In addition, solid bars signal a statistically significant difference, while empty bars signal statistically non-significant differences.

might be due to the fact that those who are unable to find employment (or obtain well-paying permanent contracts) will be more likely to live with their parents since they cannot afford to move out. Unfortunately, the data we have do not permit making causal claims. 
FIGURE 4.2 DIFFERENCES IN THE PREDICTED PROBABILITIES OF BEING EMPLOYED FOR ETHNIC/NATIONAL GROUPS COMPARED WITH WHITE IRISH OVER TIME

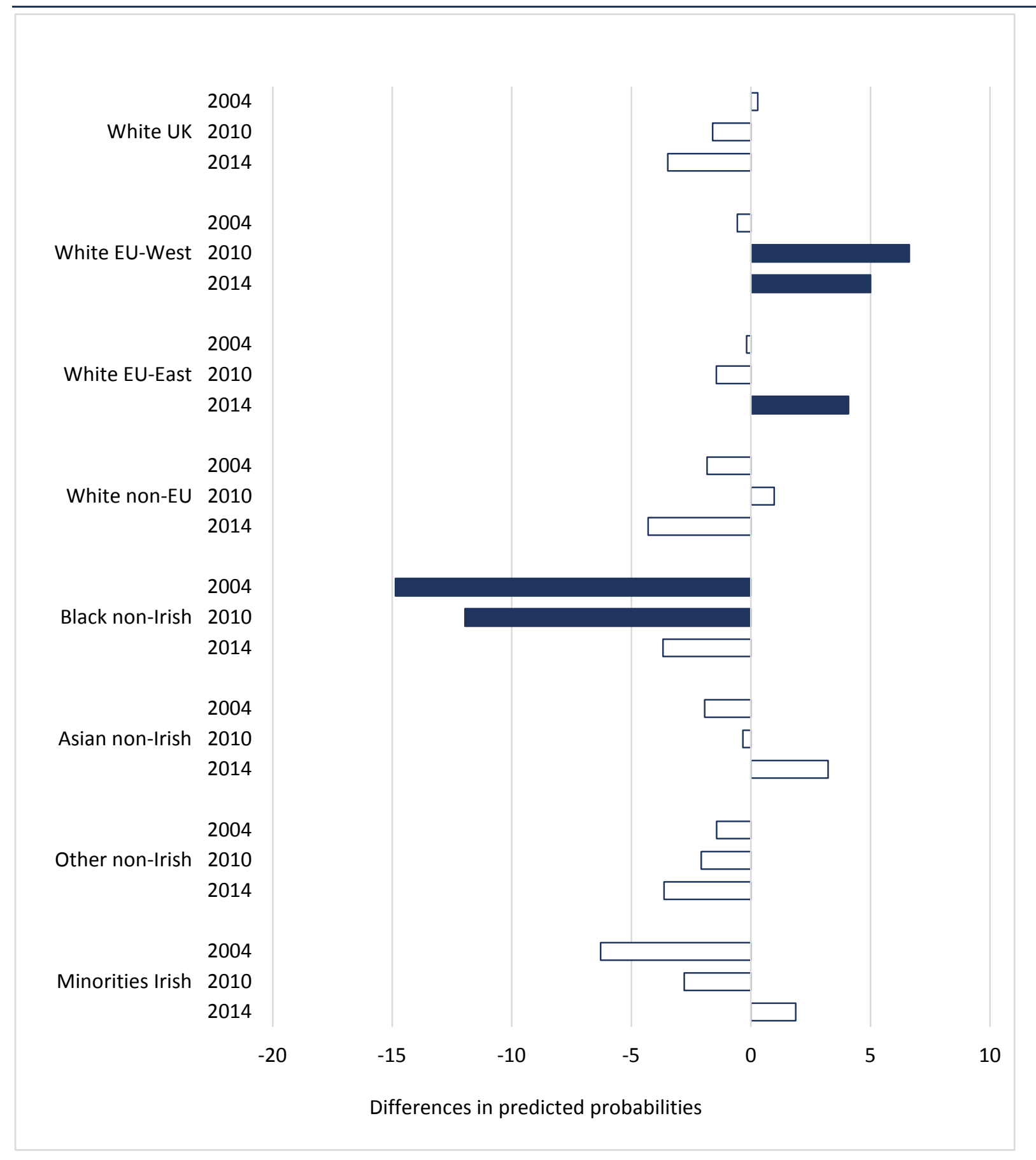

Source: QNHS Equality modules, 2004, 2010 and 2014 pooled. Labour market active adults aged 18 to 64 years old. Predicted probabilities based on Model 3 in Table 4.1 plus the interaction between ethnic/national group and year of the survey. Solid bars indicate a statistically significant result.

Note: Minorities refers to Black, Asian, and people of Other ethnicity.

As noted earlier in Model 3 of Table 4.1, Figure 4.2 shows that most of the differences between White Irish and the other groups are not statistically significant. Figure 4.2 also shows that most of the differences are within 5 percentage points. 
Concerning changes over time, we do not observe a common pattern or trend. However, if we look at the largest and statistically significant changes, we observe that while in 2004 there was no difference between White Irish and White EU-West people in 2010 and 2014, the latter are up to 7 percentage points more likely to be employed than the former. A further change is observed for White EU-East nationals who in 2014 are 4 percentage points more likely to be employed compared to White Irish, while no differences were observed in the preceding years. Finally, the largest changes in employment chances regard Black nonIrish people. This group was between 12 and 15 percentage points less likely to be employed than White Irish in 2004 and 2010. Over time, however, we observe a sort of convergence between the two groups and in 2014 we do not observe a significant difference between Black non-Irish and White Irish people.

\subsection{INEQUALITY IN ACCESS TO TOP JOBS}

In this section we only focus on employed individuals and investigate whether different ethnic and national groups have the same likelihood of accessing top jobs. Top jobs are here defined as jobs at managerial or professional level and are meant to measure privileged positions in the labour market and to be a proxy of job quality.

People occupying top jobs can be considered to have better job quality in terms of higher wages and prestige, more security of employment and more career prospects, better working conditions, and access to a wider range of employment related services and entitlements. Therefore, looking at inequality in access to top positions allows us to capture inequality in a broader sense.

Figure 4.3 shows the share of people in top jobs among employed people, by ethnic and national group. As the Figure shows, the share of people in top jobs varies widely, from 7 per cent for East Europeans to 39 per cent for Minorities Irish; in this latter group, Asian Irish present particularly high rates.

Among the other groups, around three-in-ten White Irish, UK nationals and West European nationals occupy top jobs. This proportion decreases to one-in-four for White non-EU nationals, and to slightly more than one-in-five for Asian non-Irish. Finally, lower rates are found among Black non-Irish nationals and other non-Irish people. 


\section{FIGURE 4.3 SHARE OF TOP JOBS AMONG EMPLOYED PEOPLE BY ETHNICITY AND NATIONALITY}

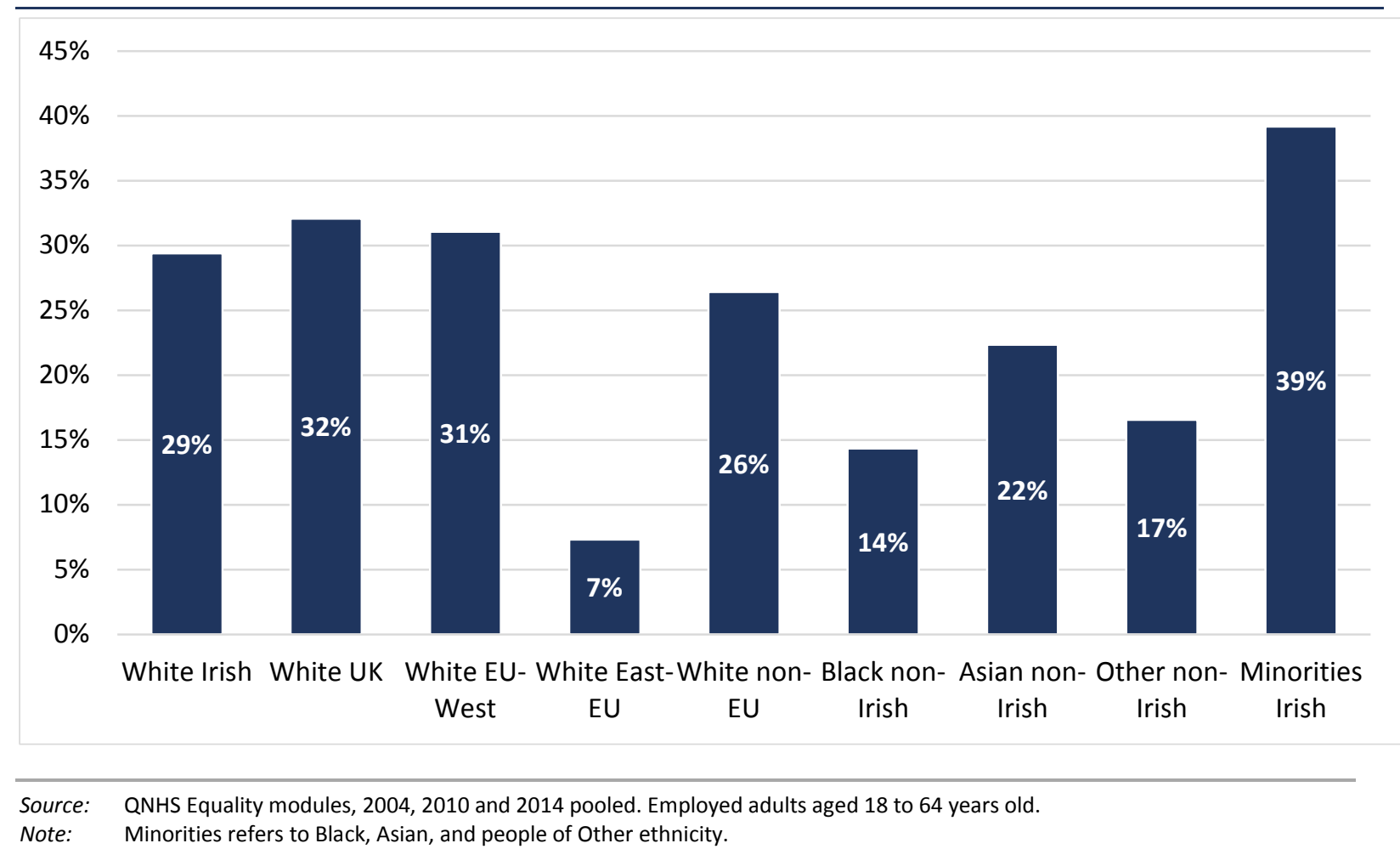

As was done in Section 4.2 when analysing employment chances, we now study the likelihood of being employed in a top job by taking into account other relevant characteristics that may affect the relationship between ethnicity and nationality and top jobs.

The regression models in Table 4.2 have the same structure and can be interpreted in the same way as the models in Table 4.1 discussed earlier. Model 1 shows how each ethnic and national group compares with the White Irish group in the likelihood of being employed in a top job, controlling for the year of the survey. Looking at the survey year, we observe a fairly consistent trend over time in the overall likelihood of occupying a top job position although the likelihood was higher and statistically significant in 2004 and 2010 compared with 2014, the difference is roughly negligible.

Turning now to ethnicity and nationality, we do not observe any significant difference between the White Irish and the other White groups, with the exception of the EU-East who emerge to be the most disadvantaged group by being about 0.2 times as likely to be in a top job position compared with White Irish people. No substantial difference is registered for Other ethnicity Irish. 
The second most disadvantaged group is Black non-Irish (odds ratio of 0.4 ), followed by other non-Irish (0.6) and Asian non-Irish (0.7). Black Irish also emerge to be particularly disadvantaged, being half as likely as White Irish to occupy top jobs. The difference between these two groups, however, is not statistically significant, possibly partly because of the very small size of the Black Irish group. Conversely to what was found up to now, one group stands out to be more advantaged than White Irish: this is the Asian Irish group who are almost three times as likely as the White Irish group to occupy a top job position.

The advantage that Asian Irish experience is likely to be associated with both the system of employment permits and naturalisation. As mentioned in Chapter 1, the employment permit system is based on a general policy of recruiting high-skilled labour from non-EU countries. The high likelihood of occupying a top position could be partly accounted for by the fact that many Asian Irish would have arrived in Ireland with a permit for a specific job offer in the high-skilled sectors. After five years of residency, many Asian individuals have successively become eligible for citizenship. McGinnity et al., (2018) in the Monitoring Report on Integration 2018, show indeed a high proportion of Asian nationals among the naturalised citizens from 2013 onwards.

In Model 2 we take into account educational level. As before, controlling for education changes the pattern substantially, making clearer the disadvantages that many ethnic and national groups experience compared with White Irish. As explained above, this is because immigrants tend to be more educated than White Irish people, and at the same time education is strongly associated with labour market success - in fact we observe people with a third-level honours degree to be nine times as likely as people with lower secondary or lower education to be employed in top jobs. 
TABLE 4.2 LOGISTIC REGRESSION FOR ACCESSING TOP JOBS (ODDS RATIOS)

\begin{tabular}{|c|c|c|c|c|}
\hline & & Model 1 & Model 2 & Model 3 \\
\hline \multirow{10}{*}{$\begin{array}{l}\text { Nationality } \\
\text { (ref. White Irish) }\end{array}$} & White UK & 1.097 & 0.822 & 0.936 \\
\hline & White EU-West & 1.174 & $0.653 * * *$ & 0.916 \\
\hline & White EU-East & $0.173^{* * *}$ & $0.120 * * *$ & $0.191 * * *$ \\
\hline & White non-EU & 0.985 & $0.514^{* * *}$ & 0.735 \\
\hline & Black Irish & 0.539 & $0.339 * *$ & $0.354^{*}$ \\
\hline & Black non-Irish & $0.366 * * *$ & $0.214^{* * *}$ & $0.295^{* * *}$ \\
\hline & Asian Irish & $2.712 * * *$ & $1.700^{*}$ & $1.863 * *$ \\
\hline & Asian non-Irish & $0.715^{*}$ & $0.365^{* * *}$ & $0.526 * * *$ \\
\hline & Other ethnicity Irish & 1.179 & 0.613 & 0.637 \\
\hline & Other non-Irish & $0.598 * *$ & $0.373 * * *$ & $0.537 * *$ \\
\hline \multirow[t]{2}{*}{ Year (ref. 2014) } & 2004 & $1.071^{*}$ & $1.399 * * *$ & $1.500 * * *$ \\
\hline & 2010 & $1.117^{* *}$ & $1.190 * * *$ & $1.216^{* * *}$ \\
\hline \multirow{3}{*}{$\begin{array}{l}\text { Education } \\
\text { (ref. Lower 2nd or } \\
\text { less) }\end{array}$} & Upper secondary & & 1.069 & $1.284^{* * *}$ \\
\hline & Third-level non-degree & & $2.225^{* * *}$ & $2.746^{* * *}$ \\
\hline & Third-level degree & & $8.947 * * *$ & $11.308 * * *$ \\
\hline \multirow[t]{2}{*}{ Age (ref. 18-24) } & $25-44$ & & & $2.188^{* * *}$ \\
\hline & $45-64$ & & & $3.135^{* * *}$ \\
\hline Sex (ref. Male) & Female & & & $0.690 * * *$ \\
\hline \multirow{4}{*}{$\begin{array}{l}\text { Family type } \\
\text { (ref. Couple no } \\
\text { children) }\end{array}$} & Couple with children & & & 1.001 \\
\hline & Lone parent & & & $0.707^{* * *}$ \\
\hline & Living with parents & & & $0.755^{* * *}$ \\
\hline & Single (childless) & & & 1.010 \\
\hline \multirow{2}{*}{$\begin{array}{l}\text { Region (ref. } \\
\text { Dublin) }\end{array}$} & Border/Midlands/West & & & 0.931 \\
\hline & South and East & & & 0.976 \\
\hline \multirow{6}{*}{$\begin{array}{l}\text { Length of } \\
\text { residence } \\
\text { (ref. Born in } \\
\text { Ireland) }\end{array}$} & $0-5$ & & & $0.600 * * *$ \\
\hline & $6-10$ & & & $0.741^{*}$ \\
\hline & $11-19$ & & & 0.963 \\
\hline & 20 or more & & & 0.883 \\
\hline & Pseudo R-squared & 0.0112 & 0.1475 & 0.1648 \\
\hline & Observations & 27,721 & 27,721 & 27,721 \\
\hline
\end{tabular}

Source: QNHS Equality modules, 2004, 2010 and 2014 pooled. Employed adults aged 18 to 64 years old. Note: $\quad * * * p<0.001,{ }^{* *} p<0.01, * p<0.05$.

We observe Black Irish, Asian non-Irish and other non-Irish to be much less likely (with odds ratios which range between 0.34 and 0.37 ) to be in a top job compared with White Irish; White non-EU and EU-West are less likely (odds ratio of 0.51 and 0.65 respectively). Compared to White Irish, the most disadvantaged group is still East Europeans who are considerably less likely (odds ratio of 0.12 ) to be employed in a top job, followed by Black non-Irish (2.14). Finally, the advantage of Asian Irish compared with White Irish decreases when education is taken into account - they are now less than two times as likely as White Irish to be in a top job. 
Finally, Model 3 controls for a set of additional characteristics. Also in this case, the characteristic that affects the relationship between ethnicity and nationality and the likelihood of being in a top job the most is the length of residence in Ireland. When we control for this characteristic, which is positively associated with the likelihood of occupying a top position, the penalty that many ethnic and national groups experience compared to the White Irish group weakens. Compared with Model 2, the association between ethnicity and nationality and top jobs weakens slightly for East Europeans, Black Irish and non-Irish, and Asian and other non-Irish. The association weakens and becomes non-significant for West Europeans and White non-EU people. On the contrary, the advantage of Asian Irish compared with White Irish strengthens slightly.

Looking at the other variables, the likelihood of being in a top job position increases with age; here age may also be interpreted in terms of work experience or tenure, which are associated with the highest positions within organisations. Being a woman, in contrast to employment chances, is negatively associated with access to top jobs. This is in line with other studies that have found that women face more barriers compared to men in accessing top positions in Ireland (Russell et al., 2017). Concerning family types, lone parents and people living with parents are less likely to be in top jobs, while we do not find any difference across regions.

\subsubsection{Changes over time?}

As a last step for this chapter, we look at whether inequalities between ethnic and national groups in accessing top job positions have changed over time. As was done before, we compare each group with the White Irish group and report the differences between them in percentage points.

First of all, Figure 4.4 shows substantial differences between White Irish and the other groups in the share of people employed in top jobs. While it is difficult to observe a very clear pattern over time, overall it seems that the disadvantage experienced by some groups is narrowing. For example, between 2004 and 2014 the gap between East Europeans and White Irish halved, from 27 to 14 percentage points. The negative gap completely closed for Black and Asian non-Irish. While in 2004 and 2010 the share of Black and Asian non-Irish people in top jobs was between 15 and 22 percentage points lower compared with White 
Irish, in 2014 we do not observe any significant differences between these groups. The trend over time for other non-Irish seems to go in the same direction. Conversely, we observe an increase in the polarisation for White non-EU, who in 2014 are about 15 percentage points less likely to be employed in a top job position compared with White Irish.

FIGURE 4.4 DIFFERENCES IN THE PREDICTED PROBABILITIES OF BEING IN A TOP JOB POSITION FOR ETHNIC/NATIONAL GROUPS COMPARED WITH WHITE IRISH OVER TIME

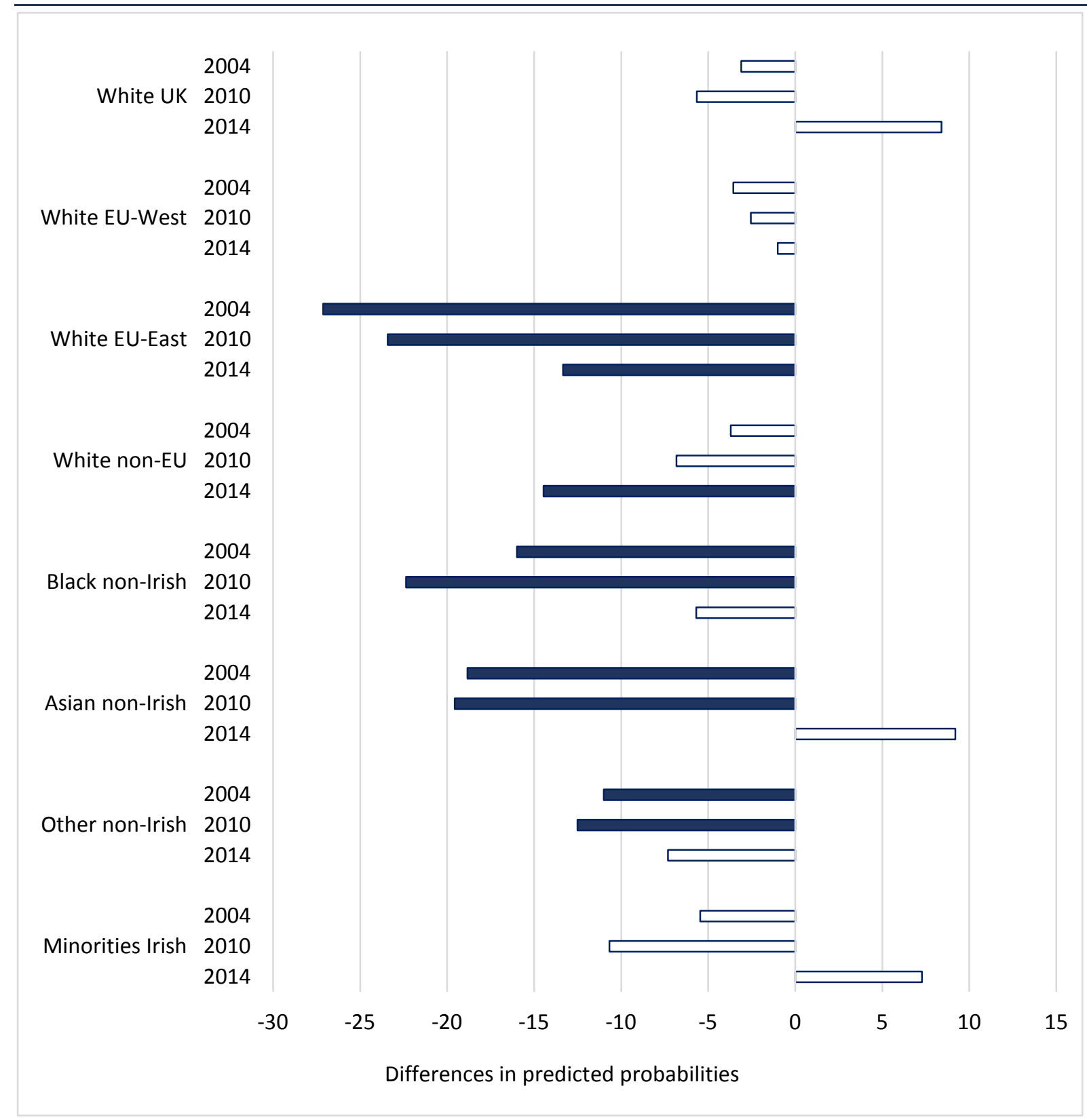

Source: QNHS Equality modules, 2004, 2010 and 2014 pooled. Employed adults aged 18 to 64 years old. Predicted probabilities based on Model 3 in Table 4.2 plus the interaction between ethnic/national group and year of the survey. Solid bars indicate a statistically significant result.

Note: Minorities refers to Black, Asian, and people of Other ethnicity. 


\subsection{SUMMARY AND CONCLUSIONS}

This chapter set out to investigate the labour market performance of ethnic and national groups looking at their employment chances and at their likelihood of occupying top job positions (defined as professional and managerial occupations). In addition, we studied whether differences in labour market outcomes between groups have changed over the period 2004-2014.

Concerning the likelihood of being employed versus unemployed, our results show substantial variation across ethnic and national groups. Compared with White Irish people, most of the groups experience lower employment chances. Exceptions are White EU-West, Black Irish and Asian Irish and non-Irish which do not differ significantly from the reference group of White Irish. When we take into account the individual level of education, most disadvantages strengthen as a result of the higher level of education characterising people other than White Irish. However, when we control for the length of stay in Ireland, the disadvantages experienced by most ethnic and national groups weaken and become not significant. Our final model that controls for these and other characteristics shows that only the Black non-Irish and Other ethnicity Irish are significantly less likely to be employed compared with White Irish (odds ratio of 0.4 and 0.35 respectively), while the White EUWest emerge to experience an advantage in the labour market (odds ratio of 1.7).

When we look at how differences in employment chances between groups have evolved over time, we do not observe a common pattern or trend. Focusing on the significant changes, we observe the advantage of the White EU-West with respect to the White Irish to emerge in 2010 onwards. Similarly we observe an advantage to emerge for White EU-East in 2014. Finally, while we observe a large penalty for Black non-Irish in 2004 and 2010, this decreases and becomes non-significant in 2014.

Turning our attention towards the access to top jobs, we observe some groups to be consistently disadvantaged across the models; these are White EU-East, and Black, Asian and Other non-Irish. We observe a penalty for Black Irish that emerges once we control for education. Overall, Black Irish and Black non-Irish people and especially White EU-East perform particularly badly, being considerably less likely to occupy a top job. Conversely, a substantial advantage compared with White Irish is experienced by Asian Irish who are 
almost twice as likely to occupy a top job position. As noted, English language skills are not measured in this survey and are likely to play a role in accessing jobs in the Irish labour market.

Also in this case, trends over time are far from being clear cut. The overall picture that emerges, however, is one of convergence between groups. Indeed, we observe that the disadvantages that some groups experience narrow over time. An exception to this trend regards White non-EU who experience an increased gap with White Irish, and in 2014 are 15 percentage points less likely to occupy a top job position. 


\section{CHAPTER 5}

\section{The experience of discrimination among ethnic and national groups}

\section{$5.1 \quad$ INTRODUCTION}

Chapter 4 investigated ethnic/national group variation in employment chances and the quality of their jobs. The focus of this chapter is the experience of discrimination. As discussed in Chapter 2, this gives a different perspective on labour market outcomes by asking respondents themselves about their experience. Discrimination is understood here as a situation in which individuals are treated differently due to their membership of a specific group, that is because of who they are. Respondents were asked whether they believed they had experienced discrimination according to a definition that reflects Irish law. ${ }^{33}$

Discrimination violates the fundamental human right of equal treatment. Established alongside other rights by the Universal Declaration of Human Rights in 1948, it can contribute to overall inequality in the labour market. To the extent that some groups are systematically discriminated against in access to jobs, these groups will tend to have lower employment rates, and poorer quality jobs when they do work. Discrimination may also have damaging consequences for the individuals involved both in terms of mental and physical health, self-esteem, and underperformance of the minority group as a whole (Schmitt et al., 2014). For example those who experience discrimination at work show higher levels of work stress and are more likely to leave their jobs (Triana et al., 2010). Perceived racial discrimination is also associated with poor health, especially mental health (Gee, 2002). Furthermore, discrimination in the labour market may be economically inefficient, as the skills of individuals are not effectively used (OECD, 2008).

This chapter asks:

1. Are there are differences between ethnic/national groups in their experience of seeking work and in the workplace, if they have a job?

\footnotetext{
33 Section 1.3.1 discusses equality and non-discrimination in Irish law: Section 3.1 describes how exactly discrimination is defined for survey respondents.
} 
2. Are these different experiences explained by other characteristics like education, age and duration in Ireland?

3. Has this experience changed over time in Ireland, during a period of dramatic labour market change (2004-2014)?

\subsection{LOOKING FOR WORK}

Evidence of discrimination against ethnic/national minorities from field experiments around the world is overwhelming (Eichhorst et al., 2018). However as Zschirnt and Ruedin (2016) note in their review of 43 studies, while typically non-White minorities experienced higher rates of discrimination than White minorities in Western labour markets, the extent of discrimination varies considerably across countries and across groups within countries.

Figure 5.1 presents the proportion of respondents from each of the groups who report experiencing discrimination seeking work in the two years prior to each survey wave in Ireland (see Chapter 3 for a description of the questions). The chart includes only those who had been seeking work in the two years prior to the survey, and presents combined responses from the surveys in 2004, 2010 and 2014. Compared to 6 per cent of White Irish, 20 per cent of Black non-Irish report discrimination seeking work in the two years prior to the survey. Other groups report much higher levels of discrimination seeking work than White Irish; 13 per cent of White non-EU, 16 per cent of Other ethnicity non-Irish and 12 per cent of the Minorities Irish group (Figure 5.1).

To what extent are these differences attributable to the personal characteristics of the individuals in different ethnic/national groups? Table 5.1 presents results of three logistic regression models of the experience of discrimination seeking work. The first model shows that certain ethnic/national groups are more likely to experience discrimination seeking work (indicated by an odds ratio greater than one) and these differences are statistically significant (indicated by asterisks in the table). Compared to White Irish, White UK are somewhat more likely to experience discrimination, as are White non-EU, Black Irish, Black non-Irish, who are over five times as likely to report experiencing discrimination, and Other ethnicity non-Irish. The odds ratios for 2004 and 2010 are less than one, indicating that respondents were less likely to experience discrimination in earlier years than in 2014. 
FIGURE 5.1 EXPERIENCE OF DISCRIMINATION SEEKING WORK BY ETHNIC/NATIONAL GROUP

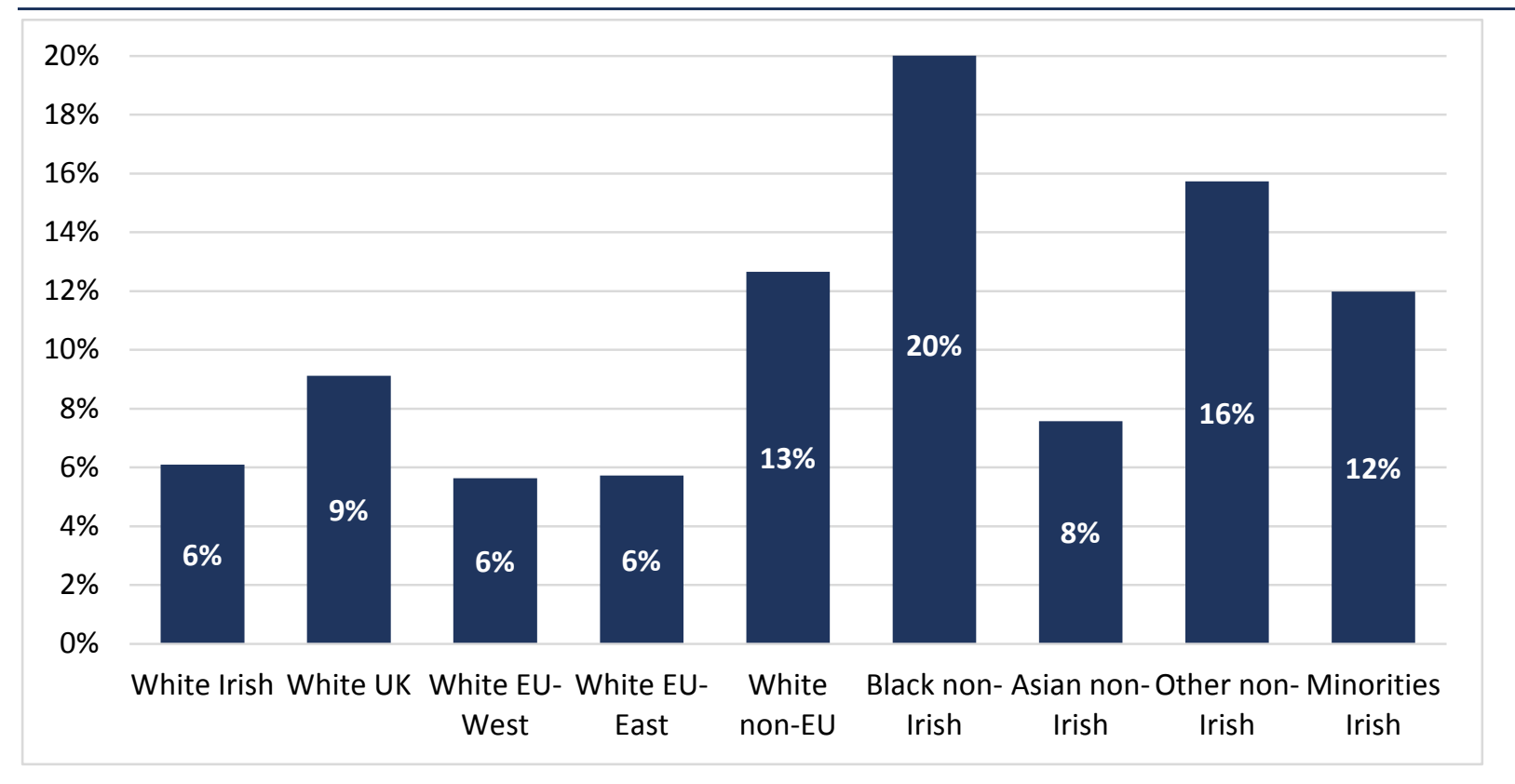

Source: $\quad$ CSO QNHS Equality modules, 2004, 2010 and 2014 pooled. Adults aged 18 to 64 years who had been seeking work in the two years prior to the survey. Weighted.

Notes: 'Minorities Irish' include people of Black, Asian and Other ethnicities.

White EU-West and EU-East nationals and Asian non-Irish do not differ from White Irish in their experience of recruitment discrimination. McGinnity and Gijsberts (2017), in their study of discrimination among new Polish migrants in 2011-2013, also find reported discrimination among Polish migrants in Ireland is relatively low, particularly compared to the experience of Poles in the Netherlands. ${ }^{34}$ Of the White EU-East group, Poles make up the largest single nationality (see Section 3.2).

While having higher qualifications is associated with experiencing less discrimination looking for work (see Model 2), it does not substantially affect which groups are most at risk of discrimination. When other factors are accounted for in Model 3 (age, gender, family type, region and length of residence), White non-EU, Black Irish, Other ethnicity non-Irish and particularly Black non-Irish still experience higher rates of discrimination in recruitment. Even after accounting for factors like age, education and length of residence, Black non-Irish

34 The questions combined experience of recruitment discrimination, discrimination in access to housing, poor treatment by institutions or experience or harassment or physical violence in a public place. The combined proportion of new Polish migrants experiencing discrimination in any of these domains was less than 10 per cent for the initial survey and follow up 18 months later (see McGinnity and Gijsberts, 2017). 
respondents are five times as likely to report discrimination in recruitment than White Irish. ${ }^{35}$ Black Irish are also more likely to report recruitment discrimination, but to a lesser extent (over twice as likely as White Irish). This suggests that being an Irish citizen may be an advantage in terms of recruitment for Black respondents; Black Irish citizens do not need an employment permit whereas many Black non-Irish do.

With the exception of Asian non-Irish, other non-EU groups tend to report higher levels of discrimination in recruitment. This may be a reflection of the work restrictions non-EU nationals in Ireland face compared to the situation for EU nationals, who can live and work in Ireland without restriction or an employment permit (see Section 2.2). Given the contrast between White Irish/EU and White non-EU groups in particular, as well as Irish and non-Irish groups, this would suggest that nationality plays a role particularly in recruitment. That said, given that Black non-Irish are reporting higher levels of discrimination among non-Irish groups, many of whom would also be subject to the same employment permit system (apart from those who are beneficiaries of international protection), discrimination on the basis of ethnicity is an important factor for persons of Black ethnic or cultural background.

Model 3 in Table 5.2 shows that other factors have the anticipated effect on the experience of discrimination and are consistent with previous research. Those with higher education are less likely to report discrimination than those with lower secondary education or less. Older working age adults (aged 45-64) are more likely than other groups to experience discrimination in recruitment. Lone parents are somewhat more likely to report discrimination seeking work than those living as part of a couple with no children. More recent arrivals to Ireland - those living in the country for five years or less - are also more likely to experience discrimination. This is what we might expect from theories of migrant integration (see Chapter 2). It also underscores the importance of accounting for duration in Ireland in the models.

35 Note that while the experience of discrimination measured in 2014 for Black non-Irish in recruitment is higher than the other ethnic/national groups in this report, the experience of discrimination in recruitment was considerably higher for Irish Travellers than for any other ethnic minority group (see McGinnity et al., 2017 for details). 
TABLE 5.1 LOGISTIC REGRESSION OF DISCRIMINATION SEEKING WORK (ODDS RATIOS)

\begin{tabular}{|c|c|c|c|c|}
\hline & & Model 1 & Model 2 & Model 3 \\
\hline \multirow{10}{*}{$\begin{array}{l}\text { Nationality } \\
\text { (ref. White Irish) }\end{array}$} & White UK & $1.687^{* *}$ & $1.752 * * *$ & 1.373 \\
\hline & White EU-West & 1.300 & 1.465 & 1.244 \\
\hline & White EU-East & 0.926 & 1.034 & 0.917 \\
\hline & White non-EU & $2.486 * * *$ & $2.723 * * *$ & $2.237^{* *}$ \\
\hline & Black Irish & $2.282^{*}$ & $2.442^{*}$ & $2.332^{*}$ \\
\hline & Black non-Irish & $5.259 * * *$ & $5.707 * * *$ & $5.023 * * *$ \\
\hline & Asian Irish & 1.727 & 1.931 & 1.924 \\
\hline & Asian non-Irish & 1.368 & 1.530 & 1.332 \\
\hline & Other ethnicity Irish & 2.184 & 2.441 & 2.190 \\
\hline & Other non-Irish & $3.182 * * *$ & $3.424 * * *$ & $2.816^{* * *}$ \\
\hline \multirow[t]{2}{*}{ Year (ref. 2014) } & 2004 & $0.703 * * *$ & $0.656 * * *$ & $0.675^{* * *}$ \\
\hline & 2010 & $0.707^{* * *}$ & $0.684 * * *$ & $0.695^{* * *}$ \\
\hline \multirow{3}{*}{$\begin{array}{l}\text { Education } \\
\text { (ref. Lower secondary } \\
\text { or less) }\end{array}$} & Upper secondary & & $0.627 * * *$ & $0.719 * * *$ \\
\hline & Third-level non-degree & & $0.677^{* * *}$ & $0.810^{*}$ \\
\hline & Third-level degree & & $0.631 * * *$ & $0.758^{* *}$ \\
\hline \multirow[t]{2}{*}{ Age (ref. 18-24) } & $25-44$ & & & 1.008 \\
\hline & $45-64$ & & & $1.719 * * *$ \\
\hline Sex (ref. Male) & Female & & & $0.833^{* *}$ \\
\hline \multirow{4}{*}{$\begin{array}{l}\text { Family type } \\
\text { (ref. Couple no } \\
\text { children) }\end{array}$} & Couple with children & & & 1.041 \\
\hline & Lone parent & & & $1.527^{* * *}$ \\
\hline & Living with parents & & & $1.541^{* *}$ \\
\hline & Single (childless) & & & 1.114 \\
\hline \multirow[t]{2}{*}{ Region (ref. Dublin) } & Border/Midlands/West & & & 1.112 \\
\hline & South and East & & & 0.953 \\
\hline \multirow{6}{*}{$\begin{array}{l}\text { Length of residence } \\
\text { (ref. Born in Ireland) }\end{array}$} & $0-5$ & & & $1.629 * *$ \\
\hline & $6-10$ & & & 1.063 \\
\hline & $11-19$ & & & 1.048 \\
\hline & 20 or more & & & 1.103 \\
\hline & Pseudo R-squared & 0.0165 & 0.0217 & 0.0323 \\
\hline & Observations & 18,998 & 18,998 & 18,998 \\
\hline
\end{tabular}

Source: QNHS Equality modules, 2004, 2010 and 2014 pooled. Adults aged 18 to 64 years old who had been seeking work in the two years prior to the survey.

Women are somewhat less likely to experience discrimination seeking work than men (0.8 times as likely in Table 5.1) (see also McGinnity et al., 2017). Is this the case for all the ethnic/national groups considered? White Irish women are somewhat less likely to experience discrimination than Irish men. By contrast, West European women and ethnic minority Irish women are more likely to experience discrimination seeking work than their 
male co-ethnics. Among other ethnic/national groups there are no significant gender differences in the experience of discrimination seeking work. ${ }^{36}$

\subsubsection{Change over time?}

Up to now, results have been based on all three waves of the Equality modules - 2004, 2010 and 2014. Have these patterns changed over time? Figure 5.2 shows differences in the predicted probabilities of experiencing discrimination between White Irish and every other ethnic and national group at different points in time. As in Chapter 4, predicted probabilities are computed based on a model that adds the interaction between ethnic and national groups and the year of the survey to Model 3 in Table 5.1. In addition, in contrast to the models presented in Table 5.1, we aggregate Black Irish, Asian Irish and Other ethnicity Irish into Minorities Irish. This was necessary because of the small size of these groups. The bars in Figure 5.2 represent differences in percentage points. Positive values indicate that the group is more likely to experience recruitment discrimination than White Irish; negative values indicate they are less likely to experience discrimination. In addition, solid bars signal a statistically significant difference, while empty bars signal statistically non-significant differences. In general we find a tendency for the gaps between ethnic/national groups to become smaller over time, though patterns differ between groups. For White EU-West nationals we find that in 2004 they were 8.5 percentage points more likely to experience discrimination than White Irish, but in later years do not differ from White Irish. For the White EU-East group, by 2014 they were actually less likely to experience discrimination in recruitment than White Irish, though the difference is not large. The Black non-Irish group was around 20 percentage points more likely to experience discrimination in recruitment compared to White Irish in 2004 and 2010. By 2014 the difference is much lower (around 10 percentage points) though still substantial. So while more respondents overall are reporting recruitment discrimination in 2014 , differences between ethnic/national groups are smaller.

36 Results available from the authors on request. Note these do not control for other characteristics. 


\section{FIGURE 5.2 DIFFERENCES IN THE PREDICTED PROBABILITIES OF EXPERIENCING RECRUITMENT DISCRIMINATION FOR ETHNIC/NATIONAL GROUPS COMPARED TO WHITE IRISH OVER TIME}

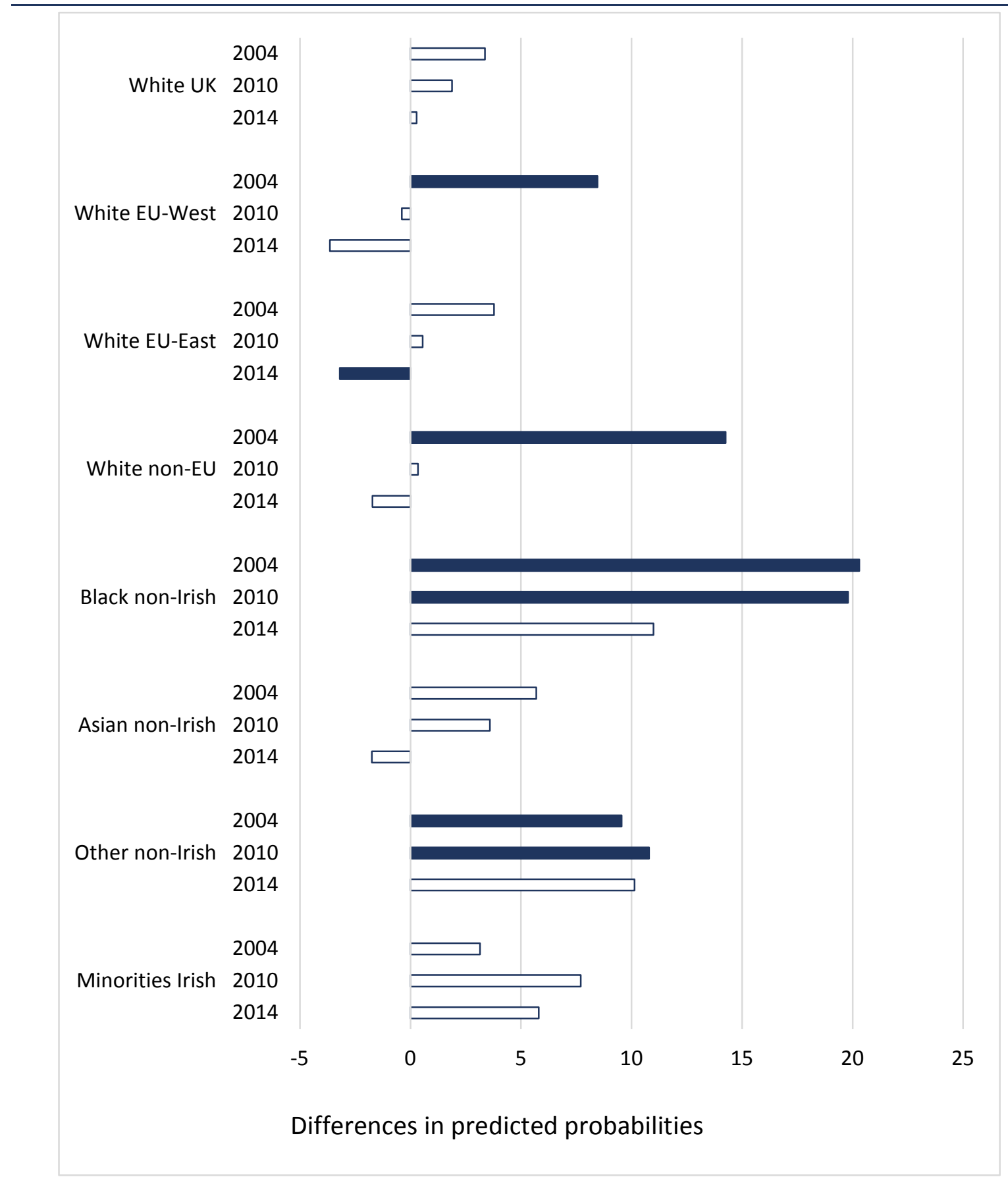

Source: $\quad$ QNHS Equality modules, 2004, 2010 and 2014 pooled. Adults aged 18 to 64 years old.

Notes: $\quad$ Predicted probabilities based on Model 3 in Table 5.1 plus the interaction between ethnic/national group and year of the survey. 'Minorities Irish' refers to Black, Asian, and people of Other ethnicity.

One factor to keep in mind could be the change in composition of ethnic/national groups. For example a big shift between 2004 and 2010 for the White non-EU group would have been the increased restrictions on the issuing of employment permits and shift in policy towards permits being issued for highly-skilled workers. This could explain the significance 
of the White non-EU groups probability of reporting discrimination from 2004-2014. By 2010, the majority of non-EU would have been considered more highly skilled than those non-EU nationals entering Ireland on the basis of an employment permit pre-2004, who would have been from a more diverse range of nationalities (including pre-accession EU Member States), as well as having a diverse range of skills and educational attainment levels (Kingston et al., 2013).

Another factor here in relation to the overall decreases since 2004 could be, as mentioned by Kingston et al. (2015); that in 2004 Ireland was a relatively new country of immigration and employers may not have had as much experience with immigrant groups, in contrast with 2014 when immigrant groups will have been more established.

\subsection{DISCRIMINATION IN THE WORKPLACE}

Workplace discrimination focuses on the experience of discrimination in the previous two years for those who were at work. Workplace discrimination can include bullying or harassment, unfair treatment in terms of working conditions, promotion, pay and other forms of discrimination. ${ }^{37}$ Note that respondents who experienced high levels of recruitment discrimination may not have a job and will thus be excluded from the analysis of workplace discrimination.

Figure 5.3 presents the proportion of respondents reporting any discrimination in the workplace. Aside from White UK nationals, most ethnic/national minority groups report higher rates of workplace discrimination than White Irish: White EU-East (9 per cent); White non-EU (11 per cent); Asian non-Irish (12 per cent); and Other ethnicity non-Irish (11 per cent). Groups that report particularly high rates of workplace discrimination are Black nonIrish (19 per cent) and Minorities Irish (15 per cent).

37 By way of illustration, bullying and harassment was the most common form of discrimination, followed by working conditions in 2014 (McGinnity et al., 2017). The numbers in the ethnic/national groups are too small to allow detailed analysis of reasons for workplace discrimination in this report. 


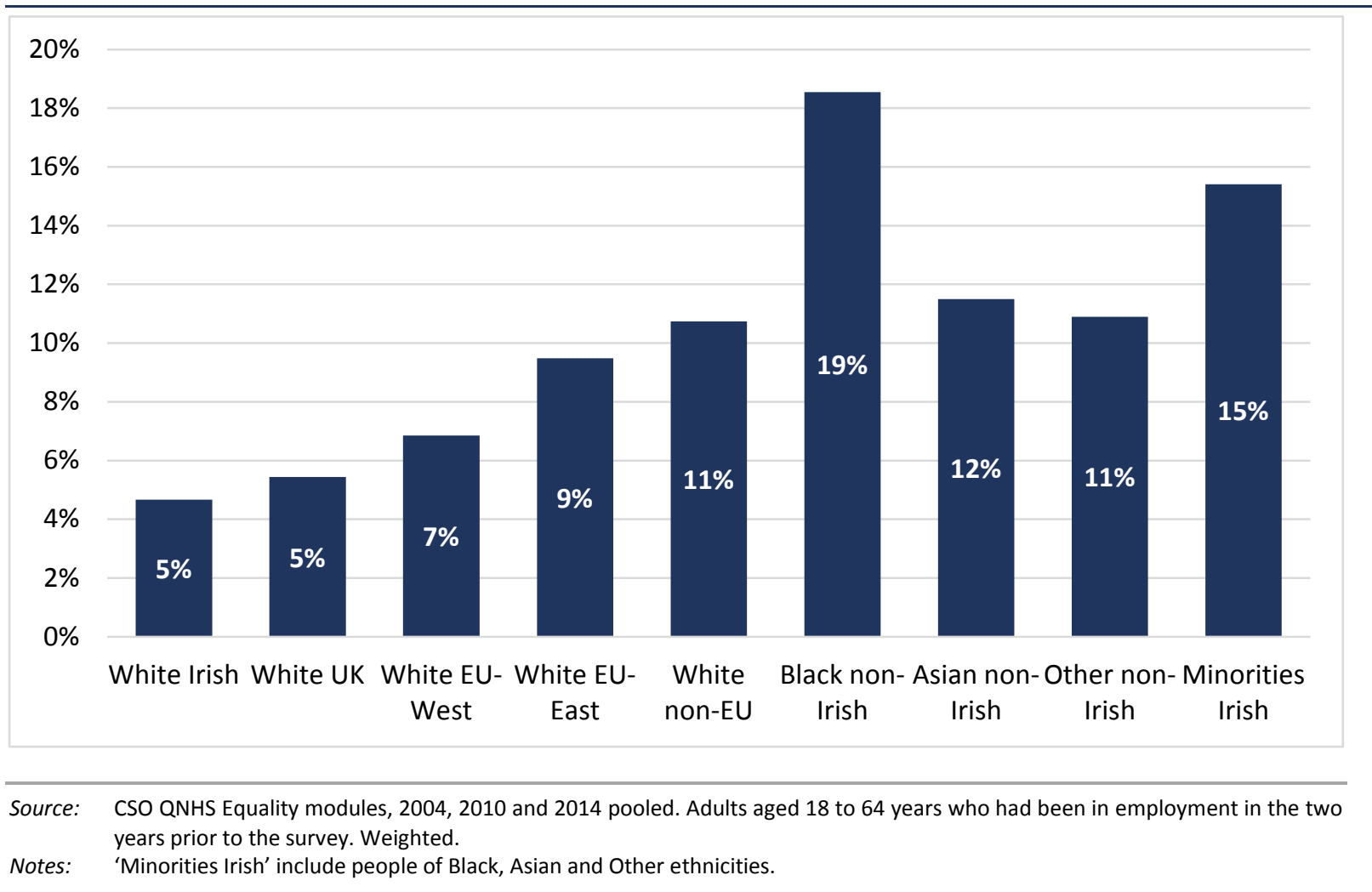

Table 5.2 presents the results of three models of workplace discrimination. Once we control for education in Model 2, White UK and White EU-West nationals do not differ from White Irish in their experience of workplace discrimination. White EU-East and White non-EU are almost twice as likely to experience discrimination in the workplace, until family type, region and duration are controlled for. After these controls these groups are around 1.5 times as likely to experience workplace discrimination (Model 3).

Even after all other factors are accounted for, including length of residence, both Black Irish and Black non-Irish are much more likely to experience discrimination in the workplace; 3.4 times as likely in the case of Black Irish and 2.7 times as likely in case of Black non-Irish (see Table 5.2). Unlike with recruitment discrimination, there is no advantage for Black respondents in being Irish. Black ethnicity is the key factor in workplace discrimination.

Asian Irish are also almost twice as likely as White Irish to experience workplace discrimination after controls for education and duration: the effect is smaller for Asian nonIrish. 'Other ethnicity' Irish are also more likely to experience discrimination, though due to the small group size, the effect is not significant. Overall in terms of the group experience of workplace discrimination, for non-White groups there is no advantage in being Irish. 
TABLE 5.2 LOGISTIC REGRESSION: DISCRIMINATION IN THE WORKPLACE (ODDS RATIOS)

\begin{tabular}{|c|c|c|c|c|}
\hline & & Model 1 & Model 2 & Model 3 \\
\hline \multirow{10}{*}{$\begin{array}{l}\text { Nationality } \\
\text { (ref. White Irish) }\end{array}$} & White UK & 1.093 & 1.049 & 0.958 \\
\hline & White EU-West & $1.601^{*}$ & 1.418 & 1.092 \\
\hline & White EU-East & $2.023 * * *$ & $1.956 * * *$ & $1.538^{*}$ \\
\hline & White non-EU & $2.220 * * *$ & $2.019 * * *$ & $1.627^{*}$ \\
\hline & Black Irish & $4.587 * * *$ & $4.358 * * *$ & $3.431 * * *$ \\
\hline & Black non-Irish & $4.323 * * *$ & $4.013^{* * *}$ & $2.695 * * *$ \\
\hline & Asian Irish & $2.729 * * *$ & $2.456^{* *}$ & $1.908^{*}$ \\
\hline & Asian non-Irish & $2.386 * * *$ & $2.114^{* * *}$ & 1.568 \\
\hline & Other ethnicity Irish & $3.181 * *$ & $2.823^{*}$ & 2.404 \\
\hline & Other non-Irish & $1.993 * *$ & $1.888 * *$ & 1.513 \\
\hline \multirow[t]{2}{*}{ Year (ref. 2014) } & 2004 & 0.934 & 0.989 & 1.008 \\
\hline & 2010 & 0.936 & 0.945 & 1.008 \\
\hline \multirow{3}{*}{$\begin{array}{l}\text { Education } \\
\text { (ref. Lower } \\
\text { secondary or less) }\end{array}$} & Upper secondary & & $1.208^{*}$ & $1.168^{*}$ \\
\hline & Third-level non-degree & & $1.693 * * *$ & $1.560 * * *$ \\
\hline & Third-level degree & & $1.612 * * *$ & $1.478 * * *$ \\
\hline \multirow[t]{2}{*}{ Age (ref. 18-24) } & $25-44$ & & & 1.136 \\
\hline & $45-64$ & & & 1.141 \\
\hline Sex (ref. Male) & Female & & & $1.517 * * *$ \\
\hline \multirow{4}{*}{$\begin{array}{l}\text { Family type } \\
\text { (ref. Couple no } \\
\text { children) }\end{array}$} & Couple with children & & & $1.164^{*}$ \\
\hline & Lone parent & & & $1.318^{* *}$ \\
\hline & Living with parents & & & 1.057 \\
\hline & Single (childless) & & & $1.278^{* *}$ \\
\hline \multirow{2}{*}{$\begin{array}{l}\text { Region (ref. } \\
\text { Dublin) }\end{array}$} & Border/Midlands/West & & & $0.669 * * *$ \\
\hline & South and East & & & $0.647 * * *$ \\
\hline \multirow{6}{*}{$\begin{array}{l}\text { Length of } \\
\text { residence } \\
\text { (ref. Born in } \\
\text { Ireland) }\end{array}$} & $0-5$ & & & 1.206 \\
\hline & $6-10$ & & & $1.481^{*}$ \\
\hline & $11-19$ & & & 1.247 \\
\hline & 20 or more & & & 0.932 \\
\hline & Pseudo R-squared & 0.0107 & 0.0152 & 0.0264 \\
\hline & Observations & 32,038 & 32,038 & 32,038 \\
\hline
\end{tabular}

Source: QNHS Equality modules, 2004, 2010 and 2014 pooled. Employed adults aged 18 to 64 years old.

Note: $\quad * * * \mathrm{p}<0.001, * * \mathrm{p}<0.01, * \mathrm{p}<0.05$.

Other findings are consistent with previous research, for example McGinnity et al. (2017).

Those with higher education tend to report more discrimination in the workplace, perhaps because of heightened awareness and higher expectations of equal treatment. Reports of workplace discrimination are lower outside Dublin, and respondents living in Ireland for six to ten years are more likely to experience workplace discrimination than those who were born in Ireland.

Women report more discrimination in the workplace, as found in McGinnity et al. (2017). Are these gender differences similar across the ethnic/national groups? Initial descriptive 
analyses suggests that while White Irish women and East and West European women experience more workplace discrimination than their male counterparts, this is not true of women from the UK, Black, Asian or Other non-Irish groups. In the 'Minorities Irish' group, men experience significantly more discrimination than women in the workplace. ${ }^{38}$

\subsubsection{Changes over time between ethnic/national groups?}

How has the experience of ethnic/national groups changed over time? In a similar way to Figure 5.2, Figure 5.4 shows differences in the predicted probabilities of experiencing workplace discrimination between White Irish and every other ethnic and national group at different points in time (2004, 2010 and 2014). ${ }^{39}$ As in Figure 5.2, Black Irish, Asian Irish and Other ethnicity Irish are grouped into Minority Irish due to the small size of the groups. The bars in Figure 5.4 represent differences in percentage points. Positive values indicate that the group is more likely to experience workplace discrimination than White Irish; negative values indicate they are less likely to experience discrimination.

In general the differences between minority ethnic/national groups and White Irish for individual years is quite small. There are no large differences among White groups, that is between White Irish and other White non-Irish groups. For Black non-Irish there is a large and significantly higher risk of workplace discrimination in 2010; for Asian Irish the large and significantly higher risk was in 2004. For Minorities Irish, a group that is increasing in size as more migrants become Irish citizens, the highest risk was in 2014, when they were over 7 percentage points more likely to experience workplace discrimination than White Irish.

38 Results available from the authors on request. Note these descriptive results do not control for different characteristics.

39 In a similar way to Figure 5.2, predicted probabilities are computed based on a model that adds the interaction between ethnic and national groups and the year of the survey to Model 3 in Table 5.2. 
FIGURE 5.4 DIFFERENCES IN THE PREDICTED PROBABILITIES OF EXPERIENCING WORKPLACE DISCRIMINATION FOR ETHNIC/NATIONAL GROUPS COMPARED TO WHITE IRISH OVER TIME

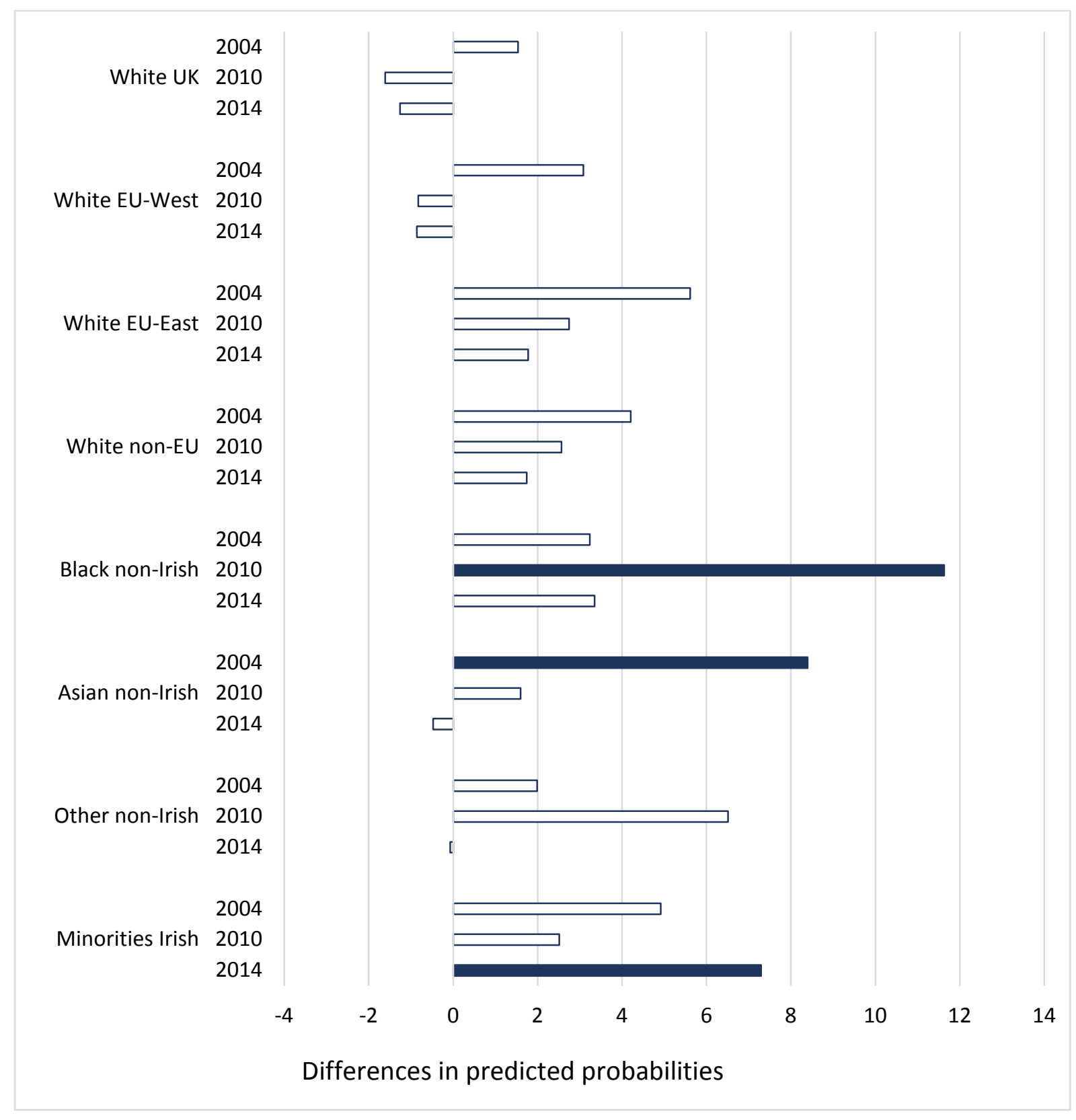

Source: QNHS Equality modules, 2004, 2010 and 2014 pooled. Adults aged 18 to 64 years old. Predicted probabilities based on Model 3 in Table 5.2 plus the interaction between ethnic/national group and year of the survey.

Note: $\quad$ Minorities refers to Black, Asian, and people of Other ethnicity.

\subsection{SUMMARY AND CONCLUSIONS}

The focus of this chapter was on individual's own experience of discrimination in the Irish labour market, both in seeking work and in the workplace. In particular, the chapter asked whether ethnic/national minority groups differed in their experience from White Irish, and whether this had changed over time. 
In terms of looking for work, once we control for other factors, White Europeans do not differ in their experience from White Irish, but non-EU respondents report higher rates of recruitment discrimination, possibly partly because of legal restrictions on their work, among other factors. The exception to this general pattern is Asian non-Irish who do not differ so clearly in their experience of discrimination from White Irish, despite being predominantly born outside the European Union. Black non-Irish respondents report very high rates of recruitment discrimination: Black Irish rates are closer to White non-EU nationals. Differences between the ethnic/national groups and White Irish have tended to become smaller in the period 2004-2014, but the gap between White Irish and Black nonIrish is still large by 2014.

In the workplace, the White UK and White EU-West groups do not differ in their experience from White Irish. Other White migrants - EU-East and non-EU - experience somewhat higher levels of discrimination than White Irish. But in general it is the non-White groups that experience the highest levels of workplace discrimination; in particular the Black groups, both Black non-Irish and Black Irish, and to a lesser extent Asian Irish and those of Other ethnicity. Compared to White Irish, the Minorities Irish group are more disadvantaged in 2014 than in earlier years. 



\section{CHAPTER 6}

\section{Conclusion}

\subsection{SUMMARY OF FINDINGS}

The period 2004 to 2014 saw considerable economic and societal change as a result of both increases in immigration to Ireland and periods of growth and recession in the Irish economy. There has always been some ethnic and national diversity in Ireland, but this has increased considerably since 2002 (see Chapter 1). In this context, this study examines the experience of immigrants and minority ethnic groups in the Irish labour market. It distinguishes individuals of working age on the basis of both their ethnicity and their nationality and country of origin and asks: do their outcomes differ from the White Irish group? Outcomes considered are employment rates and occupational position, as well as discrimination in seeking work and in the workplace. All findings discussed here are after controlling for age, education, gender, family type, broad region and length of residence in Ireland; all characteristics associated with both our outcomes and the membership of ethnic and national groups, and thus with the potential to bias the relationship between them if not controlled. Summary results are presented in Table 6.1.

For White UK nationals, differences between them and the White Irish group are minimal for all outcomes - employment rates, occupational position, and the experience of discrimination seeking work and in the workplace (see Table 6.1). White EU-West nationals are actually more likely to be employed than White Irish and we find no difference between them and White Irish in terms of occupational position, in discrimination seeking work and in the workplace (see Table 6.1). While previous studies have demonstrated the important role that language plays in gaining employment and which jobs migrants get (e.g. Barrett and McCarthy, 2007), this particular group may not be native English speakers but are not experiencing disadvantage on the Irish labour market using these outcome measures. ${ }^{40}$ For White EU-East nationals, we find no difference in employment rates or reported

\footnotetext{
40 Note however that the surveys do not include measures of English language skills, which may be excellent among this group.
} 
discrimination seeking work, as shown in Table 6.1, but this group are also somewhat more likely to experience discrimination in the workplace (1.5 times as likely). Members of this group are also considerably less likely to occupy managerial/professional jobs ( 0.2 times as likely), consistent with the findings of Voitchovsky (2014), though the gap between them and the White Irish has narrowed somewhat during the period (2004-2014) (see Table 6.1).

TABLE 6.1 SUMMARY OF MODEL FINDINGS ON LABOUR MARKET OUTCOMES AND THE EXPERIENCE OF DISCRIMINATION FOR EACH ETHNIC/NATIONAL GROUP

\begin{tabular}{|c|c|c|c|c|}
\hline Group & $\begin{array}{l}\text { Employment } \\
\text { (Table 4.1) }\end{array}$ & $\begin{array}{c}\text { Occupation (Managerial } \\
\text { /professional jobs) } \\
\text { (Table 4.2) }\end{array}$ & $\begin{array}{l}\text { Experience of } \\
\text { Discrimination } \\
\text { Seeking Work } \\
\text { (Table 5.1) }\end{array}$ & $\begin{array}{l}\text { Experience of } \\
\text { Discrimination in } \\
\text { the Workplace } \\
\text { (Table 5.2) }\end{array}$ \\
\hline White Irish & Reference group & Reference group & Reference group & Reference group \\
\hline White UK & No difference & No difference & No difference & No difference \\
\hline White EU-West & $\begin{array}{l}\text { More likely to be } \\
\text { employed }\end{array}$ & No difference & No difference & No difference \\
\hline White EU-East & No difference & $\begin{array}{l}\text { Much, much less likely } \\
(0.2)\end{array}$ & No difference & Higher - 1.5 times \\
\hline White non-EU & No difference & No difference & $\begin{array}{l}\text { Higher - } 2 \text { times as } \\
\text { high }\end{array}$ & Higher - 1.6 times \\
\hline Black Irish & No difference & Much less likely (0.35) & $\begin{array}{l}\text { Higher }-2 \text { times as } \\
\text { high }\end{array}$ & Higher - 3.4 times \\
\hline Black non-Irish & $\begin{array}{l}\text { Much less likely to be } \\
\text { employed }(0.4)\end{array}$ & Much less likely (0.3) & $\begin{array}{l}\text { V high }-5 \text { times as } \\
\text { high }\end{array}$ & Higher - 2.7 times \\
\hline Asian Irish & $\begin{array}{l}\text { More likely but not } \\
\text { significant }\end{array}$ & $\begin{array}{l}\text { More likely to be in top } \\
\text { jobs than Irish ( } 1.9 \text { times) }\end{array}$ & $\begin{array}{l}\text { Higher but not } \\
\text { significantly } \\
\text { different }\end{array}$ & Higher - 1.9 times \\
\hline Asian non-Irish & No difference & $\begin{array}{l}\text { Less likely to be in top } \\
\text { jobs }(0.5)\end{array}$ & No difference & $\begin{array}{l}\text { Borderline - } \\
1.5 \text { times but not } \\
\text { significantly different }\end{array}$ \\
\hline Other Irish & $\begin{array}{l}\text { Much less likely to be } \\
\text { employed }\end{array}$ & No significant difference & $\begin{array}{l}\text { Higher but not } \\
\text { significantly } \\
\text { different }\end{array}$ & Higher \\
\hline Other non-Irish & No difference & $\begin{array}{l}\text { Less likely to be in top } \\
\text { jobs }(0.5)\end{array}$ & $\begin{array}{l}\text { High }-2.8 \text { times as } \\
\text { high }\end{array}$ & No difference \\
\hline $\begin{array}{l}\text { Change over } \\
\text { time? }\end{array}$ & $\begin{array}{l}\text { Gap smaller for Black } \\
\text { non-Irish in } 2014\end{array}$ & $\begin{array}{l}\text { Gaps narrower in } 2014 \\
\text { (except for White non-EU) }\end{array}$ & $\begin{array}{l}\text { Gaps narrowing (a } \\
\text { little) }\end{array}$ & $\begin{array}{l}\text { Gap increased for } \\
\text { Minorities Irish. }\end{array}$ \\
\hline
\end{tabular}

Note: All findings are after controls for education, age, sex, family composition, region and length of residence in Ireland. See Tables $4.1,4.2,5.1$ and 5.2 for more details. In each case the group is compared to the White Irish group.

The White non-EU group show no difference in employment rates or occupational position compared to White Irish, but their experience of discrimination in the Irish labour market differs from their Irish counterparts. They are more likely to report discrimination seeking work, possibly related to the restrictions on their taking up employment discussed in Chapter 1 . They are also somewhat more likely to experience discrimination in the workplace than White Irish (1.6 times as likely, see Table 6.1). 
Those of Black ethnicity are distinguished according to whether they are Irish citizens or not. Is there evidence of disadvantage for those of Black ethnicity and does nationality play any role? The answer depends on the outcome measure. As shown in Table 6.1, we find that Black non-Irish are much less likely to be employed than White Irish ( 0.4 times as likely) but Black Irish show little difference to the majority White Irish population in terms of overall employment. Yet for occupational position, both groups show considerable disadvantage, being 0.3 times as likely to hold a managerial/professional job as White Irish (see Table 6.1). That said, Chapter 4 notes that the considerable gap between Black non-Irish and White Irish in terms of employment and occupational position has narrowed over the time period (2004-2014). In seeking work, both groups report higher rates of discrimination, but the effect is much larger for Black non-Irish who are five times as likely as White Irish to experience discrimination, than for Black Irish, who are twice as likely to experience discrimination. Yet in the workplace, both groups experience higher rates of discrimination than White Irish, and in fact the Black Irish group report slightly higher rates than the Black non-Irish group (see Table 6.1). In overall employment rates and in seeking work there seems to be an advantage to being Black Irish rather than Black non-Irish, but not in the workplace or occupational position of the job.

Those of Asian ethnicity are similarly distinguished according to whether they are Irish citizens or not, but a rather different story emerges. Neither of the Asian groups differ significantly from White Irish in terms of their overall employment rates (Table 6.1). But in terms of occupational position, Asian Irish are actually advantaged; that is, more likely to be working in professional/managerial occupations than White Irish (1.9 times as likely). Conversely, Asian non-Irish are less likely to be in the top jobs ( 0.5 times as likely). The advantage of Asian Irish may be related to the jobs for which they acquired employment permits, but it generally contradicts the general trend of occupational disadvantage among ethnic/national minority groups. Neither Asian group differs significantly from White Irish in reported discrimination seeking work (even though the Asian non-Irish group are predominantly non-EU). Both Asian groups report somewhat higher discrimination in the workplace than White Irish, though the difference between Asian non-Irish and White Irish is not significant (Table 6.1). 
The 'Other ethnicity' groups, both Irish and non-Irish, are very diverse (see Chapter 3 ) and we cannot distinguish how many are mixed race. In general they experience more negative outcomes than White Irish, though once again among them the Irish and non-Irish groups differ, and in some cases it is difficult to interpret the findings as the group size is very small.

\subsection{POLICY IMPLICATIONS}

The findings in this report reflect a diversity of experiences among national and ethnic groups in the Irish labour market. The findings show that many minority ethnic/national groups and particularly those of Black ethnicity experience more negative outcomes in employment and occupational attainment and are at greater risk of discrimination in recruitment and in the workplace than White Irish individuals. As outlined in Chapter 2, lower labour market outcomes identified in the findings across immigrant and ethnic minorities may be due to a range of factors which should be kept in mind when developing labour market integration policies and programmes.

\section{Discrimination - addressing employer/state behaviour}

The findings show that non-Irish individuals, especially individuals of non-White ethnicity, experience higher rates of discrimination in the labour market. In particular, the disadvantage experienced by Black Irish individuals in the workplace, despite sharing the same nationality with White Irish individuals, suggests that discrimination on the basis of ethnicity is a factor at play for Irish individuals of Black ethnicity. Nationality clearly plays a role in recruitment discrimination too with White non-EU and, in particular, Black non-Irish reporting higher rates of recruitment discrimination than their co-ethnics of Irish nationality.

This highlights the need for both government and employer-led policies to monitor, prevent and respond to incidences of discrimination in recruitment and in the workplace. While legislative measures to respond to employment discrimination have been in place in Ireland for some time (see Chapter 1), measures to prevent discrimination are equally necessary to promote equality of opportunity for ethnic/national groups.

The Public Sector Equality and Human Rights Duty is an important mechanism through which public bodies can take a proactive approach to addressing discrimination on the grounds of race, skin colour, nationality or ethnic origin and ensuring equality for ethnic 
minority groups. Research conducted with public bodies on migrant integration policies found that many of the public bodies surveyed lacked an awareness or understanding of the duty (Murphy et al., 2017). This highlights the need to enhance awareness across the public sector of the legal obligations under the duty. Raising the awareness of equality legislation among the general public is equally important. While employers that are not defined public bodies under the Irish Human Rights and Equality Commission Act 2014 are not bound by the Public Sector Equality and Human Rights Duty, they can proactively take equality and human rights into account in the workplace to ensure compliance with equality legislation.

As mentioned in Chapter 1, invoking employment equality legislation and accessing redress for discrimination relies on the individual's knowledge of their rights under equality legislation and their capacity to make a complaint. Previous research on the experience of discrimination in Ireland has highlighted how individuals who reported experiencing the highest levels of discrimination, including non-Irish ethnic minorities, are the least likely to have a good knowledge of their rights and to take official or legal action in response to discrimination (McGinnity et al., 2012). Data from the Equality module in 2014 show that the highest proportion of individuals who indicated a good understanding of rights under Irish equality law in 2014 were White UK (28.93 per cent) and White Irish (28.40 per cent) individuals, while the lowest proportion was found to be among Black non-Irish (9.35 per cent), White EU-East (8.87 per cent) and Asian non-Irish (8.21 per cent) individuals. The 2014 data also show that 26.71 per cent of Minorities Irish reported having a good understanding of rights, which suggests that the length of time spent in Ireland may impact on awareness of rights and redress mechanisms available under equality legislation. Efforts to increase awareness among employers and the public should therefore be coupled with provision of information to immigrant communities about equality legislation and the reporting and redress mechanisms available to them to ensure the effective implementation of the equality framework.

\section{Ensuring equal access and recognition of skills}

As noted in Chapter 3, all ethnic/national groups were found to have attained higher levels of education than White Irish. Yet our findings also show that non-Irish individuals, including those of Black, Asian and Other ethnicity, are less likely to occupy managerial or professional jobs. In addition, White EU-East nationals were found to be the most 
disadvantaged in terms of occupational attainment. Furthermore, discrimination in the workplace was reported by many ethnic/national groups to be higher than that reported by White Irish.

These findings may be explained by a lack of specific skills suitable for the local labour market in addition to difficulties faced by non-Irish nationals in gaining recognition of skills and qualifications attained abroad (Borjas, 1999; Voitchovsky; 2014). Bodies such as Quality and Qualification Ireland (QQI), CORU, the organisation that regulates health and social care professionals, and SOLAS, the Further Education and Training Authority, provide assistance to non-Irish nationals in having their qualifications recognised. However barriers still remain in cases where employers may not be familiar with a university or education authority from which a degree or vocational qualification was obtained. All non-Irish nationals who wish to work in a regulated profession in Ireland, such as in the health sector, must have their professional qualifications recognised by the relevant professional body, such as CORU. The EU has established rules to facilitate the mutual recognition among EU Member States of professional qualifications obtained by EU nationals and make it easier for EU nationals to practise their profession in EU countries other than their own. ${ }^{41}$ In general, such rules do not apply to non-EU nationals, who are subject to national rules concerning recognition procedures.

Previous research indicates that difficulties in obtaining recognition of foreign educational qualifications pose a barrier to labour market integration and may lead non-Irish nationals to situations of under-employment and over-qualification (MRCI, 2015), which could explain reports across ethnic/national groups of discrimination in the workplace and their lower occupational positions. The Migrant Integration Strategy sets out the need to better promote Ireland's QQI system for recognition of vocational skills accredited in other countries. It is crucial that such awareness is promoted among both immigrants and employers, to ensure that qualifications and skills obtained outside of Ireland are recognised, to prevent skills and resources being underutilised, and to ensure occupational mobility in the workplace.

41 Directive 2005/36/EC of the European Parliament and of the Council of 7 September 2005 on the recognition of professional qualifications. 
Recognition of qualifications and skills needs to be complemented with programmes to assist migrants entering and progressing through the labour market to develop their skills in Ireland. The Migrant Integration Strategy commits to ensuring further education and training courses meet the specific needs of migrants, such as in relation to language acquisition (Department of Justice and Equality, 2017). Courses that provide for migrants to acquire and develop skills relevant to the Irish labour market are necessary to address the disadvantage migrants may experience and ensure occupational progression.

\section{The international protection system}

Labour market integration policies and programmes should also take into account the experience of persons who seek international protection in Ireland from persecution or serious harm. The integration of beneficiaries of international protection into Irish society, particularly in the area of employment, can be more difficult due to conflict and trauma in the country of origin or periods spent outside the labour market in refugee camps or reception accommodation (Gusciute et al., 2016).

As outlined in Chapters 1 and 2, prior to June 2018 Ireland's international protection policy restricted the labour market access of persons awaiting a decision on their international protection application. While there is no information in the surveys about periods spent seeking protection, research that analysed Census 2011 data found that non-EU nationals from countries with relatively large numbers of international protection applicants in Ireland tend to have lower employment rates and higher unemployment rates, indicating that the exclusion of applicants from the Irish labour market had a negative effect on their employment outcomes (O'Connell, 2018). The government's decision in June 2018 to grant the right to work for international protection applicants who have not received a first instance decision within nine months of submitting an application for international protection may help facilitate the labour market integration of persons who are subsequently granted international protection.

To ensure the effective implementation of the right to seek employment, employment training programmes should address the specific needs of beneficiaries of international protection and international protection applicants granted permission to work who are re-entering the labour market (IHREC, 2018a). 


\section{Data and monitoring}

Surveys that collect information on self-reported experiences of discrimination among the population such as those examined in this report are important in measuring the extent of the problem of discrimination and to inform outreach to communities that are identified as being at particular risk of unequal treatment.

This report has pointed to some potential factors underlying the disadvantage experienced by minority ethnic/national groups in the Irish labour market. Commitments such as those set out in the Migrant Integration Strategy to analyse the barriers faced by jobseekers of African origin, and to continue data collection on employment outcomes, are positive in informing mainstream service provision and ensuring policies respond appropriately to identified needs. To this end, it is important that the implementation of the Strategy be monitored and its impact on the outcomes of minority ethnic/national groups assessed.

Ethnicity is a key locus of disadvantage in this report. However it is rarely measured in repeated survey data in Ireland.

The regular collection of ethnicity in labour market surveys is a key priority at this time. Furthermore, the acquisition of Irish citizenship among non-EU nationals and also the growing second generation brings new challenges to measure and monitor the experience of immigrants in Ireland and these challenges also have to be addressed if adequate policy responses to disadvantage are to be developed. 


\section{REFERENCES}

Arnold, S., S. Whelan and E. Quinn (2017). Illegal Employment of Non-EU Nationals in Ireland, European Migration Network, ESRI Research Series Number 64, Dublin: ESRI.

Arrow, K.J. (1973). 'The Theory of Discrimination' in O.A. Ashenfelter and A. Rees (eds.), Discrimination in Labor Markets. Princeton, NJ: Princeton University.

Barrett, A. and Y. McCarthy (2007). 'Immigrants in a Booming Economy: Analysing their Earnings and Welfare Dependence', Labour, 21(4), pp. 789-808.

Barrett, A. and D. Duffy (2008). 'Are Ireland's Immigrants Integrating into Its Labour Market?', International Migration Review, 42(3), pp. 597-619.

Barrett, A. and E. Kelly (2012). 'The Impact of Ireland's Recession on the Labour Market Outcomes of its Immigrants', European Journal of Population 28(1), pp. 99-111.

Barret, A., A. Bergin, E. Kelly and S. McGuinness (2016). 'Ireland's Recession and The Immigrant Native Earnings Gap' in Kahanec, M., and K.F. Zimmermann (Eds.) Labor Migration EU Enlargement and the Great Recession.

Barrett, A., F. McGinnity and E. Quinn (eds.) (2017). Monitoring Report on Integration 2016. Dublin: ESRI/The Department of Justice and Equality.

Becker, G. (1975). Human Capital. A Theoretical and Empirical Analysis, with Special Reference to Education. Chicago: The University of Chicago Press.

Blank, R.M., M. Dabady and C.F. Citro (eds.) (2004). Measuring racial discrimination. Washington DC: The National Academies Press.

Borjas, G.J. (1999). 'The Economic Analysis of Immigration' in O. Ashenfelter and D. Card (eds.) Handbook of Labor Economics, Volume 3. Amsterdam: North-Holland.

Burton, J., A. Nandi and L. Platt (2010). 'Measuring ethnicity: challenges and opportunities for survey research', Ethnic and Racial Studies, 33 (8), pp. 1332-1349.

Central Statistics Office (2002). Census 2002: Principal Demographic Results, available at: www.cso.ie/en/media/csoie/census/documents/pdr_2002.pdf (accessed 19 July 2018).

Central Statistics Office (2012). Measuring Ireland's Progress 2011, Dublin and Cork: Central Statistics Office. 
Central Statistics Office (2017). Census 2016 Summary Results - Part 1, available at: $\quad$ www.cso.ie/en/media/csoie/newsevents/documents/census2016 summaryresultspart1/Census2016SummaryPart1.pdf.

Chiswick B.R. and P.W. Miller (1995). 'The Endogeneity between Language and Earnings: International Analyses', Journal of Labor Economics 13(2), pp. 246-288

Department of Justice and Equality (2017). The Migrant Integration Strategy: A Blueprint for the Future. Dublin: Department of Justice and Equality.

Eichhorst, W. and A.P. de Souza (eds.)(2018). 'The Future of Work - Good Jobs for All', in International Panel on Social Progress (IPSP) (eds.) Rethinking Society for the 21st Century: Report of the International Panel on Social Progress. Volume 1: Socio-economic Transformations. Cambridge: Cambridge University Press.

Equality and Rights Alliance (2015). A New Public Sector Equality \& Human Rights Duty. Dublin: Equality and Rights Alliance.

Esser, H. (2004). 'Does the "New" Immigration Require a "New" Theory of Intergenerational Integration?', International Migration Review, 38(3), pp. 1126-1159.

European Agency for Fundamental Rights (FRA) (2017). EU-MIDIS II: Second European Union Minorities and Discrimination Survey - Main results. Luxembourg: Publications Office of the European Union.

European Union Agency for Fundamental Rights (FRA) (2017). Second European Union Minorities and Discrimination Survey - Main results, Luxembourg: Publications Office of the European Union.

Eurostat (2018). 'Acquisition of citizenship statistics', available at http://ec.europa.eu/eurostat/statistics-explained/index.php/ Acquisition_of_citizenship_statistics (accessed 28 June 2018).

Fanning, B. and L. Michael (2017). 'Racism and anti-racism in the two Irelands', Ethnic and Racial Studies, pp. 1-17.

Gee, G.C. (2002). 'A multilevel analysis of the relationship between institutional and individual racial discrimination and health status', American Journal of Public Health, 92(4), pp. 615-623.

Gusciute, E., E. Quinn and A. Barrett (2015). Determining Labour and Skills Shortages and the Need for Labour Migration in Ireland, European Migration Network, ESRI Research Series Number 49, Dublin: ESRI.

Gusciute, E., S. Arnold and E. Quinn (2016). Integration of Beneficiaries of International Protection into the Labour Market: Policies and Practices in Ireland. European Migration Network, ESRI Research Series Number 52, Dublin: ESRI. 
Heath, A. and S.Y. Cheung (eds.) (2007). 'Unequal Chances: Ethnic Minorities in Western Labour Markets', Proceedings of the British Academy. Oxford: Oxford University Press.

Heath, A., T. Liebig and P. Simon (2013). 'Discrimination against Immigrants Measurement, Incidence and Policy Instruments' in OECD (eds.) International Migration Outlook 2013. Paris: OECD Publishing.

IHREC (2018a). Access to the labour market for applicants for international protection, available at: www.ihrec.ie/app/uploads/2018/05/Access-tothe-labour-market-for-applicants-for-international-protection.pdf.

IHREC (2018b). Annual Report 2017. Dublin: Irish Human Rights and Equality Commission.

Joseph, E. (2017). 'Whiteness and racism: Examining the racial order in Ireland', Irish Journal of Sociology, Vol. 26, No. 1, pp. 46-70.

King-O'Riain, R.C. (2007). 'Counting on the "Celtic Tiger": Adding ethnic census categories in the Republic of Ireland', Ethnicities, 7(4), pp. 516-542.

Kingston, G., P. O'Connell and E. Kelly (2013). Ethnicity and Nationality in the Irish Labour Market: Evidence from the QNHS Equality Module 2010. Dublin: The Equality Authority and the ESRI.

Kingston, G., F. McGinnity and P.J. O'Connell (2015). 'Discrimination in the Labour Market: Nationality, Ethnicity and the Recession', Work, Employment and Society, 29(2), pp. 213-232.

Labour Court (2015). Annual Report 2014, available at: www.workplacerelations.ie/en/Publications_Forms/Archived_Publicatio ns/Labour-Court-Annual-Report-2014-English-.pdf.

Labour Court (2016). Annual Report 2015, available at: www.workplacerelations.ie/en/Publications_Forms/Labour_Court_Annu al_Report_2015.pdf.

McGinnity F. and P. Lunn (2011). 'Measuring Discrimination Facing Ethnic Minority Job Applicants: An Irish Experiment', Work, Employment and Society 25(4), pp. 693-708.

McGinnity, F., E. Quinn, P.J. O'Connell and N. Donnelly (2011). Annual Monitoring Report on Integration 2010. Dublin: ESRI/The Integration Centre.

McGinnity, F., D. Watson and G. Kingston (2012). Analysing the Experience of Discrimination in Ireland: Evidence from the QNHS Equality Module 2010. Dublin: The Equality Authority and Economic and Social Research Institute.

McGinnity, F., E. Quinn, G. Kingston and P.J. O'Connell (2014). Annual Monitoring Report on Integration 2013. Dublin: Economic and Social Research Institute and The Integration Centre. 
McGinnity, F. and M. Gijsberts (2017). 'The experience of discrimination among newly arrived Poles in Ireland and the Netherlands', Ethnic and Racial Studies, 41(5), pp. 919-937.

McGinnity, F., R. Grotti, O. Kenny and H. Russell (2017). Who experiences discrimination in Ireland? Evidence from the QNHS Equality Modules. Dublin: ESRI/The Irish Human Rights and Equality Commission.

McGinnity, F., É. Fahey, E. Quinn, S. Arnold, B. Maître and P. O'Connell (2018). Monitoring Report on Integration 2018. Dublin: ESRI/The Department of Justice and Equality.

Michael, L. (2015). Afrophobia in Ireland: Racism against people of African descent. Dublin: ENAR Ireland.

Migrant Rights Centre Ireland (2015). Workers on the Move: Past Lessons and Future Perspectives on Ireland's Labour Migration. Dublin: Migrant Rights Centre Ireland, available at: www.mrci.ie/wpcontent/uploads/2015/12/Workers-on-the-Move_SPS.pdf.

Murphy, C., L. Caulfield and M. Gilmartin (2017). Developing Integration Policy in the Public Sector: A Human Rights Approach. Maynooth: Maynooth University, available at: www.maynoothuniversity.ie/sites/default/files/assets/document/MU \%20Developing\%20Integration\%20Policy\%20in\%20the\%20Public\%20Sect or\%20FOR\%20WEB_0.pdf.

Ní Raghallaigh, M., M. Foreman and M. Feeley (2016). Transition from Direct Provision to life in the community: The experiences of those who have been granted refugee status, subsidiary protection or leave to remain in Ireland. Dublin: Taskforce on Transitional Supports for Persons Granted Status in Direct Provision.

O'Connell P.J. (2013). 'Cautious Adjustment in a Context of Economic Collapse: The Public Sector in the Irish Crisis', in Vaughan-Whitehead, D. (ed). Public Sector Shock: The Impact of Policy Retrenchment in Europe, Cheltenham: Edward Elgar.

O'Connell, P.J. (2018). 'Why Are So Few Africans at Work in Ireland? Immigration Policy and Labour Market Disadvantage', Geary WP2018/16. Dublin: UCD Geary Institute for Public Policy.

O'Connell, P.J. and F. McGinnity (2008). Immigrants at Work: Ethnicity and Nationality in the Irish Labour Market. Equality Research Series. Dublin: $\mathrm{ESRI} /$ The Equality Authority.

OECD (2008). 'The Price of Prejudice: Labour Market Discrimination on the Grounds of Gender and Ethnicity,' in OECD Employment Outlook 2008. Paris: OECD.

OECD (2013). 'Discrimination against immigrants - Measurement, incidence and policy instruments', in International Migration Outlook 2013. OECD Publishing. 
OECD (2015). Settling In: OECD Indicators of Immigrant Integration. Paris: OECD.

Office of the Refugee Applications Commissioner (2014). Annual Report 2014, available at www.orac.ie.

Pager, D. and H. Shepherd (2008). 'The Sociology of Discrimination: Racial Discrimination in Employment, Housing, Credit and Consumer Markets', Annual Review of Sociology, 34, pp.181-209.

Reception and Integration Agency (2015). Annual Report 2014, Dublin: Reception and Integration Agency.

Ruhs, M. (2005). 'Managing the Immigration and Employment of Non-EU Nationals in Ireland', Studies in Public Policy, Vol. 19, pp.1-152.

Russell, H., F. McGinnity and G. Kingston (2014). Gender and the Quality of Work: From Boom to Recession. Dublin: Equality Authority and Economic and Social Research Institute.

Russell, H., D. Watson, S. McCoy, R. Grotti and O. Kenny (2017). A study of gender in senior civil service positions in Ireland. Economic and Social Research Institute (ESRI) Research Series.

Schmitt, M., N. Branscombe, T. Postmes and A. Garcia (2014). 'The consequences of perceived discrimination for psychological well-being: A meta-analytic review', Psychological Bulletin, Vol. 140, pp. 921-948.

Tattarini, G., R. Grotti and S. Scherer (2018). 'The buffering role of the family in the relationship between job loss and self-perceived health: Longitudinal results from Europe, 2004-2011', Health \& place, 52, pp.55-61.

Triana, M.C., M.F. García and A. Colella (2010). 'Managing diversity: How organisational efforts to support diversity moderate the effects of perceived racial discrimination on affective commitment', Personnel Psychology, 63(4), pp. 817-843.

Voitchovsky, S. (2014). 'Occupational downgrading and wages of New Member States immigrants to Ireland', International Migration Review, 48(2), pp. 500-537.

Watson, D., O. Kenny, F. McGinnity (2017). A Social Portrait of Travellers in Ireland. Dublin: ESRI.

Workplace Relations Commission (2018). Annual Report 2017. Dublin: Workplace Relations Commission.

Zschirnt, E. and D. Ruedin (2016). 'Ethnic discrimination in hiring decisions: a meta-analysis of correspondence tests 1990-2015', Journal of Ethnic and Migration Studies, 42(7), pp.1115-1134. 
16-22 Sráid na Faiche,

Baile Átha Cliath 7, D07 CR20

16-22 Green Street,

Dublin 7, D07 CR20

Guthán/Phone + 353 (0) 18589601

Ríomhphost/Emailinfo@ihrec.ie

Idirlíon/Web www.ihrec.ie
Whitaker Square,

Sir John Rogerson's Quay Dublin 2

Phone +35318632000

Fax +35318632100

Email admin@esri.ie

Web www.esri.ie 